NISTIR 7974

\title{
Nondestructive Testing (NDT) and Sensor Technology for Service Life Modeling of New and Existing Concrete Structures
}

Kenneth A. Snyder

Li-Piin Sung

Geraldine S. Cheok

This publication is available free of charge from:

https://doi.org/10.6028/NIST.IR.7974

National Institute of 
NISTIR 7974

\title{
Nondestructive Testing (NDT) and Sensor Technology for Service Life Modeling of New and Existing Concrete Structures
}

\author{
Kenneth A. Snyder \\ Li-Piin Sung \\ Materials and Structural Systems Division \\ Engineering Laboratory \\ Geraldine S. Cheok \\ Intelligent Systems Division \\ Engineering Laboratory
}

December 2013

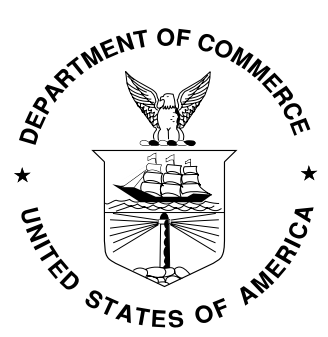

U.S. Department of Commerce

Penny Pritzker, Secretary 


\section{ABSTRACT}

Nondestructive test (NDT) methods and sensor technologies are evaluated in the context of providing input parameters to service life prediction models for reinforced concrete structures. Relevant NDT methods and sensors are identified that are based on diverse technologies including mechanical impact, ultrasonic waves, electromagnetic waves, nuclear, and chemical and electrical methods. The degradation scenarios of reinforcement corrosion, alkali-silica reaction, and cracking are used to identify gaps in available NDT methods for supporting condition assessment and service life prediction. Common gaps are identified, along with strategies for resolving those gaps. 
Disclaimer:

Certain commercial products are identified in this paper to specify the materials used and procedures employed. In no case does such identification imply endorsement or recommendation by the National Institute of Standards and Technology, nor does it indicate that the products are necessarily the best available for the purpose. 


\section{TABLE OF CONTENTS}

ABSTRACT

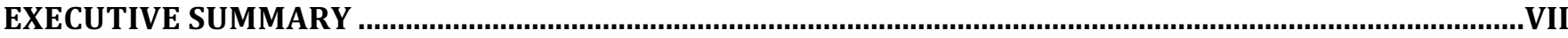

LIST OF FIGURES

LIST OF TABLES

ABBREVIATIONS

1 INTRODUCTION

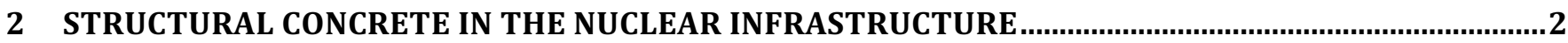

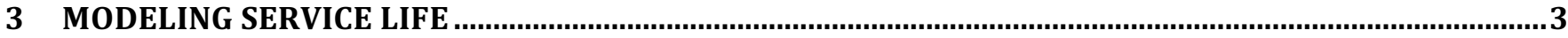

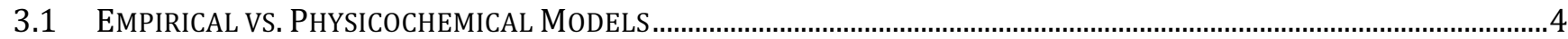

3.2 CONCEPTUAL SERVICE LIFE MODEL

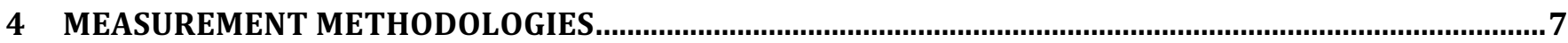

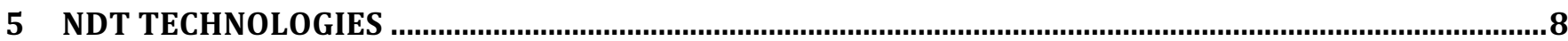

5.1 ELECTRO-MECHANICAL STRAIN GAUGES

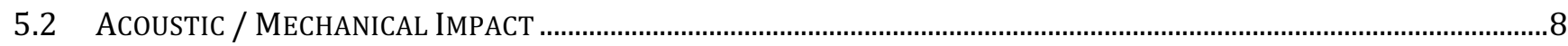

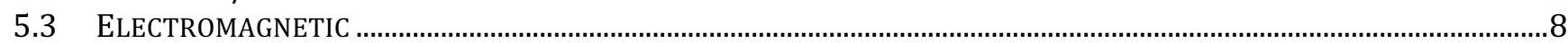

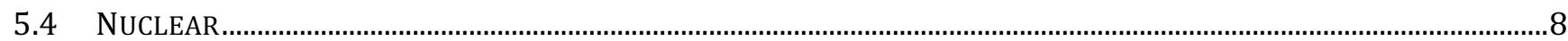





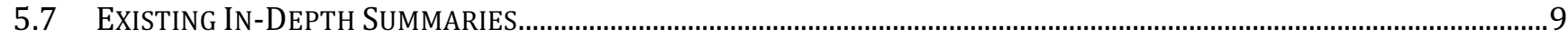

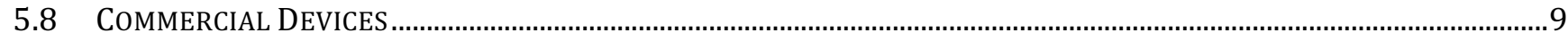

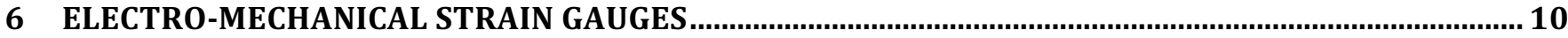



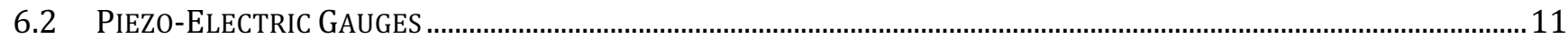



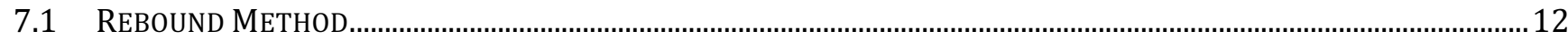

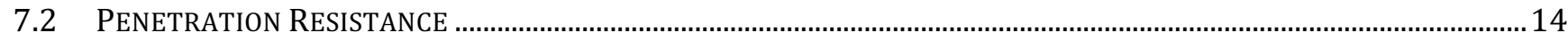

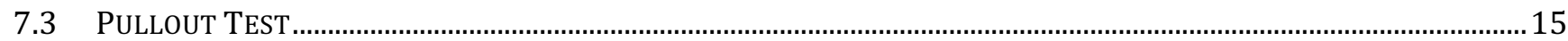

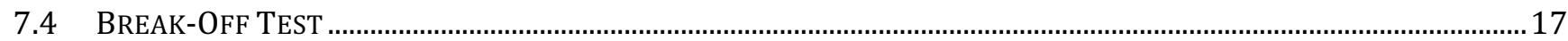

7.5 RESONANT FREQUENCY METHODS.

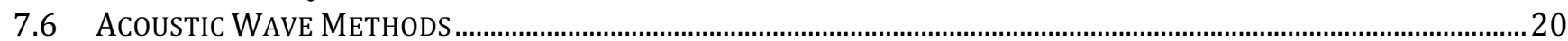

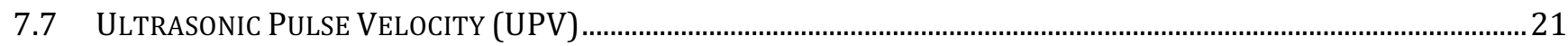

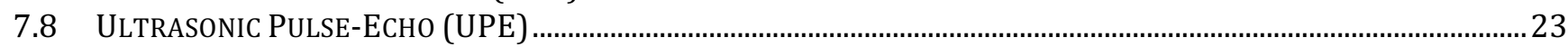

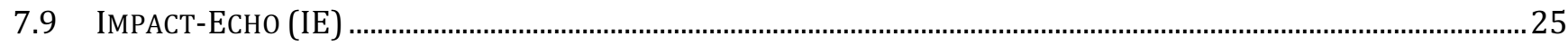

7.10 SPECTRAL ANALYSIS OF SURFACE WAVES

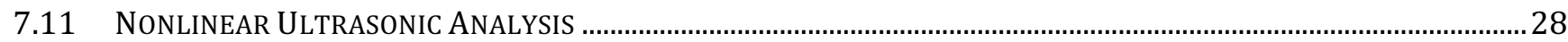



7.13 Ultrasonic PhaSED ARRAYS / UltraSONIC PHASE SPECTROSCOPY ….................................................................32

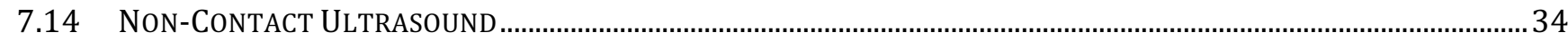

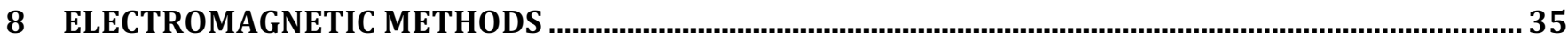

8.1 TIME-DOMAIN REFLECTOMETRY

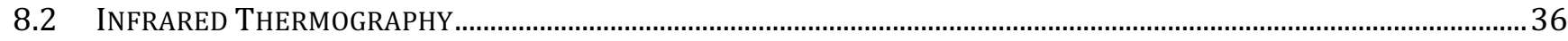

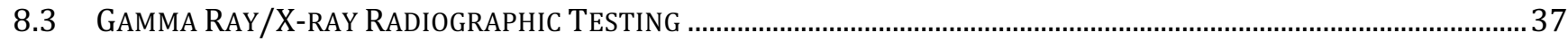

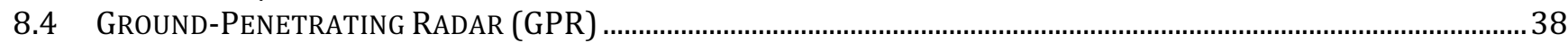

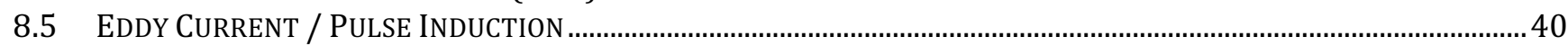




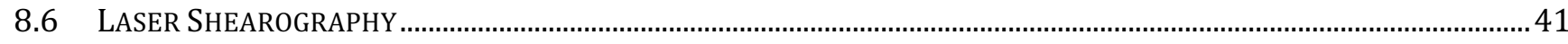

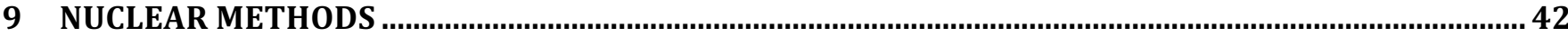



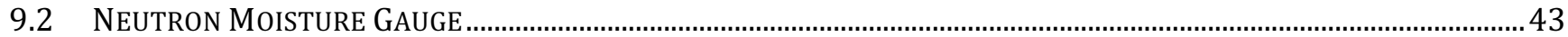

10 CHEMICAL / ELECTRICAL METHODS

$10.1 \quad \mathrm{PH}$





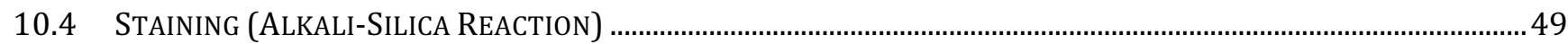

10.5 MATURITY / THERMOMETRY

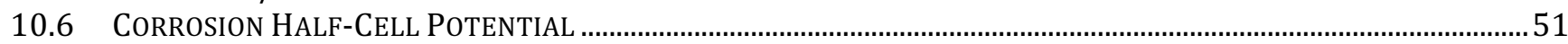

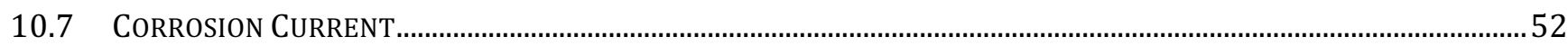

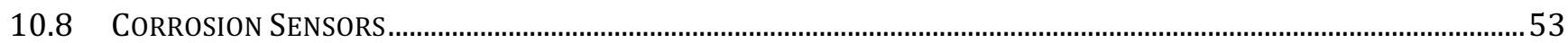

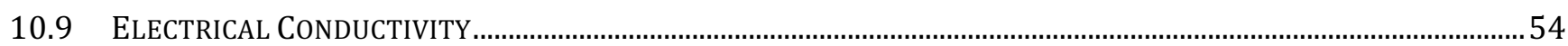

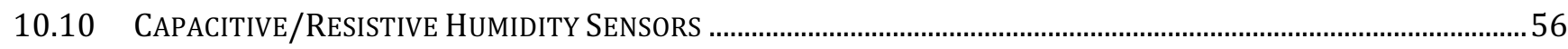

11 MASS TRANSPORT METHODS



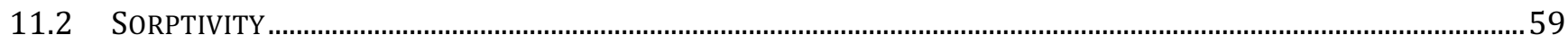

12 RECENT RESEARCH ON NDT FOR ESTIMATING MECHANICAL PROPERTIES ..................................60

13 SERVICE LIFE PREDICTION

14 DEGRADATION SCENARIOS

14.1 CORROSION OF STEEL REINFORCEMENT

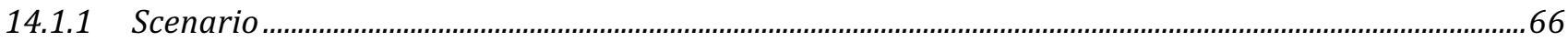

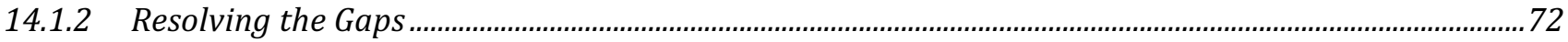

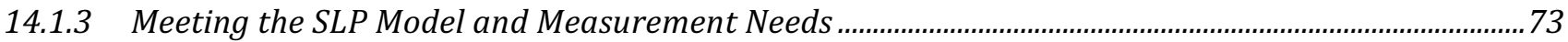



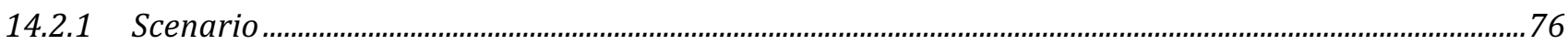



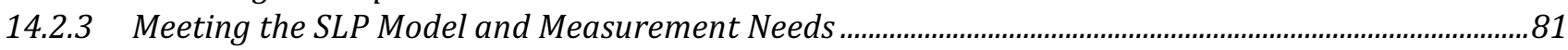

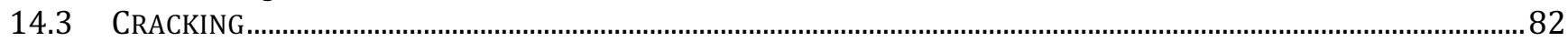

14.3.1 Scenario

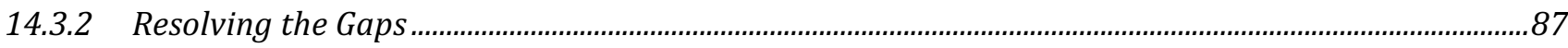



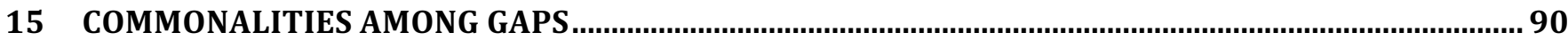

16 SUMMARY

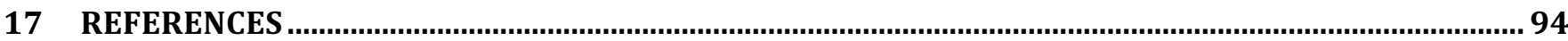




\section{EXECUTIVE SUMMARY}

Nondestructive testing (NDT) methods and sensor technologies for concrete structures are discussed in the context of service life prediction. The present paradigm of NDT methods is to determine the current state of a structure. Although this approach has important application in condition assessment, the techniques have the potential to support tools for predicting the future performance. These tools are typically computational service life prediction (SLP) tools that use an assessment of the current state of a structure, along with the environmental exposure, to estimate how long before the concrete will begin to degrade. Unfortunately most SLP models were not developed to use specific NDT methods, and NDT methods were not developed in direct support of specific SLP models. Although a number of NDT methods and sensor technologies are suitable for use in conjunction with some SLP models, this report seeks to identify those gaps that remain and identify strategies for their resolution.

A number of NDT methods and sensor technologies were identified that may have relevance to SLP models. The common attributes of SLP prediction models are discussed with respect to the input material parameters and the environmental parameters that may have the greatest influence on the duration of the usable service life. Based on the common material properties and environmental factors used by SLP models, various NDT methods and sensor technologies were identified that can be used to either measure the property directly, or provide an indirect measure (often through correlation).

The scope of NDT methods considered was made as broad as possible. For this report, the definition of nondestructive was interpreted to mean that when the measurement is performed on a structure, there was no appreciable degradation to the performance or serviceability of the structure.

There are a number of possible degradation scenarios that may affect concrete in nuclear installations, and other components of the broader nuclear infrastructure relevant to the Nuclear Regulatory Commission. Among these, there are three concrete degradation scenarios that, together, would account for a majority of the significant degradation throughout the nuclear infrastructure: corrosion of the steel reinforcement; cracking (due to unanticipated mechanical stresses); and alkali-silica reaction. For each of these degradation scenarios, the factors contributing to the onset and extent of the degradation are discussed to help identify relevant NDT methods. Those NDT methods that are deemed relevant are classified as either a standardized test method or a method that is still in the research or development phase. In some cases, there were no NDT methods or sensor technologies one could use to assess a particular material parameter or condition, resulting in gaps in NDT and sensor technologies.

Based on the gaps that were identified, strategies were presented for resolving these gaps. For all three degradation scenarios, there were a number of commonalities among the gaps that were identified. In some cases, the gap occurred due to limited knowledge of the underlying physical and chemical processes that contribute to the degradation. For degradation scenarios that typically happen over relatively short time frames (e.g., corrosion of the reinforcement), the loss in structural capacity may occur quickly, so an improved understanding of the underlying physics and chemistry is vital to characterizing the rate of strength loss and determining the minimum monitoring frequency. The slower degradation mechanisms like alkali-silica reaction are considerably more complex. Therefore, developing a comprehensive understanding may require years of research, which may not be the most efficient approach. Instead, having robust NDT methods and sensors that can be used to accurately estimate remaining structural capacity, along with the knowledge of, or a means of predicting, the rate at which remaining structural capacity decreases, would be sufficient to determine the current condition and to establish a reliable monitoring strategy having a sufficiently rapid frequency. 


\section{LIST OF FIGURES}

Figure 1. Schematic of the pullout test for cast-in-place concrete (from Malhotra and Carino 2004).

Figure 2. Schematic of the break-off test (Reprinted, with permission, from ASTM C1150-96 Standard Test Method for the Break-Off Number of Concrete, copyright ASTM International, 100 Barr Harbor Drive, West Conshohocken, PA 19428.) Note: This standard test method was withdrawn by ASTM International in 2002.

Figure 3. Acoustic wave spectrum and the frequency range for different acoustic NDT methods (adapted from Aktan and Krueger, 2007)

Figure 4. Schematic of (a) through-transmission UPV test system, and (b) effects of defects on the travel time of ultrasonic pulse (adapted from ACI 2004).

Figure 5. Schematic of ultrasonic pulse-echo and pitch-catch methods (adapted from ACI 2004).

Figure 6. Schematic representing the operation of the impact-echo method, and the output of results (adapted from ACI 2004).

Figure 7. Schematic illustrating the principle of the AE process, and the characteristics of typical burst signals recorded from the sensor (adapted from Aktan and Krueger, 2007).

Figure 8. Schematic of $\mathrm{pH}$ probe. 44

Figure 9. Image (20 mm field width) of phenolphthalein indicator applied to a concrete sample cross section. The upper surface was exposed to the atmosphere. The boundary between the unaffected and the stained (pink) region is the depth of carbonation. From Walker et al. (2006).

Figure 10. Schematic of four-point Wenner probe for determining the conductivity of field concrete.

Figure 11. Schematic of corrosion of the steel reinforcement due to external chloride ions (on the left side) diffusing to the steel reinforcement, leading to expansive corrosion products and, eventually, cracking (adapted from Yang et al. 2012).

Figure 12. Schematic representation of alkali-silica reaction in concrete (from Deschenes et al. 2009) .............................. 75

Figure 13. Common causes of cracking in concrete structures (from TRB 2006).

Figure 14. Some types of cracks from TRB (2006): (a) vertical cracking; (b) horizontal cracking or near surface, and parallel cracks, which may cause delamination; (c) cracking induced from chemical attacked from steel reinforcement bar corrosion; (d) map cracking by ASR. The black lines in (a)-(d) indicate cracks as labeled in (a). 


\section{LIST OF TABLES}

Table 1. Example critical events for modeling the service life of different degradation mechanisms..................................... 3

Table 2. Examples of boundary and initial conditions that a physicochemical model might consider..................................... 6

Table 3. Properties that may provide indirect information about quantities more directly related to service life estimation....... 6

Table 4. The acoustic wave properties in three different media: steel, concrete, and air (Source: Aktan and Krueger 2007).

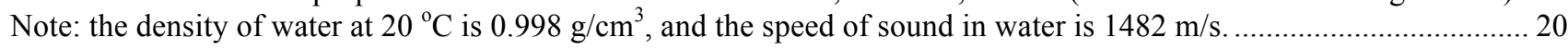

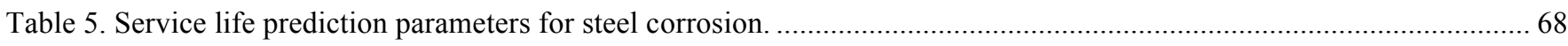

Table 6. Methods applicable to service life prediction parameters for alkali-silica reaction. ............................................... 78






\section{ABBREVIATIONS}

\begin{tabular}{|l|l|}
\hline & \\
\hline AASHTO & American Association of State Highway and Transportation Officials \\
\hline ACI & American Concrete Institute \\
\hline AE & Acoustic Emission \\
\hline ASR & Alkali-Silica Reaction \\
\hline ASTM & ASTM International \\
\hline CEN & European Committee for Standardization \\
\hline FHWA & Federal Highway Administration \\
\hline IE & Impact Echo \\
\hline NIST & National Institute of Standards and Technology \\
\hline NDT & Nondestructive Testing \\
\hline NRC & Nuclear Regulatory Commission \\
\hline NPP & Nuclear Power Plant \\
\hline SASW & Spectral Analysis of Surface Waves \\
\hline SHM & Structural Health Monitoring \\
\hline SLP & Service Life Prediction \\
\hline TDR & Time-Domain Reflectometry \\
\hline UPV & Ultrasonic Pulse Velocity \\
\hline UT & Ultrasonic Testing \\
\hline
\end{tabular}


xiii 



\section{INTRODUCTION}

A known challenge in ensuring the continued safe operation of nuclear facilities is the long-term performance of the concrete. Under ideal conditions, concrete is a mechanically and chemically stable material. Under most practical conditions, however, concrete can be subjected to mechanical stresses that originate externally (e.g., seismic) or internally (e.g., alkali silica reaction of the aggregate). If the stresses are greater than the designed capacity of the concrete, these stresses can initiate cracks that can degrade the mechanical properties of the element. If the degradation continues sufficiently, the concrete can lose the capacity to perform its function, and the structure will have failed.

Failing to perform the intended function constitutes the end of service life for a concrete element. Therefore, predicting the service life of a concrete element means predicting the period of time until the failure occurs. More practically, the end of service life occurs sooner: when the engineer is not confident that the concrete element can continue to perform its intended function, and the element must be either repaired or replaced.

Given that concrete elements are used in critical elements of the nuclear infrastructure, identifying and quantifying the extent of degradation play a critical role in managing the long-term performance of the concrete. Many of the most common degradation mechanisms progress slowly, particularly for the types of large-scale concrete elements found in nuclear power plants and waste isolation facilities. It can be difficult to quantify the loss in mechanical strength (due to limitations in physical access or limitations on sampling), but it is relatively easier to detect the effects of degradation: cracking, reaction products, etc. Therefore, monitoring the health of a concrete element often means identifying and quantifying the extent of these degradation indicators.

The relationship between the stresses and loss in strength depends upon changes in the microstructure. In the absence of changes in the microstructure, there would be no changes in the mechanical properties of the concrete element. Therefore, predicting the degradation of concrete requires understanding how chemical reactions and mechanical stresses change the microstructure. Initially, chemical reactions may result in changes consisting of loss of material (e.g., leaching) or creation of reaction products (e.g., sulfate attack). Upon sufficient chemical reaction, there may be sufficient loss of strength (from leaching) or sufficient mechanical stress (from sulfate attack reaction products) to initiate crack formation, further changing the microstructure. These cracks can localize stress and propagate, or may act as "superhighways" that accelerate the ongoing degradation chemical reactions.

Service life prediction (SLP) of a concrete requires characterizing the current state of the system and then predicting how existing and future stresses will change the system. To achieve this, one must fully characterize the current state of the system, and then use reliable models for how the concrete will react to its (mechanical or chemical) exposure environment. This is a primary role for nondestructive testing (NDT), the outputs from which serve as inputs to service life prediction models. These models may be based on empirical data taken from similar concretes exposed to similar environments, or they may be based on physicochemical predictive models that incorporate the relevant physical and chemical processes that may occur for a particular exposure environment. Each type of model requires different types of information. Therefore, the selection of NDT techniques must be performed in concert with the type of service life model being employed. 


\section{STRUCTURAL CONCRETE IN THE NUCLEAR INFRASTRUCTURE}

The nuclear infrastructure considered here includes the engineered concrete elements designed as structural elements or as physical/chemical barriers; the elements not considered are those where the concrete is intended to immobilize the waste, such as saltstone grouts designed to immobilize waste incidental to reprocessing.

Structural concrete in nuclear installations is reinforced or pre-stressed concrete. Thus, knowledge of the characteristics and state of the two principal components, concrete and reinforcement, is critical in the evaluation the structural performance of these structures. Generally, the structural concrete elements to be considered are those associated with nuclear power plants and low-level waste vaults. Moreover, these concrete elements do not exist in isolation, but play an integral role in the inter-related elements of the facility. As such, there are a number of special considerations for these elements:

- Heavily reinforced: nuclear power plant base mat

- Thick sections (1 m or more)

- Lined structures: containment, spent fuel pool

- Non-accessible/Accessible components

- Exposure to prolonged elevated temperatures: containment building, dry storage casks

- Exposure to radiation: gas evolution, pressure build-up

- Pre-stressed cables + raceway: loss of grease, corrosion

The capacity of these structural elements can be diminished when one of three things happens: the compressive strength of the concrete decreases, the tensile strength of the steel reinforcement decreases, the mechanical bond between the concrete and the steel reinforcement degrades. Some types of chemical attack can affect these degradation scenarios. For example, chloride ingress can eventually lead to corrosion of the steel reinforcement (loss of steel cross section and, thus, tensile capacity), the corrosion products can degrade the concrete-steel bond, and the reaction products can crack the concrete, which can reduce its compressive strength. 


\section{MODELING SERVICE LIFE}

To best understand what NDT techniques are relevant to service life prediction, one must understand the basic commonalities among the service life models.

There are a number of different approaches to predicting the service life of a concrete structure under particular exposure conditions. The models based on physical processes, however, have a certain commonality, and they differ in the degree to which they consider specific details. Generally, there are four components to these models:

- Characterize the environment

- Characterize the concrete

- Characterize transport and reaction

- Define critical event(s) that denotes the end of service life

Characterizing the environment and the concrete will determine which, if any, degradation mechanisms should be considered. For example, an absence of sulfates in contact with the concrete means that one should not have to consider sulfate attack, provided that the concrete does not already contain a high sulfate content. Another important aspect is that, when a concrete is exposed to multiple degradation mechanisms (e.g., chloride attack and leaching), a more robust model would be able to account for the synergistic effects of the two mechanisms occurring simultaneously: the leaching can change the mineral composition and the transport coefficients, which can affect chloride binding and the rate at which chlorides propagate toward the steel.

Ultimately, the model must decide when a critical state has been reached to indicate the end of the service life. Because no model currently exists that can transition from stress production through crack initiation and growth, to a quantitative estimate of strength loss, the models must choose more preliminary, yet quantifiable, critical events. A list of common critical events for a number of degradation mechanisms appears in Table 1 below.

Table 1. Example critical events for modeling the service life of different degradation mechanisms.

\begin{tabular}{|l|l|}
\hline Degradation Mechanism & Example Critical Events \\
\hline Corrosion of the Steel & Onset of corrosion at the steel reinforcement \\
\hline Sulfate Attack & Reaction products fill available pore space \\
\hline Leaching & Loss of material leads to critically high porosity \\
\hline Freeze-Thaw & $\begin{array}{l}\text { Available pore space (including air voids) are } \\
\text { saturated with water to a critical degree }\end{array}$ \\
\hline Alkali-Silica Reaction & $\begin{array}{l}\text { Reaction gel completely fills the available pore } \\
\text { space. }\end{array}$ \\
\hline
\end{tabular}




\subsection{Empirical vs. Physicochemical Models}

There are two distinct approaches to modeling the service life of a concrete: empirical models and physicochemical models. Each approach has distinct advantages and disadvantages.

The empirical model is calibrated using the anticipated materials and environmental exposure conditions. The modeler measures the time-dependent behavior of the system and then uses regression to relate those data to a "best-fit" curve (that can either be merely an algebraic function, or a physically-motivated function, such as the standard error function for diffusion). Because the model is calibrated using the field conditions, one is merely interpolating the response of the system; the approach has large model uncertainty if the material or the environment changes. The advantage to this approach is that one does not need to understand, or even be aware of, all of the details of the physical and chemical mechanisms involved. Only the response is characterized, which is what the practicing engineer is most interested in. The challenge in calibrating these models is ensuring that the critical exposure conditions are included in the calibration process; the testing conditions must incorporate all the relevant exposure conditions.

By contrast, the physicochemical service life model attempts to numerically simulate the response of a material to its environment. The physicochemical model first conceptualizes all the possible relevant mechanisms that can lead to degradation in a particular application, and breaks these down into the fundamental physical and chemical processes. For example, the mechanism of corrosion of steel reinforcement can be broken down into processes of transport (diffusion), surface binding, chemical reaction, leaching (and its effect on subsequent transport), and electrochemical reaction. The modeler then develops a means of simulating each of these processes, with each process "calibrated" using independent laboratory experiments. If developed comprehensively, these models will also be able to adapt to changes in the environment. The process parameters are the initial/internal conditions, and the exposure environment parameters are the boundary conditions.

The physicochemical approach offers distinct advantages and disadvantages. The process of chemical reaction is conceptually identical whether one is considering corrosion, sulfate attack, acid leaching, etc. The differences arise in assuring that the reaction/thermodynamic database includes parameters for the relevant reactions. Similar considerations hold for transport, binding, and the other processes. Moreover, because these processes are (largely) independent, they can occur simultaneously. For example, incorporating the effects of leaching during chloride diffusion is very straightforward, and does not require any modifications to the overall model. Another advantage to these models is that these processes are validated and calibrated by independent means; one does not calibrate and then use the same data to validate the model. A disadvantage to these models is the "up front" development costs. For example, modeling chloride-induced corrosion using only a transport model may not work reliably under field conditions because the important effects of binding are not included. Therefore, the model will not be usable until all the important processes are included, which can dramatically increase the initial model development time. Conceptually, this has an advantage: if the current model is not accurate enough, it indicates that an important process has been overlooked or misunderstood.

The biggest advantage of a comprehensive physicochemical model is the ability to extrapolate. Once the relevant material properties have been determined, and the exposure conditions quantified, such a model should reliably predict the service life of a concrete without "calibration" data from exposure experiments. Moreover, once the exposure conditions have been appropriately established, these models are also very useful in materials development because the engineer can ask virtual "what if" questions regarding changes in the mixture proportions or the field conditions. 


\subsection{Conceptual Service Life Model}

As physicochemical models are more comprehensive than empirical models, and because they require a "superset" of NDT techniques, they are used as the starting conceptual framework for identifying NDT techniques that may be relevant to service life prediction.

Physicochemical models share a common conceptual model. This commonality is a consequence of reconciling the fact that reactions are occurring at the micrometer length scales, but service life is defined by the performance at the meter length scales. Therefore, the details of each reaction and the details of the microstructure cannot be fully represented in a practical service life model. For this reason, the details are "smeared" out to the extent that the concrete is treated as a homogeneous material, with quantifiable properties such as porosity, diffusivity, saturation, etc. Although the details may vary among service life models, each model typically incorporates, either explicitly or implicitly, each of the following concepts:

- Concrete is a porous material composed of multiple mineral phases

- The type and quantity of the mineral phases present are known, or can be predicted

- The microstructure contains both capillary and "nano"-sized pores connected throughout

- The pores are (partially) saturated with an aqueous pore solution

- The pore solution is in local equilibrium with all the mineral phases present

- The environment interacts mainly through the pore solution, along with temperature and humidity

- The environmental interaction (through transport) changes the pore solution

- The ensuing chemical reactions can dissolve or precipitate mineral phases

- Dissolution: increased porosity, increased transport, and reduced mechanical stiffness

- Precipitation: pores fill; once filled, stresses build up

- Sufficient stress can initiate cracks and fractures

- Reactions / Cracks change microstructure and transport properties

- Cracking/Fractures lead to a loss of mechanical properties

- Upon sufficient mechanical loss: concrete element fails to perform its intended purpose

These models typically work by solving partial differential equations. As such, the conceptual model framework follows that for solving a partial differential equation having boundary conditions and initial internal conditions, a number of which are given in 
Table 2 below. 
Table 2. Examples of boundary and initial conditions that a physicochemical model might consider.

\begin{tabular}{|l|l|}
\hline Condition & Examples \\
\hline Boundary Conditions & Composition of the groundwater \\
& Hydraulic head \\
& Temperature \\
& Radiation \\
& Mechanical Stress \\
& Relative Humidity or Precipitation Events \\
\hline Initial Conditions & Dimensions and location of steel reinforcement \\
& Temperature \\
& Type and quantity of mineral phases present \\
& Porosity/Density \\
& Composition of the pore solution \\
& Saturation \\
& Extent of cracking \\
& Diffusion coefficient \\
& Hydraulic conductivity (permeability) coefficient \\
& Sorptivity \\
& Vapor diffusion coefficient \\
& Elastic/Viscoelastic Moduli \\
& Coefficient of Thermal Expansion \\
\hline
\end{tabular}

Moreover, not all the material properties need to be measured directly. In a number of cases, there may exist other "surrogate" properties from which one can make reliable estimates of the desired property. A number of these related properties are given in Table 3 below.

Table 3. Properties that may provide indirect information about quantities more directly related to service life estimation.

\begin{tabular}{|l|l|}
\hline Surrogate Property & Relevant Property \\
\hline Electrical Conductivity & $\begin{array}{l}\text { Diffusion Coefficient } \\
\text { Hydraulic Conductivity }\end{array}$ \\
\hline Vapor Diffusion Coefficient & Hydraulic Conductivity \\
\hline Gas Permeability & Hydraulic Conductivity \\
\hline Impact Hardness & Strength; Elastic moduli \\
\hline
\end{tabular}

The advantage of this approach is that (with the possible exception of modeling the changes in properties due to continued hydration at earlier ages) it does not distinguish between new and existing structures. The initial condition can consist of the properties of either a newly constructed concrete element, or an existing structure. One possible difference may be how they are determined: the initial conditions of a new structure might be predicted from a hydration model. Regardless, the process by which someone would determine the boundary or the initial conditions in the field would be identical. 


\section{MEASUREMENT METHODOLOGIES}

The types of NDT techniques to be considered are those measurement techniques that do not prevent the structure from performing its intended function. Such tests could include one or more of the following:

- External Probes/Sensors

- Internal Probes/Sensors

- Material Removal and Analysis

For structures in the nuclear infrastructure, NDT methods that require material removal will likely be less desirable due to the perception of "reduced" structural integrity upon material removal, due to any possible health physics issues regarding the material being removed, and due to the creation of an initiation point for any subsequent concrete degradation. 


\section{NDT TECHNOLOGIES}

The following discussion divides the NDT techniques into six technology categories:

- Electro-Mechanical Strain Gauges

- Acoustic/Mechanical Impact

- Electromagnetic

- Nuclear

- Electrical / Chemical

- Mass Transport

\subsection{Electro-Mechanical Strain Gauges}

These tests include internal and external sensors that can be used to determine the extent of strain occurring in the structural element. The sensors may be external mechanical gauges with an indicator, or an internal piezoelectric sensor.

\subsection{Acoustic / Mechanical Impact}

These tests produce static or dynamic stress fields that are mechanically coupled to the concrete element. The static tests typically go beyond elastic behavior to determine the point of failure (strength), and the dynamic tests typically stay within the elastic regime and provide information about the mechanical condition of the element (modulus).

\subsection{Electromagnetic}

The electromagnetic tests generate electromagnetic waves passing through the element, and either the transmitted or reflected waves are analyzed. The waves are not electrically coupled to the element, so there is no net electrical current passing through the element (to distinguish these tests from the electrical tests discussed below). These tests typically detect changes in the properties of element, and can be used to image inclusions (steel reinforcement) and voids within the element.

\subsection{Nuclear}

The nuclear tests analyze neutrons that pass through the element. Because the neutron scattering cross section for hydrogen is large, neutrons are an effective means of detecting water. Due to safety considerations of generating sufficiently high-energy neutrons to pass through large concrete elements, however, the application of nuclear tests is limited.

\subsection{Electrical / Chemical}

The electrical and chemical tests use either electrical or electrochemical instrumentation to determine the state of the system. The electrical methods are electrically coupled to the element, so there is a net alternating or direct current through the element. The chemical tests typically use electrochemical techniques and a reference cell to infer the chemical state from the electrochemical potentials that are measured. The chemical tests may also include the direct application of a chemical, with inference of the chemical state from the chemical response, which is usually a visual indication (e.g., staining test). 


\subsection{Mass Transport}

The mass transport tests are used to estimate a particular transport coefficient, or a coefficient that is key to transport, such as porosity. These coefficients may include diffusivity, hydraulic conductivity (D’Arcy permeability), vapor diffusion (drying rate), and sorptivity (water uptake).

\subsection{Existing In-Depth Summaries}

The technology summaries that appear below are meant to convey enough information that one can comprehend its use in service life modeling. A number of the summaries are relatively brief because they appear in more in-depth NDT summaries (FHWA 1997, IAEA 2002, Malhotra and Carino 2004, IAEA 2005, Naus 2009). Those technologies that do not appear in such summaries are given a more thorough summary here.

\subsection{Commercial Devices}

Certain trade names and company products are mentioned in the text or identified in an illustration in order to adequately specify the experimental procedure and equipment used. In no case does such an identification imply recommendation or endorsement by the National Institute of Standards and Technology, nor does it imply that the products are necessarily the best available for the purpose. 


\section{ELECTRO-MECHANICAL STRAIN GAUGES}

\subsection{Mechanical Gauges}

Summary: Mechanical strain gauges are typically mounted on a surface and measure the deformation of the surface. They are used to measure surface strain and monitor crack width growth.

Physical Principle: Mechanical gauges measure the change in distance between two reference points over a period of time. The reference points can be drilled directly into the structure or attachments with predrilled holes can be mounted onto the surface.

Advantages: Simple to use and can measure strains beyond material fracture.

Limitations: These sensors can be bulky and can be dislodged.

Relevance to Service Life Prediction: Monitoring of strains in a structure results in understanding of the structural behavior and enables the estimation of its future behavior and useful life. Models that couple mechanical deformation to ongoing transport and degradation mechanisms can be validated with data from these mechanical gauges.

Standardization: None

Commercial Availability: Yes

References:

- Huston (2011) 


\subsection{Piezo-Electric Gauges}

Summary: A piezoelectric strain gauge is a thin extensoresistive (piezoresistive) or extensoelectric (piezoelectric) device that can be used to measure the strain experienced by a porous solid.

Physical Principle: Piezoelectric materials generate an electric charge when a load is applied to them. This charge is proportional to the applied force and is converted to an output voltage. Piezoelectric materials are conventionally used in sensors such as load cells, accelerometers, pressure gauges, ultrasonic sensors, and acoustic emission sensors.

Piezoelectric strain sensors are commonly made from piezoceramics, lead zirconate titanate, and piezopolymers, polyvinylidene fluoride, and piezoelectric ceramic/polymer composites.

Advantages: Piezoelectric sensors have high strain sensitivity up to $100 \mathrm{pC} / \mu \varepsilon$ (Gautschi, 2002). Piezoelectric strain gages have better signal to noise ratio compared to metal foil strain gages and are good for dynamic applications. These sensors can be made in small sizes and can be made in various forms.

Limitations: Piezoelectric strain gauges may be temperature dependent, and are not suited for measuring steady-state or low frequency signals. They only measure low strain levels.

Relevance to Service Life Prediction: Monitoring of strains in a structure results in understanding of the structural behavior and enables the estimation of its future behavior and useful life. These strains can be indicators of on-going degradation, and could be correlated to the degree of degradation that has occurred.

Standardization: None. (There is a related standard: ASTM E251-92 for metallic bonded resistance strain gauges)

Commercial Availability: Yes.

References:

- Huston (2011)

- Gautschi (2002) 


\section{MECHANICAL / ACOUSTIC METHODS}

\subsection{Rebound Method}

Summary: This test determines the surface hardness of concrete. This method is primarily used to assess in-situ concrete uniformity and relative quality.

Physical Principle: The method is based on the principle that the rebound of a spring-driven mass after impacting the concrete surface is related to the concrete strength. Correlation relationships between the rebound number and the compressive and flexural strengths of the concrete are required and are used to estimate the compressive and flexural strengths.

The main components of the rebound method (rebound hammer or Schmidt Hammer) are an outer body, a plunger, a hammer mass $(1.8 \mathrm{~kg})$ and a spring. The rebound distance is measured on an arbitrary scale from 10 to 100 . The rebound distance is recorded as a rebound number. The procedure involves extending the plunger, holding the instrument perpendicular to the surface, and pushing the body towards the concrete surface to stretch the spring. The spring is then released to force the hammer towards the surface and the rebound number is recorded.

\section{Advantages:}

- inexpensive

- simple

- rapid

\section{Limitations:}

Results are affected by (Malhotra and Carino 2004):

- smoothness of test surface

- size, shape, and rigidity of specimens

- surface and internal moisture conditions of the concrete

- type of coarse aggregate

- type of cement

- type of mold

- carbonation of the concrete surface

Other limitations:

- Correlation relationships between the rebound number and the compressive and flexural strengths require calibration with cores or cast samples. Included in the European standard, EN 13791 (2007), are guidelines for determining relationships between indirect test methods such as the rebound hammer test and the in-situ strength. A study by Monteiro and Goncalves (2009) assessed the two alternative methods provided in EN 13791 for establishing the relationship between the in-situ strength and the rebound number.

- The coefficients of variation in the compressive strengths averaged $19 \%$ according to Malhotra and Carino (2004).

- The accuracy of estimating concrete compressive strength is $\pm 25 \%$ according to Malhotra and Carino (2004).

- The variation in the estimated flexural strength is larger than that for compressive strength.

- Strengths estimated using this method are not as reliable as other in-place methods. 
Relevance to Service Life Prediction: Concrete uniformity may also be used to monitor changes in mechanical properties and relate these relative changes to those predicted by a service life model. Also, as the rebound hammer can be sensitive to surface hardness, it may be an indicator of an external degradation mechanism.

Standardization: ASTM C805, EN13791

Commercial Availability: Yes

References:

1. Malhotra and Carino (2004)

2. ACI Committee 228

3. EN 13791 (2007)

4. Monteiro and Goncalves (2009) 


\subsection{Penetration Resistance}

Summary: This method measures the hardness of concrete or the penetration resistance of concrete. This method can be used to determine the relative strength of concrete. It can also be used to estimate the concrete compressive strength through developed relationships between compressive strength and the penetration depth.

Physical Principle: The method is based on the principle that the depth of penetration of a probe driven into concrete is related to the concrete strength. The basic procedure consists of driving a probe into hardened concrete by a driver unit and measuring the penetration depth. The probe could either be a hardened steel rod (Windsor Probe) driven by a powder charge or a hardened steel pin driven by a spring. A relationship between penetration depth and compressive strength can be developed, and this relationship is then used to estimate the compressive strength.

Advantages:

- simple

- quick

- less affected by surface conditions than the rebound hammer test

Limitations:

Results are affected by:

- for gun-driven probe: type of coarse aggregate

- for spring-driven pin: tests impacting coarse aggregate are disregarded

- distance to reinforcement

Other limitations:

- for gun-driven probe: use for concrete strengths $<40 \mathrm{MPa}$ (6000 psi)

- for spring-driven pin: use for concrete strengths $<28 \mathrm{MPa}$ (4000 psi)

- size of member to be tested

- minimum distance to any edges or between two test locations ranges from $150 \mathrm{~mm}$ to $200 \mathrm{~mm}$

- minimum thickness of members is 3 times expected penetration depth

- Creates a disturbance on a small area of the concrete surface which will have to be patched

- Relationships between penetration depth and compressive strength may be supplied by the manufacturer of the equipment; however, these are generally empirical. More reliable results may be obtained if the relationships were calibrated using extracted cores.

Relevance to Service Life Prediction: Results may also be used to monitor changes in mechanical properties and relate these relative changes to those predicted by a service life model.

Standardization: ASTM C 803/C 803M

Commercial Availability: Yes (Windsor probe)

\section{References}

1. Malhotra and Carino (2004)

2. ACI Committee 228 


\subsection{Pullout Test}

Summary: The test determines the force required to pull out an insert embedded in concrete. The concrete compressive strength can be estimated based on developed relationships between the pullout force and compressive strengths.

Physical Principle: The pullout force is slowly applied (static load) by a loading system that reacts against the concrete surface through a reaction ring that is concentric with the insert (see

Figure 1). As the load is applied, an approximately cone-shaped section of concrete is extracted. The pullout strength is equal to the maximum load recorded. A relationship between pullout strength and concrete compressive strength is required to determine the concrete strength. A large number of studies have indicated that this relationship is linear, but some research has suggested that the relationship is non-linear and that a power-law function may be more appropriate (Malhotra and Carino 2004).

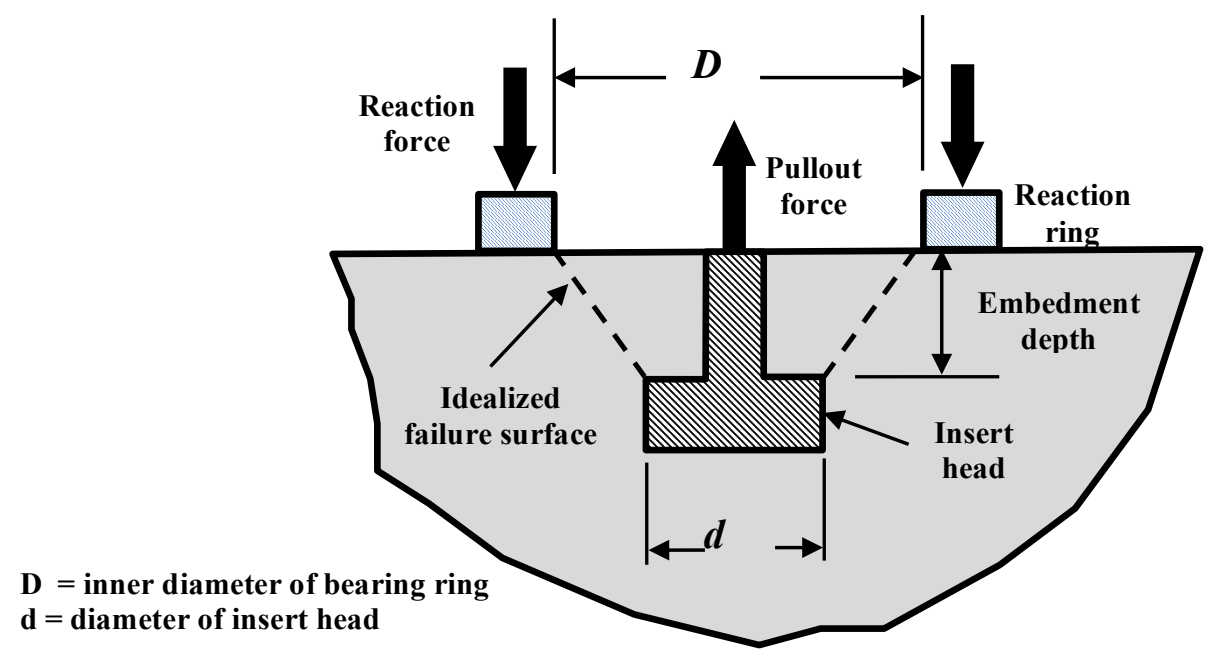

Figure 1. Schematic of the pullout test for cast-in-place concrete (from Malhotra and Carino 2004).

For new construction, the insert may be 1) attached to the formwork before placing concrete, 2) attached to formwork with special hardware for testing deep within the concrete, or 3) placed into the surface of the freshly placed concrete (Malhotra and Carino 2004). For existing construction, the procedure involves drilling a hole perpendicular to the concrete surface. An undercut slot is cut and milled, and an insert is expanded into the slot. The insert is then pulled out of the concrete. This procedure results in a failure mechanism similar to that for the standard cast-in-place pullout test and is included in ASTM C900.

There are other methods to determine the pullout strength of concrete for existing construction that require drilling a hole (without the undercut slot) and inserting an expanding insert. These methods do not result in the same failure mechanism as the standard cast-in-place pullout test and are not included in ASTM C900.

Advantages:

- Pullout test is a reliable method to estimate the concrete compressive strength 
- Pullout tests have good repeatability; the average value of the coefficient of variation for the pullout test is about $8 \%$. The variability is lower in mortar and lightweight concrete than in normal weight concrete (Malhotra and Carino 2004)

Limitations:

- Results may depend upon the size and type of coarse aggregate. As a result, the recommended practice is to develop the strength relationship for the particular concrete material used (Malhotra and Carino 2004).

- The test method removes material, creating a void in the concrete that will likely have to be patched or repaired.

Relevance to Service Life Prediction: Concrete strength is used to determine the structural integrity of a component. It may also be used to monitor changes in mechanical properties to monitor changes to the structural integrity.

Standardization: ASTM C900

Commercial Availability: Yes

Yes (e.g., LOK-TEST for new construction and CAPO (cut and pullout) for existing construction)

References

1. Malhotra and Carino (2004)

2. ACI Committee 228 


\subsection{Break-Off Test}

Summary: This method measures the force to break off a cylindrical specimen in a concrete structure. This force is used to estimate the compressive strength based on developed relationships between the break-off force and compressive strength. This method may also be used to evaluate the bond strength between concrete and overlay materials.

Physical Principle: The break-off test is based on breaking off a cylindrical specimen of in-place concrete. The failure of the cylindrical specimen is due to combined bending and shearing stresses and the failure plane is parallel to the concrete surface. The cylindrical specimen is $70 \mathrm{~mm}$ high with a $55 \mathrm{~mm}$ diameter. This method may be used for new or existing construction.

For new construction, the test specimen is made with a disposable tubular plastic sleeve attached to the formwork or inserted into fresh concrete. For existing construction, a special core bit is used to cut the core and the counter core. A hydraulic pump is used to apply the force to the core and the maximum pressure gauge reading in units of bars is called the break-off number of the concrete (see Figure 2) This value is used to estimate the compressive strength using a pre-established relationship between the break-off number and compressive strength.

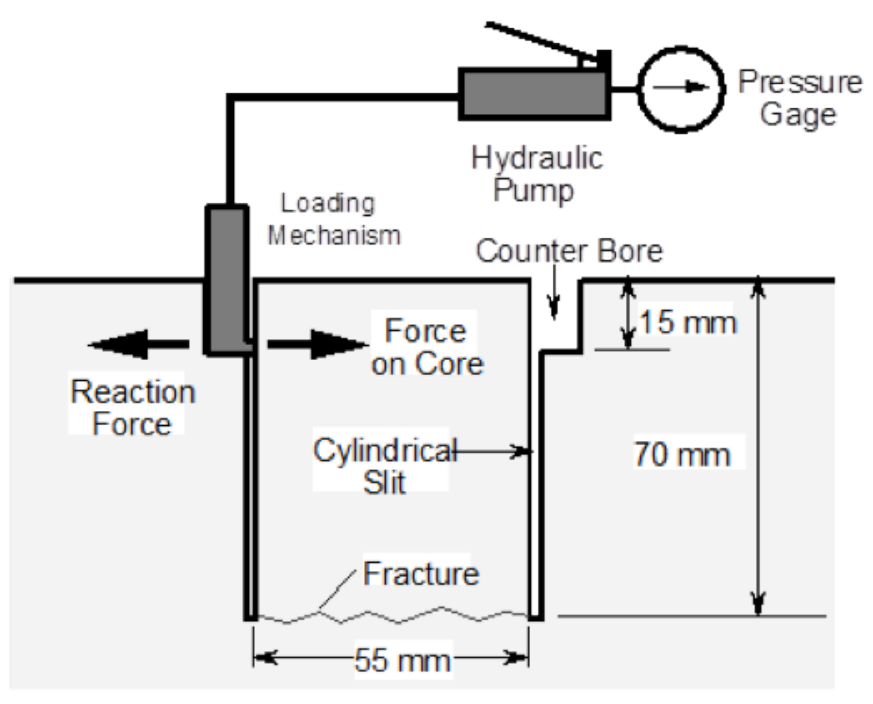

Figure 2. Schematic of the break-off test (Reprinted, with permission, from ASTM C1150-96 Standard Test Method for the Break-Off Number of Concrete, copyright ASTM International, 100 Barr Harbor Drive, West Conshohocken, PA 19428.) Note: This standard test method was withdrawn by ASTM International in 2002.

\section{Advantages:}

- Measures a direct strength parameter.

Limitations:

- Maximum aggregate size limited to $13 \mathrm{~mm}$ 
- Test not recommended for concrete with maximum nominal aggregate size greater than $25 \mathrm{~mm}$ (1 in)

- Variability of break-off number increases for larger aggregate sizes

- Strength relationships must be developed for a particular concrete mixture

Relevance to Service Life Prediction: Concrete strength is used to determine the structural integrity of a component. It may also be used to monitor changes in mechanical properties and relate these relative changes to those predicted by a service life model.

Standardization: ASTM C1150 (historical standard). This method is not widely used and ASTM discontinued the test method in 2002 (Malhotra and Carino 2004).

Commercial availability: Yes.

References

1. Malhotra and Carino (2004)

2. ACI Committee 228 


\subsection{Resonant Frequency Methods}

Summary: This method is used to primarily measure the dynamic modulus of elasticity of concrete. The modulus of rigidity and Poisson's ratio may also be calculated.

Physical Principle: This method is based on evaluating the natural frequency of a system. The natural frequency of vibration of an elastic system is primarily related to its dynamic modulus of elasticity and its density. The testing kit consists of equipment to generate the vibrations and equipment to measure them.

Two methods are used to measure the resonant frequency: forced resonance and impact resonance (Ferraro 2003). In the forced resonance method, a specimen is excited by a vibrating force. The driving frequency is varied and the specimen's maximum response corresponds to the resonant frequency. This test requires some operator skill and experience. The impact resonance method is similar to the forced resonance method and uses a small impactor to generate the vibrations in the specimen.

The dynamic modulus of elasticity is typically larger than the static modulus of elasticity.

Limitations:

Results are affected by:

- Percentage of total aggregate

- Properties of aggregate

- Size of specimen used in the measurements. It is not recommended that results be compared for specimens of different sizes or shapes.

- Curing conditions

The test method is usually conducted using small specimens in a laboratory environment instead of structural members in the field because the boundary conditions significantly affect the measurements.

Relevance to Service Life Prediction: It may also be used to monitor changes in mechanical properties and relate these relative changes to those predicted by a service life model. This test probes the entire cross section, so it may be more informative than surface hardness tests, and the resonant frequency can be related to the Young's modulus.

Standardization: ASTM C 215.

Commercial availability: Yes. Sonometer

References:

- Malhotra and Carino (2004)

- Ferraro (2003) 


\subsection{Acoustic Wave Methods}

These types of NDT methods are based on the propagation of stress waves and involve the interpretation of acoustic waves. The stress waves from a surface impact will propagate through a material and reflect back to a receiver when the wave encounters an internal flaw, void, or surface boundary (e.g., reinforcement). Three types of bulk waves are produced after the initial impact: compression, shear, and surface waves. Measuring the change in acoustic wave behavior in various materials, see Table 4, at various surface, interface, and defects within the material provides the means to detect reinforcing bars, voids, cracks, delaminations, and other interfaces or inclusions. These methods included ultrasonic testing (UT), acoustic emissions (AE), impact-echo, impact velocity, and other advanced UT phase array methods.

Table 4. The acoustic wave properties in three different media: steel, concrete, and air (Source: Aktan and Krueger 2007). Note: the density of water at $20{ }^{\circ} \mathrm{C}$ is $0.998 \mathrm{~g} / \mathrm{cm}^{3}$, and the speed of sound in water is $1482 \mathrm{~m} / \mathrm{s}$.

\begin{tabular}{|l|c|c|c|c|}
\hline Material & $\begin{array}{c}\text { Density, } \mathbf{g} / \mathbf{c m}^{\mathbf{3}} \\
\left(\mathbf{l b} / \mathbf{f t}^{\mathbf{3}}\right)\end{array}$ & $\begin{array}{c}\text { Velocity, } \mathbf{m} / \mathbf{s} \\
\text { (ft/s) }\end{array}$ & $\begin{array}{c}\text { Frequency, } \\
\mathbf{k H z}\end{array}$ & $\begin{array}{c}\text { Wavelength, } \mathbf{~ m m} \\
\text { (in) }\end{array}$ \\
\hline Steel & 7.83 & 5950 & 1000 & 6 \\
& $(490)$ & $(19520)$ & & $(0.25)$ \\
\hline Concrete & 2.4 & 4000 to 5000 & 50 & 80 to 100 \\
& $(150)$ & $(13,123$ to 16,404$)$ & & (3.1 to 4$)$ \\
\hline Air & 0.001 & 343 & 0.02 to 20 & $\begin{array}{c}16 \text { to } 16,000 \\
(0.63 \text { to } 630)\end{array}$ \\
\hline
\end{tabular}

There are two general categories based on detection configuration: methods using a through transmission mode such as ultrasonic pulse velocity for determination of elastic properties such as E-modulus, porosity, etc., and those using reflection mode, such as ultrasonic-echo and impact-echo methods for detection of flaws (e.g., honey combing, voids). Figure 3 shows the acoustic wave spectrum and the frequency range for different acoustic NDT methods (Aktan and Krueger, 2007). Each UT method will be described separately in the following paragraphs.

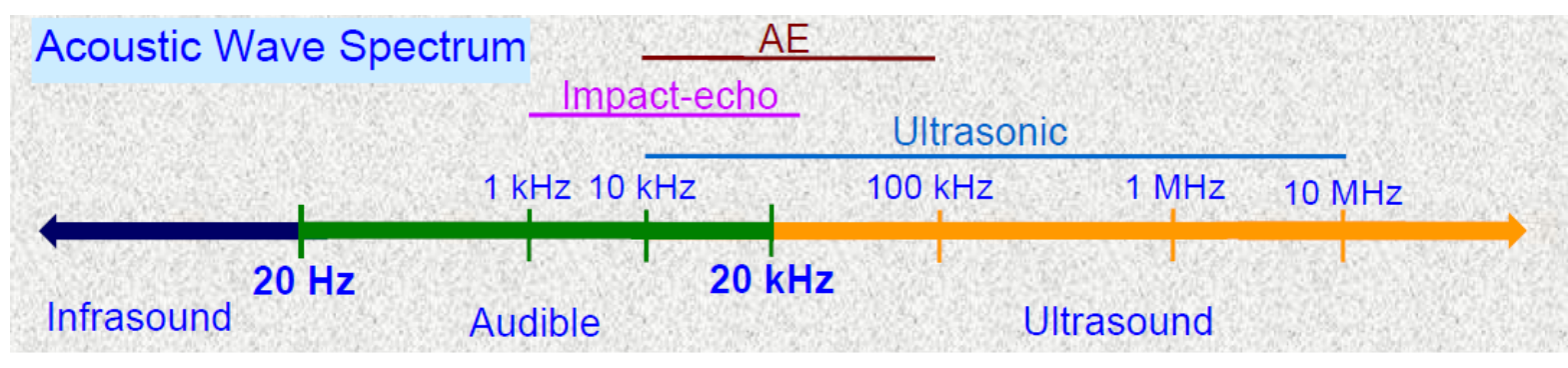

Figure 3. Acoustic wave spectrum and the frequency range for different acoustic NDT methods (adapted from Aktan and Krueger, 2007). 


\subsection{Ultrasonic Pulse Velocity (UPV)}

Summary: This method determines the relative condition (elastic properties) of concrete. Ultrasonic Pulse Velocity (UPV) is also used to detect anomalies in materials and setting behavior. Using the transmission method, the extent of defects, such as voids, honeycombing, cracks, and segregation may be determined. This test is the most widely used UT method to non-destructively assess concrete conditions.

Physical Principle: The test measures the time for an ultrasonic pulse to travel through concrete. A pulse of ultrasonic energy is introduced into the concrete by a transmitting transducer and is detected by a receiving transducer on the opposite surface. Figure 4 illustrates the effects of defects on travel time of an ultrasonic pulse, and shows a schematic of a through-transmission test system.

(a)

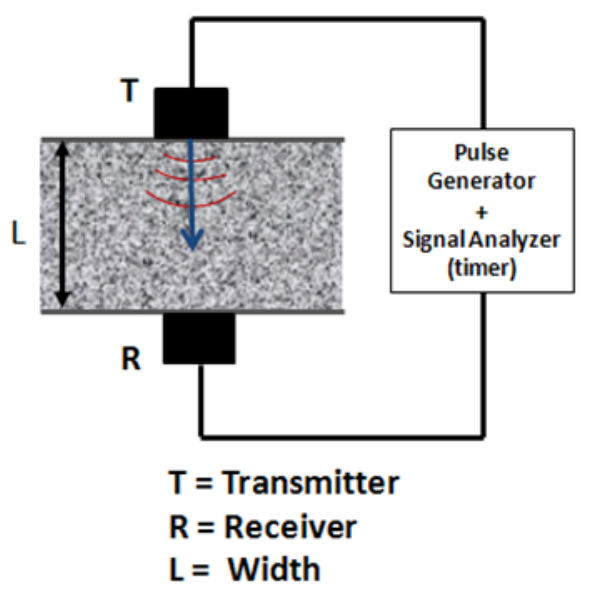

(b)

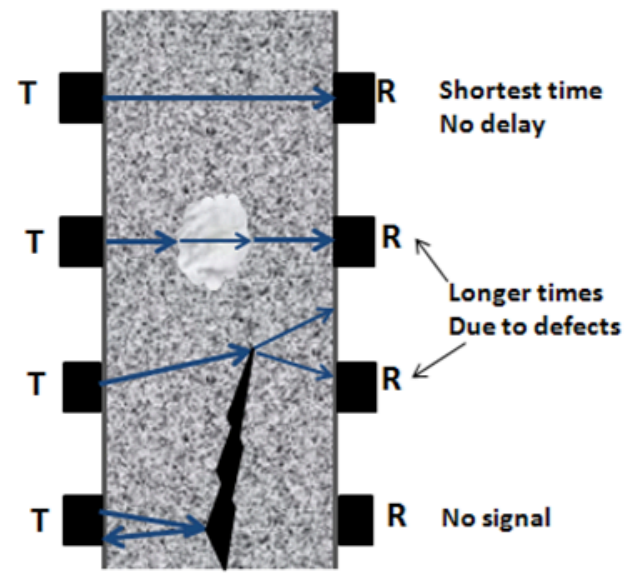

Figure 4. Schematic of (a) through-transmission UPV test system, and (b) effects of defects on the travel time of ultrasonic pulse (adapted from ACI 2004).

This method is suitable for locating regions of concrete of different quality, i.e., concrete uniformity (ACI 437). The dynamic modulus of elasticity may be computed using the ultrasonic pulse velocity method, if Poisson's ratio and material density are known or assumed. However, this is not recommended, because an inaccurate estimation of Poisson's ratio can result in significant error and the equation relating wave velocity and the dynamic modulus of elasticity is based on homogeneous materials (Malhotra and Carino 2004). For these reasons and because the relationship between the dynamic modulus of elasticity and concrete strength is nonlinear, the ultrasonic pulse velocity method may be used to estimate the in-situ concrete strength only if correlations between the pulse velocity and compressive strength for the given type of concrete have been established.

\section{Advantages:}

- Test procedure is simple and the equipment is easy to use

- Excellent for determining the quality and uniformity of concrete

- It can rapidly survey large areas and thick members 
- Path lengths of $10 \mathrm{~m}$ to $15 \mathrm{~m}$ can be inspected with suitable equipment

Limitations:

- Proper surface preparation is required

- It is a point measurement technique, which can be time consuming

- Although the equipment is easy to use, expertise is needed to interpret the results

- Moisture variations, amount and type of aggregates, and the presence of steel reinforcement can affect results

- It works better on single phase, homogenous materials

- It requires access to both sides of the concrete element (difficult for below grade elements)

Relevance to Service Life Prediction: This method can be used as a durability measure to evaluate the compressive strength of the concrete. Using the transmission method, the extent of defects, such as voids, honeycombing, cracks, and segregation may be determined. It may also be used to monitor changes in mechanical properties and relate these relative changes to those predicted by a service life model.

Standardization: ASTM C597

Commercial Availability: Yes

References:

- Aktan and Krueger (2007)

- ACI Committee 228

- Malhotra and Carino (2004)

- ACI Committee 437

- ACI (2004)

- Lawson et al. (2011)

- Trtnik et al. (2009) 


\subsection{Ultrasonic Pulse-Echo}

Summary: This method is used for testing and evaluating the integrity of various materials such as metals, alloys, and other homogeneous and fine-grained materials, and it can also been used as sonar for underwater detection and ranging. Recently, this method has been adapted for concrete NDT application with specialized hardware and software to improve the detection resolution. The system works well for concrete walls and slabs with a thickness of $30 \mathrm{~cm}$ or less.

Physical Principle: The ultrasonic pulse-echo (UPE) method measures the change in acoustic impedance at various interfaces, air voids, water-filled voids, reinforcing bars, cracks, delaminations, and other interfaces or inclusions within the concrete causes a portion of the input energy to reflect (echo) back to the surface (REMR 1991). Figure 5 illustrates the schematics of the UPE principle and a representative instrument setup (ACI 2004): (a) pulse-echo (source and receiver are one transducer) configuration, and (b) pitch-catch set up by using a separate receiving transducer located close to the transmitting transducer. An ultrasonic (acoustic) wave was generated by exciting a piezoelectric material with a high-amplitude, transient electric pulse from a high-voltage, high-current pulser (transmitter) and transmitted into concrete and travel forward various interfaces within. The amount of the reflected energy or signals detected by receiver based on the area of reflecting surface, angle of reflecting surface, and acoustic impedance of the reflecting materials(REMR 1991)

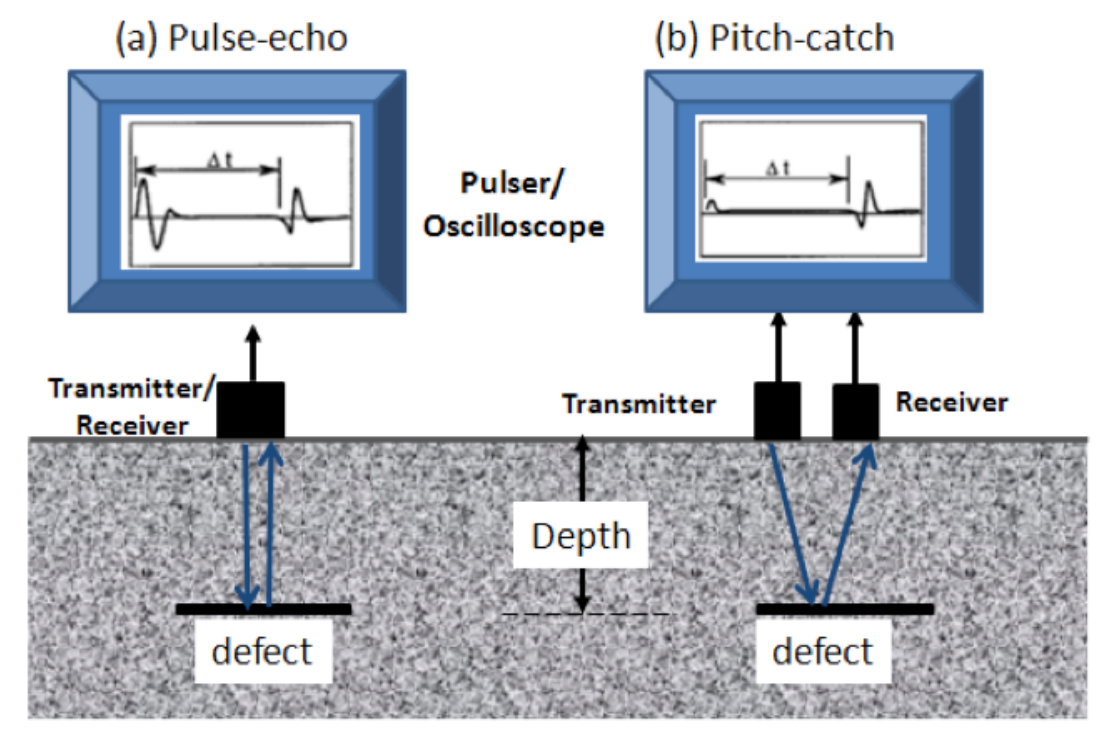

Figure 5. Schematic of ultrasonic pulse-echo and pitch-catch methods (adapted from ACI 2004).

Advantages:

- Portable, simple and inexpensive to operate

- Signal can be recorded and data can be post-processed

- High penetrating power to detect flaws deep in the concrete

- High sensitivity to detect extremely small flaws

- Only requires one accessible surface 
- More accurate than other nondestructive methods in determining the depth of internal flaws and the thickness of parts with parallel surfaces

- Some capability of estimating the size, orientation, shape and nature of defects

- Nonhazardous to operators or to nearby personnel.

- Capable of highly automated operation

Limitations:

- Requires experienced and trained technician

- Extensive technical knowledge is required for the development of inspection procedures

- Need high level of expertise to interpret the results, and calibrating standards are required

- Not suitable for detection in the rough, irregular in shape, very small or thin, or not homogeneous parts

- Proper surface preparation is required, clean surfaces without loose objects/materials

- Couplants are needed for better transfer of ultrasonic wave energy between transducers and parts being inspected

Relevance to Service Life Prediction: Determine the quality and condition of surface and interior concrete in dry and underwater environments. Ultrasonic-echo-short pulse can be used to locate delaminations and voids in thin concrete elements, which can then be incorporated into models for remaining service life.

Standardization: (not specifically written for use in reinforced concrete)

ASTM E317 Practice for Evaluating Performance Characteristics of Ultrasonic Pulse-Echo Testing Instruments and Systems without the Use of Electronic Measurement Instruments

ASTM E114 - 10 Standard Practice for Ultrasonic Pulse-Echo Straight-Beam Contact Testing

Commercial Availability: This technique is primarily in the research stage

References:

- ACI (2004)

- REMR (1991)

- Ultrasonic testing - Wikipedia 


\subsection{Impact-Echo (IE)}

Summary: This method determines the location and extent of defects such as delaminations, voids, honeycombing cracks, and debonding in plain, reinforced and post-tensioned concrete structures.

Physical Principle: Similar to UPV, the impact echo (IE) method is a stress wave technique based on the use of impact-generated stress (sound) waves that propagate through the structure and are reflected by internal defects and external surfaces. An impact is generated by tapping a steel ball bearing on a surface, and the impact causes $\mathrm{p}$-waves to radiate through the material. P-waves rebound upon encountering a surface, and rebounds are monitored at the transducer locations and recorded and displayed in a timevoltage graph (ACI 2004), as shown in Figure 6. The location and extent of detects such as voids, delaminations, deboning can be determined by analyzing the dominant frequencies, which appear as peaks in the spectrum, are associated with multiple reflections of stress waves resulting from surface or interface displacement within the structure.

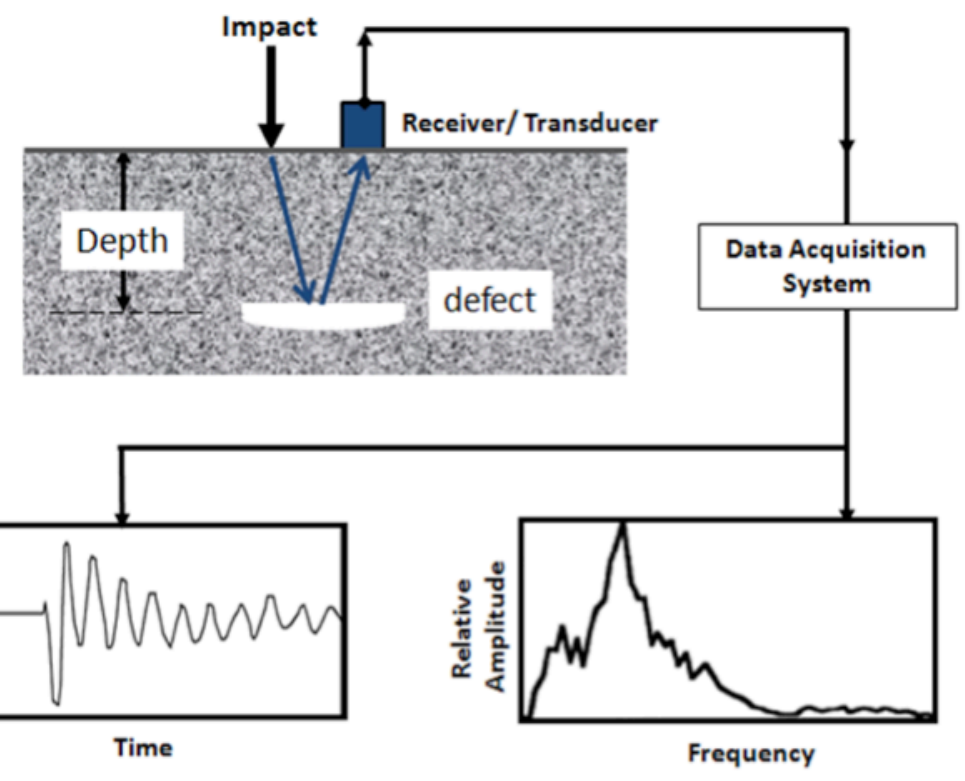

Figure 6. Schematic representing the operation of the impact-echo method, and the output of results (adapted from ACI 2004).

Advantages:

- Portable and easy to use

- Not affected by the presence of steel reinforcing bars

Limitations:

- Need expertise and experience to optimize testing parameters, recognize valid recorded wavefronts, and interpret the test results

- For small flaw detection, the results can be affected by

1. the type of flaw and its orientation

2. the depth of the flaw

3. the contact time of the impact 
Relevance to Service Life Prediction: This method can be used to identify the location of flaws (honeycombing, voids), and to detect and determine a crack's depth and width, which can then be incorporated into models for remaining service life.

Standardization: ASTM C 1383

Commercial Availability: Yes

References:

- Carino (2001)

- ACI (2004)

- Cho, Hong, and Lee (2009)

- Malhotra and Carino (2004) 


\subsection{Spectral Analysis of Surface Waves}

Summary: The spectral analysis of surface waves (SASW) method is used for the preliminary assessment of material stiffness and condition, and layer thickness. This method measures changes in the elastic properties of concrete slabs during curing, the detection of voids, and assessment of damage.

Physical Principle: The SASW method utilizes the dispersive characteristics of surface Rayleigh waves (R-wave) to determine the variation of the shear wave velocity (stiffness) of layered systems with depth (ACI 2004). The range of R-wave obtained by receivers contains a range of components of different wavelengths depending on the contact time of the impacts. The impacts may come from surface opening cracks, honeycomb zones, and other flaws (acting like an effective "layer"). The theoretical shear wave velocity profiles of these low velocity materials with a depth are estimated from the experimental dispersion curves (surface wave velocity versus wavelength) obtained from SASW measurements through an inversion process. If the calculated and experimental curves match, the problem is solved and the assumed stiffness profile is correct. If there are significant discrepancies, the assumed layered system is changed or refined and a new theoretical curve is calculated. This process continues until there is good agreement between the theoretical and experimental curves.

\section{Advantages:}

- Portable equipment, compact, lightweight, and easy to use

- Real-time waveform display while testing

Limitations:

- The complexity of the signal processing. There is also the possibility for non-unique solutions to dispersion curves (several sets of parameters can yield the same dispersion curve)

- Requires an accessible surface for receiver attachments

- The extent of the accessible surface limits the investigation depth

Relevance to Service Life Prediction: Measures relative concrete quality, estimates surface-opening crack depths, fire damage and freeze-thaw damage depths. It can be used for condition assessment of concrete liners in tunnels, slabs, and other structural concrete members.

Standardization: Not specifically developed for use in reinforced concrete.

ASTM D6758-02: Standard test method for measuring stiffness and apparent modulus of soil and soil aggregate in-place by an electro-mechanical method.

Commercial Availability: Yes- the simple version.

\section{Reference:}

- ACI (2004)

- Cho, Hong, and Lee (2009)

- IAEA (2005) 


\subsection{Nonlinear Ultrasonic Analysis}

Summary: Nonlinear ultrasonic techniques (UT) analyze the effect of non-linearities on acoustic/ultrasonic signals propagating through defect/damage of the materials. Nonlinear UTs offer unique advantages in their ability to detect small scale and incipient damage due to highly selective sensitivity to damage with nonlinear properties. They have been shown to be sensitive to nonlinear dynamic behavior produced by contact interfaces and inhomogeneities associated with structural damage such as micro-cracks/micro-damages or degradation, delaminations, etc. in materials.

Physical Principle: Conventional or linear UT is based on linear theory, which assumes that the presence of defects changes the phase and/or amplitude of output signals, but the frequency of the output signal remains the same as the input signal. Conventional UT measures some particular parameters of the propagating signal to determine the elastic properties of a material or detect defects. Conventional UT is sensitive to gross defects and open cracks, but less sensitive to evenly spaced microcracks or degradation. These types of defects change the frequency of the output signal from that of the input signal due to some kind of nonlinear mechanical behavior before significant plastic deformation or materials' damages occur (Jhang 2009, Payan et al. 2010, Zaitsev et al. 2006).

There are many different approaches using nonlinear ultrasonic properties. By generating and analyzing different frequencies, the nonlinear UT phenomena induced in solid materials can be categorized into four types (Jhang 2009): high harmonic generation; sub- harmonic generation, shift of resonance frequency, and mixed frequency response. The mixed frequency response is also called nonlinear wave modulation spectroscopy. Two methods exist for employing the nonlinear wave modulation spectroscopy or frequency modulation method (Haroon and Adams 2008): impact-modulation (IM) with an impulsive excitation of the natural frequencies and vibro-modulation (VM) with forced harmonic vibration. These methods are very close to the conventional linear pulse-echo technique supplemented with an additional, lower-frequency pump source in order to produce the crack/damage modulation. These modulation methods provide two major advantages: (1) Separation of the nonlinear signals caused by defects from the probe signals scattered from boundaries and other geometric features, which makes these methods highly sensitive to damage and relatively insensitive to geometry. (2) Utilization of relatively low ultrasonic frequencies with lower dissipation, which allows the inspection of larger structures with fewer numbers of transducers. There are other similar non-linear spectroscopic methods. These methods can again be split into two groups (Matysik et al. 2010a): (a) measurements using a single harmonic ultrasonic signal (a single frequency $f 1$ ), (b) measurements using multiple harmonic ultrasonic signals (usually, two frequencies $f 1, f 2$ ).

All non-linear UT techniques are still in the research development stages. The experimental design and signal processing tools for analyzing frequency, harmonic frequency, resonant frequency, and frequency modulation are extremely complex.

Advantages:

- High sensitivity to detect small scale and incipient damage

- Can be used for in situ monitoring of damage/degradation processes

- Can detect closed cracks

Limitations:

- Complicated experimental setup, difficult data analyses

- The complexity of the signal processing 
- Compared to conventional, single-element ultrasonic inspection systems, nonlinear UT instruments and probes are more complex and expensive

- Need extensive knowledge to plan the test and interpret results

- Nonlinear UT technicians require more experience and training than conventional technicians

Relevance to Service Life Prediction: It may be used for measuring nonlinear dynamic behavior produced by contact interfaces and inhomogeneities associated with structural damage (e.g., microcrack/micro-damages, degradation, delaminations) in materials. It may also be used for monitoring degradation processes that can produce changes in mechanical properties and relate these relative changes to those predicted by a service life model.

Standardization: No

Commercial availability: No. Still in the research stage.

References:

- Jhang (2009)

- Payan et al. (2010)

- Zaitsev et al. (2006)

- Haroon and Adams (2008)

- Matysik et al. (2010a) 


\subsection{Acoustic Emission}

Summary: Acoustic Emission (AE) is used for detecting and locating faults in pressure vessels, or leakage in storage tanks or pipe systems, monitoring welding application and corrosion processes. This method can also measure acoustic sound waves emitting from the growth of microcracking/cracking in concrete, so it can be used for corrosion monitoring.

Physical Principle: Acoustic Emission is a phenomenon that occurs when an elastic wave is generated by a rapid release of energy accumulated in the stressed material. The sensor is a transducer that converts a mechanical wave into a signal (see Figure 7). By analyzing the signal (Figure 7), the information on the location of a possible source can be determined and recorded. The quantitative AE method uses triangulation to identify the exact coordinates of the $\mathrm{AE}$ events accurately. It will need two sensors for linear, three for planar, and four for volumetric-based location determination of the source. The wave propagation velocity and exact position of the sensor is also required (Malhotra and Carino (2004).



Figure 7. Schematic illustrating the principle of the AE process, and the characteristics of typical burst signals recorded from the sensor (adapted from Aktan and Krueger, 2007).

Advantages:

- It monitors the response of an existing structure to applied load

- It is capable of detecting the onset of the failure and locating the sources of possible failures

- Since acoustical signals come from defects throughout the structure, a few transducers are sufficient to detect and locate defects over a larger area

- Off-the-shelf sensors and instruments for collecting emission data are readily available

Limitations:

- The equipment costs are high- complex electronic equipment

- Need extensive knowledge to plan the test and interpret results

- The method is not yet fully developed - laboratory 
- Most R\&D efforts focus on developing valid methodologies that relate AE signals to structural health

Relevance to Service Life Prediction: This method can be used for continuous monitoring of a structure throughout its service life to detect impending failure and monitor performance of the structure during proof testing. This method has also been used in recent years to study the initiation and growth of cracks in concrete under stress so it can be used for corrosion monitoring. The method can be used for comparative durability assessment of concrete culverts reinforced with steel and glass fiber reinforced polymer.

Standardization:

ASTM E 1316

Commercial Availability: No; still in the development stage

Reference:

- ACI (2004)

- Pei et al. (2010).

- Malhotra and Carino (2004), Chapter 16 


\subsection{Ultrasonic Phased Arrays / Ultrasonic Phase Spectroscopy}

Summary: Phased Array (PA) ultrasonics is an advanced method of ultrasonic testing. It has been used in medical imaging and industrial nondestructive testing. Recent PA applications include weld inspection, bond testing, thickness profiling, and in-service crack detection.

Physical Principle: Phased array ultrasonics systems consist a transducer assembly with multiple elements arranging in a strip (linear array), a ring (annular array), a circular matrix (circular array), or a more complex shape, that can be pulsed separately. Using the wave physics principle of phasing, by varying the time between a series of outgoing ultrasonic pulses (individual or by group), the ultrasonic beam can be controlled and focused through various angles, focal distances, and focal spot sizes in such a way that a single probe assembly is capable of examining the test material across a range of different perspectives (Olympus-NDT 2010). Using software control, specific beam shapes can be generated to account for probe and wedge characteristics, as well as the geometry and acoustical properties of the test material. Transducer frequencies are most commonly in the range from $2 \mathrm{MHz}$ to $10 \mathrm{MHz}$.

\section{Advantages:}

- Multiple probe elements produce a steerable, tightly focused, high-resolution beam

- Produces an image that shows a slice through the object

- Can be used for mapping components at appropriate angles, and simplify the inspection of components with complex geometries

- With multiple angles from a single probe, the probability of detection of anomalies is greatly increased

- The ability to focus at multiple depths also improves the ability for sizing critical defects for volumetric inspections

Limitations:

- Compared to conventional, single-element ultrasonic inspection systems, PA instruments and probes are more complex and expensive

- Need extensive knowledge to plan the test and interpret results

- PA technicians require more experience and training than conventional technicians

Relevance to Service Life Prediction: In principle, this method can be used to characterize and map the crack shape inside the concrete wall. Multiple angles from a single probe greatly increase the probability of detection of anomalies. The ability to focus at multiple depths also improves the ability for sizing critical defects for volumetric inspections. Identified changes occurring in the structure can then be compared to whether service life prediction models are predicting changes.

Standardization:

- European Committee for Standardization (CEN)

- prEN 16018, Non destructive testing - Terminology - Terms used in ultrasonic testing with phased arrays

- ISO/WD 13588 - prEN 13588, Non-destructive testing of welds - Ultrasonic testing-Use of (semi-) automated phased array technology

- ASME Section V, Article 4, 2010 ed. Ultrasonic Testing of Welds

ASME Section I, Boilers

ASME Section VIII, Pressure Vessels 
ASME B31.1, Power Piping

ASME B31.3, Petrochemical Piping

Commercial Availability: Yes, but mostly for pipe and steel applications. Applications for reinforced concrete are still in the research stage.

References:

1. Olympus-NDT (2010)

2. Paris et al. (2003)

3. Shao (2011). 


\subsection{Non-Contact Ultrasound}

Summary: The Non-Contact Ultrasound (NCU) method is based on UT NDT without a contact coupling agent. This technique has been applied to ceramics, metals, polymers, and particulate and fibrous composites for the measurement of thickness, density, velocity, defects, microstructure, mechanical properties, and imaging. Recent research efforts include cements, aggregate, reinforced concrete, and asphalts.

Physical Principle: Most UT methods use acoustic coupling medium, e.g. gel or jets of water to ensure direct bonds between transducers to the test object for transmitting the UT energy effectively. In NCU methods, special transducers and systems are designed to overcome the acoustic impedance mis-match between the coupling air and the test samples. For example, an electromagnetic acoustic transducer (Thompson 1990), is a type of non-contact ultrasound that generates an ultrasonic pulse which reflects off the sample and induces an electric current in the receiver. The result (electric current) is then analyzed and interpreted with the help of clues about the internal structure of the sample such as cracks or faults.

Research is ongoing to improve traditional transducers by applying different plastics, elastomers, and other materials. The sensitivity of these devices continues to improve; a newly developed piezoelectric transducer can produce frequencies in the $\mathrm{MHz}$ range that can easily propagate through even high acoustic impedance materials such as steel, dense ceramics, and concrete (Purnell et al. 2004).

\section{Advantages:}

- Non-contact measurements

- No couplant is needed: there are no contaminations from couplants or water, thus the reliability of the scanning process is enhanced

- Surface preparation is not required

- Facilitates testing of materials or components that are continuously rolled on a production line, in extremely hot environments, coated, oxidized, or otherwise difficult to physically contact: e.g., ceramics, metals, polymers, and particulate and fibrous composites

\section{Limitations:}

- Need routine calibration

- The transmitted ultrasonic energy is relatively low

Relevance to Service Life Prediction: This method can be used to detect defects, cracks, and delaminations, which can then be incorporated into models for remaining service life.

Standardization: None

Commercial Availability: Yes, but most of the applications are for ceramics, metals, polymers, and particulate and fibrous composites

References:

- Thompson (1990)

- Purnell, Gan, Hutchins, and Berriman (2004)

- Berriman, Gan, Hutchins, and Purnell (2003) 


\section{ELECTROMAGNETIC METHODS}

\subsection{Time-Domain Reflectometry}

Summary: This technique detects the discontinuities in metallic cable, connector, and other electric paths. TDR can also been used to determine moisture content in soil and porous media.

Physical Principle: Similar to radar, a TDR transmits a short rise time pulse along the conductor. No reflected signals returns if the conductor has uniform impedance and is properly terminated. Any impedance discontinuities, such as from cracks that intersect the conductor or variation in impedance in the pathway, will cause some of the incident signal to be sent back towards the source. The resulting reflected pulse can be recorded as a function of time and analyzed with respect to the original signal. The impedance characteristics, defect and connector locations and associated losses and estimate cable lengths can be determined.

Recent research efforts include: (1) measurement of the water content, cement content, water/cement ratio, and compressive strength; (2) the TDR combined with a coaxial-cable crack sensor embedded in a full-scale reinforced concrete for dynamic structure analysis by detecting the location of cracks (Bishop et al. 2011).

\section{Advantages:}

- Can be performed relatively quickly

Limitations:

- Still in research stage for concrete structures

- Complex data analysis

- No established standardized practice and test methods

Relevance to Service Life Prediction: Can be potentially used for measuring water content, cement content, water/cement ratio, and compressive strength; and for dynamic structure analysis. This would be very useful in applications where moisture content or changes in moisture content are important, such as concrete located below the water table.

Standardization: Not specially written for reinforced concrete structure application. ASTM D6565 - 00(2005) Standard Test Method for Determination of Water (Moisture) Content of Soil by the Time Domain Reflectometry (TDR) Method.

Commercial availability: Yes, however, it is not specifically designed for use in reinforced concrete structures.

Reference:

- Bishop, Pommerenke, and Chen (2011)

- Mollo and Greco (2011)

- Yu, Drnevich, and Olek (2004)

- Drnevich (2012) 


\subsection{Infrared Thermography}

Summary: Infrared Thermography - non-contact temperature measurement, "heat radiation".

Physical Principle: Thermal or infrared energy is part of the EM spectrum and is perceived as heat, using an infrared imaging equipment (e.g. camera), the thermal energy or hear radiation can be measured and analyzed.

Mid-wave infrared (3,000 $\mathrm{nm}$ to $6,000 \mathrm{~nm})$ can be used for non-destructive testing; long-wave $(6,000 \mathrm{~nm}$ to $15,000 \mathrm{~nm}$ ) can be used for roof inspection and building envelop inspection.

\section{Advantages:}

- Portable and permanent record can be made

- Testing can be done without direct access to surface and larger areas can be scanned rapidly using infrared cameras

- It provides area testing instead of point or line testing

Limitations:

- It's an expensive technique

- Reference standards are needed

- Requires a highly skilled and experienced operator

- A heat source to produce thermal gradient in the test specimen might be required

- Need understanding of thermal behavior and patterns to accurately interpret the results.

- Very sensitive to thermal interference from other sources and the factors affecting IR thermography, such as:

- Heat transfer phenomenon- conduction, convection, reflection or emission

- Materials properties- emissivity, heat capacity, and thermal conductivity

- Void size, shape, orientation, thickness and depth

- Moisture

- Heat source (active or passive), intensity and duration

- Observation time (function of material properties of the object and depth of the assessment)

- Environmental conditions

Relevance to Service Life Prediction: Observation and evaluation of surface temperature variations as a function of time to identify the non-uniformity of the concrete interior. It can be used for detecting delaminations, heat loss and moisture movement through concrete elements, especially flat surfaces. It can also be used for moisture detection.

Standardization:

ASTM D4788-88 Standard test method for detecting delamination in bridge decks using Infrared Thermography

Commercial Availability: Yes.

Reference:

- ACI (2004)

- IAEA (2005) 


\subsection{Gamma Ray/X-ray Radiographic Testing}

Summary: Gamma radiography (or X-ray radiography) uses the penetrating high-energy electromagnetic radiation (gamma or X-ray) to examine parts and products for imperfections. This method can be used for locating reinforcing and prestressing steel, conduits, pipes, voids, and honeycombing in the concrete structure.

Physical Principle: Degree of the attenuation of the Gamma radiation (X-ray) depends on the density and thickness of the constituent parts of the material. The attenuated radiation intensity, or 2-dimensional images can be recorded and analyzed.

\section{Advantages:}

- Applicable to a variety of materials

- Produce permanent images that are retrievable for future reference

- It can be used for field measurement

- It is capable of detecting surface, subsurface, and internal discontinuities

- Many versions of the equipment are portable

Limitations:

- Need two sides accessibility (film side and source side). It is difficult to place photographic film in the suitable position, especially in nuclear power plant (NPP) applications

- Problem for health and safety - long exposure time

- Require highly trained personnel in the subject of radiography as well as radiation safety

- The equipment and other accessories related to radiation safety are expensive

- Incapable of detecting laminar discontinuities

- Results are not instantaneous- need film processing, interpretation and evaluation

Relevance to Service Life Prediction: Mainly used for examining steel members. It can also be used to detect voids in the concrete and the position of prestressing ducts; locating internal cracks, voids, and variations in density of materials, grouting of post tensioned construction as well as locating the position and condition of reinforcing steel in concrete.

Standardization: For the operation of technique, but not for application in reinforced concrete structures ASTM E1742 / E1742M - 11 Standard Practice for Radiographic Examination.

Commercial Availability: Yes.

\section{$\underline{\text { Reference: }}$}

- ACI (2004)

- IAEA (2002)

- IAEA (2005) 


\subsection{Ground-Penetrating Radar (GPR)}

Summary: The ground-penetrating radar (GPR) method measures the dielectric constant variation in materials. GPR can be used for locating buried structures and utility lines, and studying soils and bedrock in the geotechnical, environmental and engineering fields.

Physical Principle: Analogous to ultrasonic echo methods using stress waves, GPR uses electromagnetic (EM) waves in the microwave band, GPR antennas detect and record the reflected signals from subsurface structures (e.g., voids, cracks) having different dielectric constants from the surrounding media, or reflected from the interface/boundary between layered systems having different dielectric constants. GPR antennas are generally in contact with the ground for the strongest signal strength; however, GPR air launched antennas can be used above the ground. The range of frequencies and related applications are described as following:

In the ground-coupled antennas mode:

- (900 to1600) $\mathrm{MHz}$ (penetration depth $0.5 \mathrm{~m}$ to $1 \mathrm{~m}$ ) - concrete evaluation;

- (400 to 900$) \mathrm{MHz}$ (penetration depth $1 \mathrm{~m}$ to $4 \mathrm{~m}$ ) for void detection

In the air-launched antennas mode:

- $2.2 \mathrm{GHz}$ (up to $0.75 \mathrm{~m}$ depending on medium) for pavement thickness and road condition assessment, $1 \mathrm{GHz}$ (penetration depth $1 \mathrm{~m}$ ) for highway and bridge deck evaluations.

Advantages:

- It can be used to survey large areas rapidly for locating reinforcement, voids, and cracks

- Less expensive and faster than radiography without the ionizing radiation source concerns

Limitations:

- User must have good knowledge of wave propagation behavior in materials in order to meaningfully collect and interpret results

- Results must be correlated to test results on samples obtained- understanding the relationship between radar signatures and various types of defects in the structure and how these signatures are affected by the condition of the structure (e.g. moisture)

- With increasing depth, low level signals from small targets are harder to detect due to signal attenuation

- It is expensive to use and uneconomical for surveying small areas

- Data are complex: commercial and experimental algorithms require validation

Relevance to Service Life Prediction: In principle, this method can be used to detect a number of SLP parameters: the location, depth and size of reinforcement, grouted ducts; the depth of the concrete cover; the location of voids; the location of cracks; the in-situ density, and the moisture content variations in reinforced concrete structures. This information would be useful in establishing dimensional and material parameters for a service life prediction model.

Standardization:

ASTM D4748 - 10 Standard Test Method for Determining the Thickness of Bound Pavement Layers Using Short-Pulse Radar

Commercial Availability: Yes. 


\section{Reference:}

- IAEA (2005)

- http://en.wikipedia.org/wiki/Ground-penetrating_radar 


\subsection{Eddy Current / Pulse Induction}

Summary: The eddy current (ET) testing method can be used for detecting cracks in structural components having a flat surface, and the presence of surface and subsurface discontinuities.

Physical Principle: Eddy current testing methods are based on applying an AC current around a specimen by using a coil. Inducted current (ET) is generated close to the surface of the specimen. Alternating ET in turn will produce a secondary magnetic field $\left(\mathrm{H}_{\mathrm{s}}\right)$, which is always in opposite direction with the primary magnetic field $\left(\mathrm{H}_{\mathrm{p}}\right)$. When there is a discontinuity that obstructs the ET path, it will alter the values of $\mathrm{H}_{\mathrm{s}}$, and consequently affects the resultant magnetic field $\left(\mathrm{H}_{\mathrm{p}}-\mathrm{H}_{\mathrm{s}}\right)$. Parameters that affect $\mathrm{H}_{\mathrm{s}}$ include conductivity, permeability, heat treatment, and the presence of surface and subsurface discontinuities.

Advantages:

- The results can be obtained instantaneously

- The inspection systems can be easily automated

- It is a non-contact method

- It is portable and suitable for field application

- Some equipment are made dedicated for specific measurement (e.g. conductivity, crack depth, etc.)

Limitations:

- Applicable only to conducting materials

- If it is to be used for ferromagnetic materials, the item must be magnetically saturated to minimize effects from permeability

- Requires a highly skilled and experienced operator

- Applicable only for the detection of surface and subsurface discontinuities

Relevance to Service Life Prediction: This method would be limited to applications where there is access to the metallic cladding on a concrete.

Standardization:

- ASTM E1629 - 07 Standard Practice for Determining the Impedance of Absolute Eddy Current Probes

- ASTM E1004 - 09 Standard Test Method for Determining Electrical Conductivity Using the Electromagnetic (Eddy Current) Method

Commercial Availability: Yes

References:

- $\operatorname{IAEA}(2005)$ 


\subsection{Laser Shearography}

Summary: This method may be used to detect strain fields, defects, and delaminations.

Physical Principle: Laser shearography is an interferometric technique. The basic method of laser shearography is to record images, on a CCD camera, of an object illuminated with a laser in an unstressed state and in a stressed state. These images are digitized and the two images are subtracted to obtain a displacement gradient. It has been a tool for qualitative, non-destructive inspection; although there has been some effort to obtain quantitative results (Charrett et al., 2011, Lopes et al., 2010, Groves et al. 2007). Currently, this technology is more commonly used in the aerospace and automotive sectors and for composite and polymeric materials. Some potential applications relevant to nuclear structures are given in Groves et al. (2006, 2003) where shearography was used to measure the strain distribution around cracks and to characterize the surface strain around a welded joint in a pipe.

Advantages:

- Non-contact

- Rapid defect detection

Limitations:

- Requires experienced personnel to interpret the results. Application of stress to thick or extremely stiff structures may limit the use of this technology

Relevance to Service Life Prediction: Surface strain is often an indication of internal stress, and could be used as a monitoring strategy to indicate that further testing is needed. The existence of internal stress could be compared to predictions from service life models.

Standardization: Not applicable for concrete structures.

ASTM E2581 -07, Standard Practice for Shearography on Polymer Matrix Composites, Sandwich Core Materials and Filament Wound Pressure Vessels in Aerospace Applications

Commercial availability: Yes

References:

- Charrett, Francis, Tatam (2011)

- Lopes, Ribeiro, Vaz, Gomes, (2010)

- Groves, Chehura, Li, Staines, James, and Tatam (2007)

- Groves, James, and Tatam (2003)

- Groves, Furfari, Barnes, James, Fu, Irving, and Tatam, (2006) 


\section{NUCLEAR METHODS}

\subsection{Neutron Radiography}

Summary: Neutron radiography (NR) can be used for inspecting and imaging the hydrogenous materials within the component of metals such as steel, brass, etc.

Physical Principle: Similar to the process used in X-ray radiography, neutron radiography images organic materials inside a component, and the resulting image is based on the neutron attenuation properties of the imaged object. Attenuation of X-rays is proportional to density, whereas neutron absorption is not. Many commonly used metals allow most neutrons to pass through, so they have a transparent appearance in neutron radiographic images (IAEA 2002). The experimental setup can be in forward scattering or backscattering configurations. In many cases, x-ray and neutron radiography are complementary NDT inspection processes, offering a complete picture not only of the integrity of the component, but also of the organics within that component.

\section{Advantages:}

- Can be used to determine hydrogen content quantitatively in various materials

- The method can provide visualization of water in a concrete specimen, and the time-dependent transport properties of the water

\section{Limitations:}

- Requires highly trained personnel in the subject of radiography as well as radiation safety

- The cost of the equipment and other accessories related to radiation safety are expensive

- Long exposure times could lead to health and safety issues

Relevance to Service Life Prediction: NR can be used for inspection of internal flaws such as cracks, inclusions, voids, bubbles, foreign materials, density variations and misalignments in reinforced concrete structures. It can be used to study the earlier deteriorating mechanisms in the reinforced concrete structures by following the water movement into cracks and into damaged interfaces between steel reinforcement and concrete.

Standardization: Yes

ASTM C1040: Procedures for using nuclear methods to measure the in-place density of fresh or hardened concrete- development of the calibration curve of the instrument (direct transmission nuclear gage)

ASTM E748 - 02(2008) Standard Practices for Thermal Neutron Radiography of Materials

Commercial Availability: It is widely used in the aerospace industry for the testing of turbine blades in airplane engines, components for space programs, high-reliability explosives, and to a lesser extent in other industries to identify problems during product development cycles.

Primarily used in scientific research and investigation in the reinforced concrete structure application.

References:

- $\operatorname{IAEA}(2002)$

- Wittmann (2010)

- Hignett and Evett (2000) 


\subsection{Neutron Moisture Gauge}

Summary: A neutron moisture gauge is a moisture meter utilizing neutron scattering. This method can be used to measure moisture content of concrete, soil, and bituminous materials and to map moisture migration patterns in masonry walls.

Physical Principle: This gauge measures the level of backscatter intensity of neutrons due to the number of hydrogen molecules in the water to determine moisture content in the structures such as concrete. The greater the backscatter, the more moisture there is in the concrete.

Advantages:

- The instrument is portable

- Moisture measurement can be made rapidly

Limitations:

- A minimum thickness of the surface layer is required for backscatter to be measured (50 $\mathrm{mm})$

- It emits radiation

- The results are inaccurate because hydrogen molecules of building materials are measured in addition to the water

- Calibrations are needed in order to calculate density and moisture content

- Operated by trained and licensed personnel

Relevance to Service Life Prediction: Changes in the moisture content of concrete may be important for concrete located below the water table.

Standardization: Yes

ASTM C1040: Procedures for using nuclear methods to measure the in-place density of fresh or hardened concrete- development of the calibration curve of the instrument (direct transmission nuclear gage)

Commercial Availability: Its application in concrete is limited-very recent -still in the exploratory stage.

\section{References:}

- Hignett and Evett (2000) 


\section{CHEMICAL / ELECTRICAL METHODS}

\section{$10.1 \mathrm{pH}$}

Summary: The $\mathrm{pH}$ of a solution depends upon the concentration of $\mathrm{H}^{+}$species in a solution. The chemical activity of this species (expressed as $a_{\mathrm{H}^{+}}$) is related to the concentration, and the $\mathrm{pH}$ is determined from the following mathematical expression:

$$
\mathrm{pH}=-\log _{10} a_{\mathrm{H}^{+}}
$$

Physical Principle: A pH probe measures the electrochemical potential between a sample solution and an internal solution (typically $\mathrm{KCl}$ ). The internal solution is separated from the sample solution by a thin porous glass membrane that is coated (inside and out) with a very thin gel. The gel exchanges $\mathrm{Na}^{+}$for the $\mathrm{H}^{+}$, and the $\mathrm{Na}^{+}$are transported through the glass membrane. An additional reference electrode, having a separate buffer solution and exchanging solution (via a porous glass membrane), complete the circuit. A high impedance multimeter is used to determine the voltage between the two electrodes within the $\mathrm{pH}$ probe, and the device is calibrated using standard solutions of known $\mathrm{pH}$.



Figure 8. Schematic of $\mathrm{pH}$ probe.

Advantages: A pH measurement is relatively easy to perform, and requires common instrumentation (high-impedance multimeter). 


\section{Limitations:}

- The probe must be kept wet

- The electrical response becomes nonlinear at very high and very low $\mathrm{pH}$

- High concentrations of sodium can confound the results

- The measured voltage depends on temperature

- Carbonates may damage the glass membrane

- Must be periodically recalibrated

- Relatively short service life

Relevance to Service Life Prediction: The chemical state of the pore solution in a hydrated cement paste depends strongly on the $\mathrm{pH}$. Service life prediction models that include the effects of hydration and chemical reaction can predict $\mathrm{pH}$, and the predicted value can be compared to the measurement.

\section{Standardization:}

- ASTM E70 - 07 Standard Test Method for pH of Aqueous Solutions With the Glass Electrode

- ASTM D1293 - 12 Standard Test Methods for $\mathrm{pH}$ of Water

Commercial Availability: Yes

References:

- www.astisensor.com/minimizing_user_errors_ph.pdf 


\subsection{Carbonation Depth}

Summary: The cement paste fraction of concrete is normally in equilibrium with a high $\mathrm{pH}(>12)$ aqueous solution. The effect of carbonation is to dramatically reduce the equilibrium $\mathrm{pH}$. Therefore, a color $\mathrm{pH}$ indicator can be used to detect the extent of carbonation by applying it directly to the surface of the concrete and observing the color change.

Physical Principle: A specimen is extracted (typically a core) from the structure, and a (dilute) phenolphthalein solution is applied along the side of the core. The surface previously exposed to air will have carbonated (to some degree). These outer areas will have a reduced $\mathrm{pH}$, and the unaffected concrete will have a high $\mathrm{pH}(>12)$. As a result, the phenolphthalein solution will not change color in the presence of carbonation. The depth of the boundary between these two regions is the carbonation depth. The ratio of the core diameter to the maximum aggregate size will dictate how many measurements are required on a core, and how many cores must be taken, before one can obtain a representative sample.

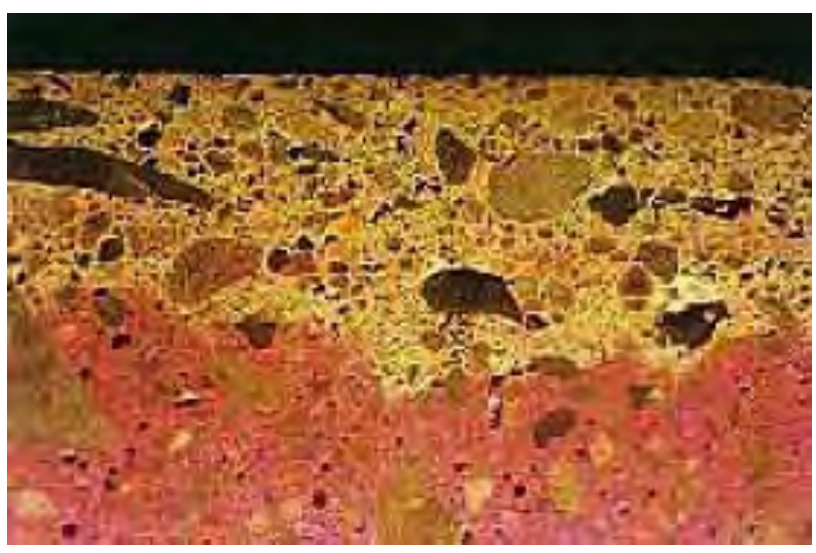

Figure 9. Image ( $20 \mathrm{~mm}$ field width) of phenolphthalein indicator applied to a concrete sample cross section. The upper surface was exposed to the atmosphere. The boundary between the unaffected and the stained (pink) region is the depth of carbonation. From Walker et al. (2006).

Advantages:

- The test is easy to perform and relatively inexpensive

- The only equipment required is the phenolthalein solution and a ruler

Limitations:

- The test requires sample extraction

- The sample must be discarded and the extraction site may require a patching compound

Relevance to Service Life Prediction: A service life model that incorporates the effects of hydration and chemical reaction could also incorporate the effects of carbonation. Measurements of carbonation depth could be compared to predictions.

Standardization: No references found.

Commercial Availability: Phenolphthalein solution is readily available from laboratory chemical supply companies. Field test kits are also readily available from commercial suppliers. 
References:

- IAEA (2002)

- $\quad$ Naus (2009) 


\subsection{Chloride Analysis}

Summary: Reinforced concrete exposed to chlorides is susceptible to corrosion of the reinforcement. Determining the chloride concentration as a function of depth provides useful feedback in estimating the remaining time before the steel becomes de-passivated, and corrosion is initiated.

Physical Principle: A chemical analysis is made on samples taken at varying depths within the concrete. A core is taken from the concrete and is ground down in layers, producing individual samples at each depth. Each sample is then analyzed for either the water-soluble or the total (acid soluble) chloride content. The testing for chlorides in solution is done with commercial apparatus, which is typically an automated titration device.

Advantages: The test method has been standardized, so it is relatively easy to perform in a repeatable manner.

Limitations:

- Only the chlorides in solution affect the de-passivation of the steel

- The water-soluble test is not as repeatable as the acid-soluble test

Relevance to Service Life Prediction: Performance prediction models that incorporate diffusion can predict the chloride profile and the onset of corrosion. A chloride analysis would provide useful validation data as part of a monitoring strategy.

Standardization:

- ASTM C1218 - Standard Test Method for Water-Soluble Chloride in Mortar and Concrete

- ASTM C 1152 - Standard Test Method for Acid-Soluble Chloride in Mortar and Concrete

Commercial Availability: Yes.

References:

- Naus (2009) 


\subsection{Staining (Alkali-Silica Reaction)}

Summary: A chemical can be applied to the surface of a concrete to detect the presence of alkali-silica reaction (ASR).

Physical Principle: Alkali-silica reaction occurs when amorphous or micro-crystalline silica in the aggregate reacts with the hydroxyl $\left(\mathrm{OH}^{-}\right)$species to form an alkali-silica gel that imbibes a relatively large amount of water. The uptake of water increases the volume of the gel considerably, so the gel expands into the surrounding cement paste. Depending on the porosity of the cement paste and the rate of the gel expansion, the gel can generate expansive forces that are great enough to create an observable expansion of the entire structure, and will likely result in cracking that can be observed at the surface.

Two staining tests have been designed to detect the alkalis in the gel. One of the first tests was the uranyl acetate test to detect the sodium under ultra-violet light (Natesaiyer and Hover 1998). A subsequent test has been developed using sodium cobaltinitrite to detect potassium (Guthrie and Carey 1997, Guthrie and Carey 1998).

Advantages: A staining test is a straightforward test, but accurate interpretation may require experience.

Limitations:

- The spot tests merely indicate the presence of the alkali, not necessarily ASR

- The uranyl acetate test involves the use of UV light, and proper disposal of waste materials

- The tests do not provide quantitative information, only an indication of the presence of ASR

Relevance to Service Life Prediction: These tests do not provide quantitative data, so they are not directly applicable to service life modeling.

Standardization:

AASHTO T 299 - Standard Method of Test For Rapid Identification of Alkali-Silica Reaction Products in Concrete

- ASTM C856 (AASHTO T299) (Petrography) - Annex: uranyl-acetate treatment

Commercial Availability: Commercial products are available.

References:

- Naus (2009)

- Guthrie and Carey (1997)

- Guthrie and Carey (1998)

- Stark (1990)

- Natesaiyer and Hover (1988) 


\subsection{Maturity / Thermometry}

Summary: The compressive strength of a concrete is correlated to the cumulative temperature history produced by the heat output from the hydration reaction.

Physical Principle: The hydration reactions that occur in the paste fraction of a concrete are exothermic, resulting in a measurable temperature increase in the concrete at early days. The relative amount of heat released (compared with the total possible heat released) is proportional to the relative compressive strength (compared to the ultimate compressive strength). A thermometer records the change in temperature, an algorithm "integrates" the heat output, and correlates the heat output to a pre-existing relationship to the concrete compressive strength. Corrections can be made for temperature changes in the field. The "integration" can be performed via thermometry, or with probes filled with a chemical that changes color.

Advantages: This is an established technology for predicting concrete compressive strength under varying temperature conditions.

Limitations:

- The method is most effective at early (typically less than 14 days) ages

- Changes in moisture content can affect the recorded temperature, thus complicating the interpretation

Relevance to Service Life Prediction: Due to the limited time over which the method is applicable, it is only applicable to early-age performance models.

Standardization:

- ASTM C1074 - 11 Standard Practice for Estimating Concrete Strength by the Maturity Method

Commercial Availability: Yes

References:

- FHWA (1997) 


\subsection{Corrosion Half-Cell Potential}

Summary: The half-cell potential test determines the degree to which the steel reinforcement is in a chemical state conducive for corrosion.

Physical Principle: The test measures the electrical potential (voltage) between the steel reinforcement and a standard copper-copper sulfate reference electrode (half-cell). The half-cell consists of a copper rod in a saturated copper sulfate solution. The copper rod is electrically coupled to the steel reinforcement by copper wire, and the copper sulfate solution is chemically coupled to the concrete via a porous membrane (wood or plastic) and a wetting solution (typically a dilute household detergent) that is applied to the concrete surface. The concrete between the half-cell and the steel reinforcement complete the electrical circuit. To determine the potential drop between the steel reinforcement and the concrete (at zero current), the voltmeter should have a very high input impedance $(>10 \mathrm{M} \Omega$ ). The potential will determine the likelihood of a corrosion reaction occurring at the steel reinforcement. An electrical potential below $-350 \mathrm{mV}$ indicates a nearly $95 \%$ chance of corrosion, and a potential below $-500 \mathrm{mV}$ suggests that corrosion products should be visible.

By measuring the half-cell potential at a number of points, one can develop a half-cell potential contour map of the concrete cover. From this, one can estimate the fraction of steel reinforcement that is likely corroding.

Advantages: The apparatus is portable and requires relatively little training to operate, although the operator must follow standardized procedures to obtain meaningful results. The test measures a physical quantity that can be estimated by a service life model that includes corrosion reactions.

Limitations: The test method does not directly indicate corrosion, nor does it provide information on the rate of corrosion. It also requires access to reinforcing bars to make electrical contact. The interpretation of the results will require an experienced operator. Moreover, congested steel reinforcement can make interpretation of the results difficult.

Also, the accuracy of the results depends upon correcting for concrete temperature and the moisture state of the concrete.

Relevance to Service Life Prediction: Current service life models include the ability to determine the electrochemical state of the pore solution. As service life models continue to become more sophisticated, they will include details of corrosion reactions and the relevant reduction-oxidation state of the system. In principle, the results of a half-cell analysis may be predicted by a service life model, provided sufficient information about the state of the concrete is known: temperature profile, chemical profile, saturation profile, etc.

Standardization: ASTM C876 Standard Test Method for Corrosion Potentials of Uncoated Reinforcing Steel in Concrete

Commercial Availability: There are a number of suppliers of apparatus meeting the ASTM C876 specification

$\underline{\text { References: }}$

- $\operatorname{IAEA}(2002)$

- $\operatorname{IAEA}(2005)$ 


\subsection{Corrosion Current}

Summary: Linear polarization resistance (LPR) and impedance spectroscopy are used to determine the corrosion current, which through Faraday's law, is an indication of the amount of corrosion reaction that has occurred. The cumulative corrosion current is used to estimate the loss in steel reinforcement.

Physical Principle: As corrosion begins on a steel surface, current begins to flow between anodic and cathodic sites on the surface of the steel. Although this current cannot be measured directly, if an external voltage is applied to the steel, the rate that current flows into the steel (from the surrounding medium) is influenced by corrosive activity on the steel. Impedance spectroscopy is used to apply a time-dependent electrical potential $E(t)$ difference (typically less than $20 \mathrm{mV}$ ) between the concrete and the steel, and the resulting time-dependent current flux $i(t)$ (having units of coul $/ \mathrm{s} / \mathrm{cm}^{2}$ ) is recorded. The polarization resistance $R_{p}$ is defined as follows:

$$
R_{p}=\left.\frac{\partial E}{\partial i}\right|_{i=0 ; d E / d t \rightarrow 0}
$$

Thus, the polarization resistance has units of ohm- $\mathrm{cm}^{2}$; the geometry of the corroding metal must be known. The corrosion current $i_{\text {corr }}$ is related to the polarization resistance via the Stern-Geary coefficient $B$ (having units of volt):

$$
i_{\text {corr }}=10^{6} \frac{B}{R_{p}}
$$

The corrosion rate, often reported in units of length-per-time (velocity), is calculated from the corrosion rate, the gram-atomic mass of the corrosion product, and the density of the corroding metal. In concrete structures, one would monitor the corrosion current in the steel reinforcement. This requires electrical contact to the steel reinforcement, which might not be available.

Advantages: The test is a direct measure of the rate at which corrosion is occurring.

Limitations: The measured value can depend on a number of factors:

- Temperature

- Conductivity of the concrete: relative humidity, moisture content

Relevance to Service Life Prediction: Current service life prediction models are typically limited to predicting the onset of corrosion. In principle, service life models could be extended to predict the ensuing rate of corrosion, and then validated with standardized corrosion current measurements.

Standardization:

ASTM G59 - 97(2009) Standard Test Method for Conducting Potentiodynamic Polarization Resistance Measurements

Commercial Availability: Yes

References:

- $\operatorname{IAEA}(2002)$ 


\subsection{Corrosion Sensors}

Summary: Corrosion sensors use sacrificial steel probes and corrosion current measurements to estimate the depth to which a critical concentration of chlorides have penetrated and corrosion has been initiated.

Physical Principle: Sacrificial steel probes are placed into a concrete (at the time of casting) and instrumented such that the corrosion current can be determined at a later time. The sacrificial probes may be configured like fingers on a hand, with each finger parallel to the exposed surface. If the sensor is oriented such that each finger is a unique depth from the surface, when corrosion has initiated on a particular "finger", one knows the depth to which chlorides have penetrated in sufficient concentration to initiate corrosion.

Advantages: These sensors are typically very robust steel sensors that can last a very long time in concrete.

Limitations: The primary limitation is that the sensor has to be installed at the time of casting. It is not practical for existing structures because the sensor would have to be grouted into the structure, and the process of grouting would change the properties of the concrete locally.

Relevance to Service Life Prediction: This test would provide a useful validation tool for service life models that can predict the depth to which a critical concentration of chlorides has progressed.

Standardization: Although the sensors are not standardized, the procedure for determining the corrosion current has been standardized.

Commercial Availability: There are commercially available devices.

References:

- IAEA (2002) 


\subsection{Electrical Conductivity}

Summary: The pore solution in the hardened cement paste phase of concrete is electrically conductive. Because the capillary and calcium silicate hydrate gel (C-S-H) pores are interconnected throughout the paste, concrete will also conduct electricity. The amount of current that will flow for a given voltage is a measure of the concrete conductivity. The conductivity is related to the rate that corrosion can occur, and it is related to the state of the pore system (e.g., degree of saturation, the concentration of ionic species). In the absence of environmental influences, the electrical conductivity is relatively constant after $28 \mathrm{~d}$ of hydration. Upon changes in the environment (temperature, humidity, salt application, etc.) the conductivity will change.

Physical Principle: An electrical circuit is set up where a portion of the concrete is used to complete the circuit. This can be accomplished by using metal probes that are electrically coupled to the concrete with a small amount of a conductive fluid. The quantity of current that flows will depend upon the arrangement and spacing of the probes, the proximity of steel reinforcement, and the dimensions of the concrete element. There will be a capacitive coupling between the metal probes and the concrete, resulting in an unpredictable voltage drop when driven with a direct current. To eliminate this effect, an alternating current is used having a frequency that negates the effects of this capacitive coupling, yielding the true resistance of the concrete. A schematic of the Wenner (1916) 4-electrode test apparatus is shown in Figure 10.

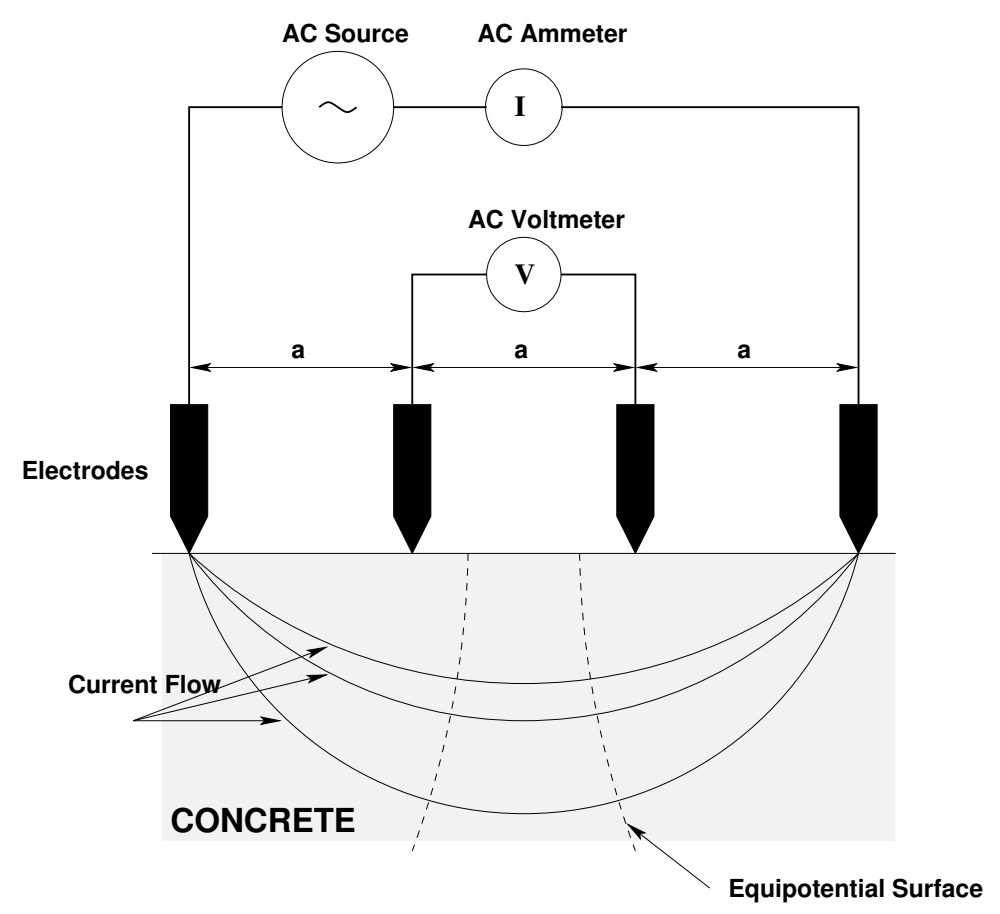

Figure 10. Schematic of four-point Wenner probe for determining the conductivity of field concrete.

Advantages: The electrical conductivity is a meaningful quantity that can be predicted by service life prediction models. The test requires relatively little training to perform; experience is needed to ensure a consistent electrical coupling to the concrete. 
Limitations: The interpretation of the results, along with assuring that sufficient additional information is obtained, require familiarity with the concepts underlying the test. The measured results must be corrected for the concrete temperature and the concrete saturation. When making absolute measurements, one must account for the geometry of the element (smaller elements and cast cylinders have larger correction factors) and the proximity of steel reinforcement. If only changes in conductivity are important (e.g., periodic inspections), then one needs to only correct for the temperature and the saturation state (and possibly the application of de-icing salts).

Relevance to Service Life Prediction: In principle, service life prediction models can predict the bulk electrical conductivity of a concrete. Although not directly related to durability, it is a means of quantifying the state of the system: temperature, saturation, concentration of ionic species in the pore solution, porosity, etc. If the measured and predicted electrical conductivity agree, one can have greater confidence in the service life model. Alternatively, electrical conductivity may be a good way of quickly identifying changes in the system in response to a changing environment.

Standardization: AASHTO TP-95 Standard Method of Test for Surface Resistivity Indication of Concrete's Ability to Resist Chloride Ion Penetration

Commercial Availability: There are commercially available devices for determining concrete conductivity nondestructively.

\section{References:}

- IAEA (2002)

- IAEA (2005)

- Wenner (1916) 


\subsection{Capacitive/Resistive Humidity Sensors}

Summary: The electrical properties of hydroscopic materials are correlated to ambient relative humidity.

Physical Principle: A capacitive humidity sensor measures the dielectric constant of a polymer (or other material) as a function of relative humidity; the material is configured like a capacitor, and the capacitor is used in a timing circuit. A capacitive humidity sensor has an accuracy of approximately $2 \%$, and can operate effectively between $5 \% \mathrm{RH}$ and $95 \% \mathrm{RH}$. A resistive humidity sensor measures the change in resistivity of a polymer or salt as a function of relative humidity. Resistive sensors are less sensitive than capacitive sensors.

Advantages: The sensors are simple, can be instrumented easily, and are inexpensive.

Limitations:

- Humidity measurement is one of the more difficult metrology challenges

- Sensors must be calibrated in air

- Sensors are subject to drift, and must be periodically recalibrated

Relevance to Service Life Prediction: Moisture transport due to varying exposure relative humidity can be significant, compared with diffusion.

Standardization: ASTM F2170 - 11 Standard Test Method for Determining Relative Humidity in Concrete Floor Slabs Using in situ Probes

Commercial Availability: Yes.

References:

- Kanare (2008) 


\section{MASS TRANSPORT METHODS}

\subsection{Permeability}

Summary: The permeability coefficient is proportional to the rate that a fluid (liquid or gas) passes through a material, at a given pressure difference; the quantity, when combined with the fluid density and viscosity, is sometimes referred to as the hydraulic conductivity. The coefficient is almost always determined at a steady-state flow condition. This permeability of a material is important when the concrete element is in contact with a hydraulic head or when the transport of gases into the concrete may influence a degradation reaction (e.g., carbon dioxide diffusion leading to carbonation).

The permeability used in this context is not related to Rapid Chloride Permeability (ASTM C1202), which is an indirect conductivity measurement. Also, it differs from sorptivity (the time-dependent uptake of water), although sorptivity depends upon the permeability.

Physical Principle: A hydraulic or pneumatic pressure difference is applied to a porous material and the steady-state flow is determined. The ratio of the two, along with information about the geometry of the measurement, is used to determine the permeability coefficient. The measurement may be conducted under saturated or partially saturated conditions.

The typical geometry of the measurement depends upon whether it is a laboratory or a field measurement. In the laboratory, the flow is typically one-dimensional. In the field, access to the entire element is either limited, or one-dimensional flow is not practical. Under these conditions, the apparatus geometry is typically concentric annuli where a vacuum is applied to an outer annulus (to hold the device against the concrete), and the flow is measured through an inner annulus.

Another approach is the Figg test. A $10 \mathrm{~mm}$ diameter, $40 \mathrm{~mm}$ deep hole is drilled, and a $20 \mathrm{~mm}$ tall plug is placed into the hole, flush with the outer surface, resulting in a $20 \mathrm{~mm}$ tall void at the bottom of the hole. A vacuum is applied to the void, and the pressure is monitored. The time required for the vacuum to fall from $-55 \mathrm{kPa}$ to $-50 \mathrm{kPa}$ is the Figg number for gas permeability. Then the void is filled with water, with the outlet going to a vertical graduated cylinder. Sufficient water is added to the void to make the water in the cylinder read a distance of $100 \mathrm{~mm}$ above the concrete surface. The water inlet is sealed, and the time required for the water in the cylinder to fall $50 \mathrm{~mm}$ is the Figg number for liquid permeability.

Advantages: A permeability measurement can yield important information about the rate that water and moisture can penetrate a concrete element. Recent instrumentation advances have simplified the process of making measurements in the field.

Limitations: Access to large concrete elements, and other constraints, may prevent through-flow measurements of bulk permeability (hydraulic conductivity). The surface measurement techniques are more useful for characterizing the surface. Due to the geometry of these systems, the fluid flow is generally limited to the outer surface of the concrete. This is appropriate for applications where the performance of the outer surface is critical to the overall performance. For applications where bulk permeability is critical to overall performance, one might infer that the surface permeability may be an upper bound on the bulk permeability. 
The value one obtains from a permeability measurement depends upon the saturation of the concrete. In principle, the sample should be saturated with the appropriate fluid phase during the experiment; liquidfilled pores for liquid permeability, and gas-filled pores for gas permeability. In the field, the concrete will (most likely) be partially saturated, so one must determine whether the concrete should be conditioned prior to measurement, or whether the concrete should be tested in its typical saturation state, realizing that the measurement itself could change the degree of saturation during the test.

Relevance to Service Life Prediction: In applications where fluid (liquid or gas) flow is critical to overall performance, the corresponding permeability coefficient (either liquid or gas) is the most important material property for service life prediction.

Standardization: There is no standardized NDT permeability test.

Commercial Availability: There are commercially available devices for determining concrete liquid and gas permeability.

References:

- IAEA (2002)

- $\quad$ Naus (2009) 


\subsection{Sorptivity}

Summary: The sorptivity is a measure of the rate at which water will enter an unsaturated concrete, much like a dry sponge will absorb water. Initial Surface Absorption Test (ISAT - BS1881) can be performed in the laboratory or the field.

Physical Principle: The partially saturated pores in the hardened cement paste phase of a concrete will draw in water.

Advantages: The test is straightforward, and requires relatively little instrumentation and equipment.

Limitations: The results can depend on a number of experimental factors:

- $\quad$ Moisture conditions of the sample (initial moisture content, and moisture history)

- $\quad$ Sample geometry

- $\quad$ The degree to which non-wetted surfaces are sealed

Relevance to Service Life Prediction: Water ingress is one of the fastest transport mechanisms in concrete (it is far more rapid than diffusion). Moreover, in a freezing environment, sorptivity is a primary factor in determining whether a concrete will become saturated with water prior to experiencing freeze-thaw cycles.

Standardization:

- $\quad$ ASTM C1585 - 11 Standard Test Method for Measurement of Rate of Absorption of Water by Hydraulic-Cement Concretes

Commercial Availability: Field sorptivity tests are becoming available.

References:

- Naus 2009

- Hall (1989)

- DeSouza (1996) 


\section{RECENT RESEARCH ON NDT FOR ESTIMATING MECHANICAL PROPERTIES}

The previous sections summarized non-destructive tests to estimate in-place concrete properties. Some of these tests have been standardized and are used to estimate concrete properties. However, there are no NDT tests to determine the strength of the reinforcing steel; the yield strength of steel can be obtained from mill test reports or destructive testing. Factors affecting the contribution of the reinforcing steel to the strength of the structure include corrosion (reduced capacity and bond), development length, and anchorage. The NDT techniques to detect corrosion and concrete deterioration have been discussed in previous sections. This section will briefly present some recent studies on non-destructive tests related to strength evaluation of reinforced concrete. This is not an exhaustive literature review and detailed information about the studies can be found in the cited references.

Studies that present methods to characterize concrete mechanical properties and the structural state of an element are presented first, followed by studies to characterize the state of the reinforcement such as the bond, the pre/post-tensioning stress level, and the location. Advances in technology (e.g., sensor, wireless communications, personal computers) have made structural health monitoring (SHM) more viable. This section concludes with a brief discussion of using SHM to help determine the structural integrity of a nuclear power plant.

Lawson et al. (2011) investigated the ultrasonic pulse velocity technique as it related to concrete compressive strength. They found that the ultrasonic pulse velocity method yielded compressive strengths that were within $\pm 10 \%$ of the true value, was low cost, and was easy to use and to deploy. Terzić and Pavlović (2010) combined the use of ultrasonic pulse velocity and image analysis to estimate the compressive strength of concrete and to characterize microstructural defects. McClaskey et al. (2010) proposed the use of acoustic emission (AE) beamforming techniques to monitor large plate-like concrete structures. The authors were able to detect an AE source with a sensor array up to $3.8 \mathrm{~m}$ away. The proposed use of this technique is the localization of damage in large concrete structures. Once localized, other NDT methods may be used to evaluate the concrete.

Zheng and Li (2011) and Ye and Peng (2009) investigated the use of the Autoclam system. The Autoclam system is used to measure the air permeability, water permeability and sorptivity of concrete structures on site or in laboratory. Zheng and Li used the system to evaluate the prestressed concrete containment buildings in two operational nuclear power plants. These plants have been in operation for 5 years. They found the system to be stable and easy to use. Ye and Peng assessed the reliability of the Autoclam system. They found that the system could be used for in-situ testing, the air permeability index was sensitive to the surface conditions, and more research was needed to more effectively use the system.

There are several nondestructive and semi-destructive methods that allow for the determination of concrete compressive strength indirectly, that is, through correlations between a measured test parameter and concrete strength. There are currently no NDT methods that directly measure the concrete compressive strength in an existing structure. To increase the reliability of these indirect methods, several NDT methods have been combined at the same time (Balayssac et al. 2009, Ploix et al. 2009, Ploix et al. 2011, Breyssea 2011, Klinghoffer et al. 2011, Naus 2009, Cho et al. 2009, Trtnik et al. 2009, Maierhofer et al. 2008, Kim and Kim 2004, Malhotra and Carino 2004, and Dérobert et al. 2002).

Balayssac et al. (2009) and Ploix et al. (2009) presented some of the results from a large experimental French project called SENSO which involves several universities and agencies. The aim of SENSO is to 
develop methods for the non-destructive evaluation of concrete based on multiple NDT techniques (e.g., radar, electrical resistivity and capacity, infrared thermography, impact echo and ultrasound).

Klinghoffer et al. (2011) combined the results from a Multichannel Analysis of Spectral Waves (MASW) technique with finite element simulations using the measured results from MASW to improve the accuracy and reliability of the MASW results. MASW is a seismic method to evaluate the dynamic, linear, elastic modulus of materials. It may be used to determine concrete thickness, mechanical properties, and the quality of bond between the concrete and steel liner.

Two studies combined the use of an artificial neural network (ANN) with NDT methods to better predict concrete compressive strength. One by Trtnik et al. (2009) who combined ultrasonic pulse velocity and ANN and the other by Cho et al. (2009) who combined the impact-echo method and spectral analysis of surface waves (SASW) with ANN.

Maierhofter et al. (2008) fused data from radar and ultrasonic echo methods to obtain information from structures with dense reinforcement, tendon ducts, and air voids and gaps. The paper also described different methods of combining the data.

Kim and Kim (2004) combined the impact-echo method and SASW method to determine the thickness of a concrete containment structure in a nuclear power plant. The measured thickness $(1.14 \mathrm{~m})$ was in good agreement with the actual value of $1.2 \mathrm{~m}$. Kim and Kim were not able to determine the depth to the reinforcing bar using the impact-echo method but suggested the combination of impact-echo and GPR as a potential solution.

Most of the research on NDT methods has been conducted on uncracked concrete. The concrete compressive strength is estimated from the results of an NDT technique or from concrete cores. For cracked reinforced concrete elements, however, the interpretation of the results requires careful consideration. If the method has been validated for cracked concrete, the engineer can use the estimated value to evaluate the capacity of the element. For uncracked concrete, the ACI 318 building code provides estimates for the tensile strength and the modulus, based on the compressive strength and the unit weight. If, however, the concrete is cracked, there is no assurance that these relationships still hold, especially given the evidence that the loss in tensile strength and modulus are not proportional to the loss in compressive strength (Smaoui et al. 2006).

The other component of reinforced concrete is the reinforcing steel - regular reinforcement and the prestressing/post-tensioning tendons. Dérobert et al. (2002) used a post-tensioned bridge beam to evaluate several NDT methods: GPR, covermeter, gamma-ray radiography, and impact-echo methods. The bridge beam was part of a prestressed concrete bridge that was demolished. The evaluation of the NDT methods was based on information required by a structural engineer:

- localization of prestressed tendons (layout, concrete cover thickness) and reinforcement bars (layout, concrete cover thickness and bar diameter)

- prestressing quality: injection state, severity of steel reinforcement corrosion and tendon fractures

Details of the evaluation of each of the NDT techniques may be found in Dérobert et al. (2002). One of the findings of this study was that NDT methods could be combined to reduce ambiguities of findings obtained from the use of only one NDT method. For example, combining GPR with gammagraphy or GPR and impact echo. 
To improve the quality of information on the state of a bridge deck for maintenance purposes, Cui et al. (2010) combined information obtained from the half-cell potential method, GPR, and an anode ladder corrosion monitoring system. The conclusion from this study was that the fused data enabled improved evaluation of the bridge deck.

Kim et al. (2011) mechanically impacted one end of a grouted 7-wire prestressing strand and monitored the longitudinal stress wave responses at the other end. They postulated that the longitudinal vibration characteristics of the bonded tendons can be used to estimate the prestress force in the tendon. Muravin and Ilina (2010) reported on the successful use of Quantitative Acoustic Emission (QAE) method to detect the decrease of the pre-stressing level in cables and reinforcement and embrittlement of reinforcement. They also reported that the QAE method was shown to be successful in revealing, locating, typifying and assessing other flaws such as micro- and macro cracks, debonding of reinforcement, spallation, porosity, local stress concentration zones, uniformity of concrete strength distribution, and change in the magnitude and orientation of the main stresses. Other researchers have also reported on the use of the QAE non-destructive method (Busse et al. 2007). Other recent studies include Chaki and Bourse (2009), who used guided ultrasonic waves to estimate the stress in prestressed 7-wire cables, Ramadan et al. (2008), who reported on the use of acoustic AE to detect stress corrosion cracking of prestressing steel and concluded that AE could be used for real-time monitoring, and Shao (2011), who proposed a low cost imaging system using synthesized aperture focusing technology.

In addition to the traditional methods of non-destructive testing to obtain information to predict service life, information from other sources may also be used. For example, information obtained from SHM may also be used to predict service life. Chang and Hung (2012) developed a new technique that enables real-time monitoring of concrete internal temperature and humidity via wireless signal transmission. They integrated a radio frequency integrated circuit (RFIC) with temperature and humidity sensors into a RFIC transmitter. The signal reception distance for a sensor embedded in reinforced concrete was $7.3 \mathrm{~m}$ in the presence of obstacles. Henault et al. (2011a, 2011b) investigated the use of a distributed optical fiber sensing system for SHM - in particular, strain and temperature monitoring. They used the optical frequency domain reflectometry technique to obtain the strain and temperature profiles along a fiber. Initial results show promise. A review of fiber optic sensors, piezoelectric sensors, magnetostrictive sensors and self-diagnosing fiber reinforced composites for structural health monitoring of civil engineering structures was conducted by Sun et al. (2010). Some recent studies on piezoelectric sensors include those by Zhao (2011) and Yenilmez (2007) and on the use of piezoelectric sensors for structural health monitoring include those by Saad (2011), Duan et al. (2010), and Rao et al. (2006).

Most NDT methods yield information in a localized area rather than for the whole structure. Another method of monitoring structural health is to monitor the structural integrity of the whole structure. This can be accomplished by monitoring the dynamic response of the structure subjected to ambient vibrations. Two studies in this area that relate to nuclear plants are those by Andonov et al. (2010) and Choi et al. (2010). In a similar approach, Hora and Patzak (2007) proposed the use of a numerical model to predict the structural behavior of a nuclear containment structure under various conditions. The model was calibrated with measurements of the in-situ conditions of the containment structure. Another area of SHM involves the use of smart materials such as a prestressing strand (a smart fiber-reinforced polymer reinforcement bar bundled with six steel strands) that can monitor prestress loss (Zhou et al. 2009) and smart aggregates (piezoelectric patch) for early-age concrete strength monitoring and impact detection (Song et al. 2008). 


\section{SERVICE LIFE PREDICTION}

The standardized tests that are related to the service life of a concrete application are divided between those tests that predict a useful model parameter that would allow one to estimate how long before a structure would fail, and those tests meant to determine whether a degradation mechanism would occur with sufficient probability. The latter tests are almost always used as acceptance/rejection criteria for a material (aggregate, binders, etc.) or for the entire concrete mixture.

For example, there are no industry guidelines for estimating how long a concrete mixture can withstand the effects of freezing and thawing in a particular environment. There is, however, test method ASTM C666 that submerges a sample of the concrete in water and subjects the sample to 300 freezethaw cycles. A common performance criterion is whether, after 300 cycles, the loss in modulus is less than a specified value. If the loss in modulus is less than the limiting value, the mixture is qualified. Otherwise, the mixture is rejected. Although it may seem useful to develop a service life model (to predict the duration of service) for a particular concrete mixture in a particular exposure environment, for a degradation mechanism like freeze-thaw, the ASTM C666 test is sufficiently stringent that relatively few concretes that pass the test fail in the field.

By comparison, there are few, if any standardized test methods that yield an estimate for the expected service life of a concrete. The primary reason for this is three-fold: there are no standardized methods for characterizing the field conditions; there are no reliable accelerated tests from which one can extrapolate the expected service life in the field; and physicochemical models of the behavior in the field are sufficiently complex (there are a myriad of mechanisms potentially at play) that standardizing a single approach is not justified. The solution to this situation is either to develop accelerated tests or to develop test methods for the relevant model parameters for the physicochemical calculations. Accelerated tests are problematic because material response is not a monotonic function of exposure; increased concentrations or temperatures can lead to the formation of phases that would not have been present under field conditions. Therefore, identifying service life model parameters and the tests to obtain those parameters, either in the laboratory or in the field, has been the primary approach in recent years. 


\section{DEGRADATION SCENARIOS}

Common degradation scenarios are used as a framework for identifying and evaluating the needs for NDT method development. The following degradation scenarios were chosen because they are important to new and existing nuclear power plants, and because the current industry approach for performance tests includes both the service life model parameter approach and the accept/reject approach. Corrosion of the steel reinforcement in concrete is the leading degradation mechanism of virtually all structural concrete applications, including nuclear power plants. Similarly, alkali-silica reaction (ASR) has been an important degradation mechanism for half a century, primarily in dams (Stanton 1940) and more recently in highway structures, and, because the degradation mechanism is relatively slow, it often manifests itself in structures that must perform for many decades, such as nuclear power plants.

Corrosion of the steel reinforcement in structural concrete provides an ideal foundation to address new and existing concretes from both the service life model parameter and the accept/reject perspectives. Because a number of service life models exist for corrosion of the steel reinforcement, there are a number of tests for the relevant properties such as the concrete diffusivity, the concrete conductivity, and the corrosion current at the steel reinforcement. For new construction, one can consider strategies for controlling the transport properties, and also consider other strategies such as corrosion inhibitors, coated steel reinforcement bars, or stainless steel reinforcement bar.

The alkali-aggregate reaction (ASR) scenario is dominated by the accept/reject approach. The primary reason for this is that the chemistry and the conditions that control the rate and the extent of the reaction are complex (and still not fully understood), and validated service life models do not exist with which one can evaluate designs for new construction. As a result, the strategies for avoiding ASR are limited to accept/reject tests for the aggregates or for mixture design.

The last scenario is cracking, which may arise during construction or during service. Regardless of the cause of the cracking, the effects of cracking are the same: accelerate transport and degradation, and reduce strength. The degree to which this occurs depends strongly on the morphology of the cracks. Therefore, there is a need for common strategies for detecting the onset of cracks, the propagation of cracks, the spatial extent of the cracks, and the impact of the cracks on transport and strength. 


\subsection{Corrosion of Steel Reinforcement}

As noted by Dorf et al. (2009), the durability of reinforced concrete structures is a function of the durability of the concrete and reinforcing steel. The residual service life of concrete is characterized by the:

- concrete strength being able to meet the design requirements

- ability of the concrete to protect the steel reinforcement bars

- integrity of the concrete (e.g., cracks, defects)

The residual service life of the reinforcing steel is characterized by:

- steel strength meeting design requirements

- reduction of the cross-sectional area of the steel reinforcement bars due to corrosion

Besides loss of steel area, corrosion also affects the bond between the steel and concrete. Since reinforced concrete relies on the composite action of the concrete and reinforcing steel, the bond (or loss) of bond between the reinforcement and the concrete due to corrosion is an issue. As alluded to in Section 12 , the loss of bond will reduce the development length of the reinforcement and anchorage.

Corrosion of the steel reinforcement is one of the main durability problems for reinforced concrete. Corrosion of steel reinforcement requires the following conditions (Malhotra and Carino 2004):

1. Loss of passivation

2. Presence of moisture

3. Presence of oxygen

The two major causes for the loss of passivation or the loss of the protective passive oxide film around the steel reinforcement are carbonation and the presence of chloride ions. In general, chloride-induced corrosion of the reinforcement is considered the major problem associated with long-term durability of reinforced concrete structures as it impacts both serviceability and structural integrity. Therefore, the transport properties of concrete are important factors. Properties that affect transport include the chloride ion diffusivity of the concrete, the sorptivity, the permeability, the thickness of the concrete cover, the existence of cracks, and the chemical composition and viscosity of the pore solution (Yang 2010). Other factors affecting corrosion include carbonation depth, temperature, and humidity (van Breugel 2006, Vennesland et al. 2007).

A schematic relating the damage level and the progression of corrosion is given in Figure 11. 




Figure 11. Schematic of corrosion of the steel reinforcement due to external chloride ions (on the left side) diffusing to the steel reinforcement, leading to expansive corrosion products and, eventually, cracking (adapted from Yang et al. 2012).

\subsubsection{Scenario}

Corrosion of the steel reinforcement within structural concrete elements progresses in the following scenario:

- Externally dissolved chloride ions are in contact with the concrete

- Ingress of chlorides (and carbon dioxide) through the concrete cover

- De-passivation of reinforcing steel occurs

- Upon achieving a critical chloride concentration at the depth of the steel reinforcement, $\mathrm{C}_{\text {crit }}$, corrosion begins

- Corrosion produces an expansive reaction product (rust) and reduces the cross sectional area and the ductility of the reinforcing steel

- The expansive product leads to tensile stresses in the concrete surrounding the steel reinforcement bars

- When the tensile stress limit of concrete is reached, cracks are initiated

- There is loss of bond between the steel reinforcement bars and the concrete

- The cracks propagate to the surface of the concrete

- The cracks could accelerate the rate of transport of liquids or dissolved ions

- The accelerated transport could hasten the effects of other possible degradation mechanisms 
Service life prediction parameters for steel corrosion are given in Table 5 along with methods for determining these parameters. 
Table 5. Service life prediction parameters for steel corrosion.

\begin{tabular}{|c|c|c|}
\hline SLP Parameters & Standardized Methods & Methods in Development/Research \\
\hline $\begin{array}{l}\text { External (e.g., soil) and surface } \\
\text { chloride concentration }\end{array}$ & $\begin{array}{l}\text { - Chloride surface concentration: NT BUILD } 208 \\
\text { - Chloride concentration in the soil: } \\
\circ \quad \text { ASTM D512 - Standard Test Methods } \\
\text { for Chloride Ion in Water } \\
\circ \quad \text { D4327 - Standard Test Method for } \\
\text { Anions in Water by Suppressed Ion } \\
\text { Chromatography } \\
\circ \quad \text { AASHTO T 291 - Standard Method of } \\
\text { Test for Determining Water-Soluble } \\
\text { Chloride Ion Content in Soil }\end{array}$ & $\begin{array}{l}\text { Test procedure for determining chloride and sulfate } \\
\text { contents in soil developed by the Texas DOT, Tex- } \\
620-\mathrm{J} \text { (Texas DOT 2005) }\end{array}$ \\
\hline $\begin{array}{l}\text { Internal chloride concentration } \\
\text { profile }\end{array}$ & $\begin{array}{l}\text { - ASTM C-1152 - Standard Test Method for } \\
\text { Acid-Soluble Chloride in Mortar and Concrete } \\
\text { - ASTM C1218 - Standard Test Method for } \\
\text { Water-Soluble Chloride in Mortar and Concrete } \\
\text { - ASTM C114 - Standard Test Methods for } \\
\text { Chemical Analysis of Hydraulic Cement, } \\
\text { Reference Method } 19 .\end{array}$ & $\begin{array}{l}\text { Volhard method - Method proposed by RILEM } \\
\text { Technical Committee TC 178-TMC (RILEM TC 178- } \\
\text { TCM 2002, Castellote and Andrade 2006) based on a } \\
\text { round-robin test. The round-robin test consisted of } 30 \\
\text { laboratories worldwide and } 64 \text { different analyses of } \\
\text { triplicate specimens for three different chloride } \\
\text { contents. }\end{array}$ \\
\hline $\begin{array}{l}\text { Critical chloride content } \\
\text { required to initiate } \\
\text { reinforcement corrosion }\end{array}$ & & $\begin{array}{l}\text { - Although a standardized test does not exist (Angst et } \\
\text { al. 2009), Darwin et al. (2009) have developed a } \\
\text { method based on ASTM G109. }\end{array}$ \\
\hline $\begin{array}{l}\text { Chloride Diffusion Transport } \\
\text { Coefficient }\end{array}$ & $\begin{array}{l}\text { - } \text { Rapid migration test has been standardized by } \\
\text { Nordtest as NT Build } 492 \text { (Shi 2004) } \\
\text { - ASTM C1556 - 11a Standard Test Method for } \\
\text { Determining the Apparent Chloride Diffusion } \\
\text { Coefficient of Cementitious Mixtures by Bulk } \\
\text { Diffusion } \\
\text { - Concrete conductivity (when combined with } \\
\text { pore solution conductivity): ASTM C1760 - } \\
\text { Standard Test Method for Bulk Electrical } \\
\text { Conductivity of Hardened Concrete } \\
\text { - ASTM C1202 - Standard Test Method for } \\
\text { Electrical Indication of Concrete's Ability to } \\
\text { Resist Chloride Ion Penetration. } \\
\text { - AASHTO TP095 -11 "Surface Resistivity }\end{array}$ & $\begin{array}{l}\text { Wenner Probe test for surface conductivity (under } \\
\text { ballot in ASTM), when combined with pore solution } \\
\text { conductivity measurements. }\end{array}$ \\
\hline
\end{tabular}




\begin{tabular}{|c|c|c|}
\hline & $\begin{array}{l}\text { Indication of Concrete's Ability to Resist } \\
\text { Chloride Ion Penetration" (Wenner Probe) }\end{array}$ & \\
\hline Pore Solution Conductivity & & $\begin{array}{l}\text { - Pore press to obtain pore solution for conductivity } \\
\text { measurement (Barneyback 1983, Barneyback and } \\
\text { Diamond 1981, Longuet et al. 1973, Longuet 1976). } \\
\text { - Virtual rapid chloride permeability test (Bentz 2007) } \\
\text { http://ciks.cbt.nist.gov/poresolncalc.html - } \\
\text { estimates the pore solution conductivity based } \\
\text { on composition of cementitious materials and } \\
\text { mixture proportions with assumed dissolution } \\
\text { rates for alkalis. }\end{array}$ \\
\hline Permeability & & $\begin{array}{l}\text { Back propagation artificial neural network-based and } \\
\text { regression-based prediction model for the Rapid } \\
\text { Chloride and Boil Tests to reduce the duration of the } \\
\text { test (Yasarer 2010) } \\
\text { - ASTM C642 - Standard Test Method for Density, } \\
\text { Absorption, and Voids in Hardened Concrete } \\
\quad \text { o Indirect measurement } \\
\end{array}$ \\
\hline Depth of steel reinforcement & & $\begin{array}{l}\text { - Ground penetrating radar } \\
\text { - } \quad \text { Gamma radiography (or X-ray radiography) }\end{array}$ \\
\hline Presence of corrosion & $\begin{array}{l}\text { ASTM C876 - Standard Test Method for } \\
\text { Corrosion Potentials of Uncoated Reinforcing } \\
\text { Steel in Concrete }\end{array}$ & $\begin{array}{l}\text { - A new method using electromagnetic waves at } \\
\text { frequencies around } 100 \mathrm{GHz} \text { is being developed to } \\
\text { identify the "fingerprint" and quantify the corrosion of } \\
\text { steel used in the infrastructure (e.g. steel } \\
\text { reinforcement, wrapped pipes, steel under paint) } \\
\text { using the spectral response of anti-ferromagnetic iron } \\
\text { corrosion products like hematite, goethite, and } \\
\text { akaganeite (Sung et al. 2011, Chou et al. 2012, Baker- } \\
\text { Jarvis et al. 2013). } \\
\text { Related research } \\
\text { Electromagnetic waves in the terahertz range } \\
\text { were used to detect corrosion under } 25.4 \text { mm } \\
\text { thick tiles in the space shuttle thermal } \\
\text { protection system (Madaras et al. 2008). } \\
\text { A sub-terahertz imaging system was used to } \\
\text { detect adhesion defects of ceramic tiles on } \\
\text { concrete and to detect the diffusion of water } \\
\text { into concrete (Oyama et al. 2009). }\end{array}$ \\
\hline
\end{tabular}




\begin{tabular}{|c|c|c|}
\hline Depth of carbonation & $\begin{array}{l}\text { European Standard EN } 14630 \text { - Products and } \\
\text { systems for the protection and repair of concrete } \\
\text { structures - Test methods - Determination of } \\
\text { carbonation depth in hardened concrete by the } \\
\text { phenolphthalein method }\end{array}$ & \\
\hline Extent of cracking & See section on cracking & \\
\hline $\begin{array}{l}\text { Rate of corrosion/Corrosion } \\
\text { Potential }\end{array}$ & $\begin{array}{l}\text { - ASTM G102 - Standard Practice for } \\
\text { Calculation of Corrosion Rates and Related } \\
\text { Information from Electrochemical } \\
\text { Measurements } \\
\text { - ASTM C876 - Standard Test Method for } \\
\text { Corrosion Potentials of Uncoated Reinforcing } \\
\text { Steel in Concrete } \\
\text { - ASTM G59 - 97 Standard Test Method for } \\
\text { Conducting Potentiodynamic Polarization } \\
\text { Resistance Measurements }\end{array}$ & $\begin{array}{l}\text { A recommended test method uses the Polarization } \\
\text { Resistance technique to estimate the instantaneous } \\
\text { corrosion current density, } \mathrm{i}_{\text {corr }} \text { (Andrade and Alonso } \\
\text { 2004). } \\
\text { Linear polarization resistance without the need to have } \\
\text { a direct connection to the steel reinforcement - } \\
\text { eliminates the need to break off the cover concrete. } \\
\text { (Sadowski 2010, Millard and Sadowski 2009). }\end{array}$ \\
\hline $\begin{array}{l}\text { Detection of debonding of } \\
\text { reinforcing steel }\end{array}$ & & $\begin{array}{l}\text { - ASTM D4580 - Standard Practice for Measuring } \\
\text { Delaminations in Concrete Bridge Decks by Sounding } \\
\text { O Cannot measure deep defects and method } \\
\text { depends on experience of operator } \\
\text { - Ground penetrating radar } \\
\text { - Use of Quantitative Acoustic Emission (QAE) method } \\
\text { to detect the decrease of the pre-stressing level in } \\
\text { cables and reinforcement and embrittlement of } \\
\text { reinforcement (Muravin and Ilina 2010). The QAE } \\
\text { method was also able to reveal, locate, typify and } \\
\text { assess other flaws such as debonding of } \\
\text { reinforcement. } \\
\text { Use of guided ultrasonic waves to detect presence of } \\
\text { corrosion and debonding (Sharma and Mukherjee } \\
\text { 2010). } \\
\text { Ultrasonic method and electromagnetic pulse method } \\
\text { were used to evaluate the debonding caused by } \\
\text { corrosion (Uchida et al. 2009). }\end{array}$ \\
\hline $\begin{array}{l}\text { Improve concrete } \\
\text { quality/decrease concrete } \\
\text { permeability }\end{array}$ & & $\begin{array}{l}\text { - Use of synthetic layered double hydroxides (LDHs) or } \\
\text { modified hydrotalcites (MHTs) to improve the } \\
\text { corrosion protection of reinforced concrete (Yang }\end{array}$ \\
\hline
\end{tabular}


2010).

- Viscosity Enhancers Reducing Diffusion In Concrete Technology (VERDICT) - method to decrease diffusive coefficients by using nano-sized viscosity modifiers (Bentz et al. 2008)

- Addition of nitrite (2\% in cement mass in the water) resulted in delayed depassivation of steel and significantly reduced the corrosion rate (Rebolledo and Andrade 2010, Rosenberg et al. 1977). 


\subsubsection{Resolving the Gaps}

As seen in Table 5, standard test methods are lacking in the areas of pore solution conductivity, permeability (water ingress), diffusivity, depth of steel reinforcement, and debonding of steel reinforcement. Of these areas, the most critical are diffusivity and permeability as they are the most important material property for service life prediction (see Mass Transport Section). Depth of steel reinforcement correlates to the concrete cover - more cover, better corrosion protection, and debonding results from the formation of corrosion products. Currently, there are no reliable methods to detect debonding of the steel.

The critical chloride content, a parameter listed in Table 5, has been identified as a key input parameter in probabilistic service life modeling of concrete structures. Reviews of studies over the past 50 years on the critical chloride content have shown that there is a lot of variability in reported values and there is no general consensus on a value and there is currently no standard test method to measure the critical chloride content (Angst et al. 2009). Darwin et al. (2009) have developed a method that is based on ASTM G 109.

Another important input parameter to service life prediction models is the corrosion rate. Since the corrosion rate current is affected by factors such as the concentration of chloride, permeability, temperature, and cracking and methods to measure the corrosion rate yield a single data point in time, the prediction models have to 1) use a constant rate, 2) use an extrapolated value by observing measurements made over a period of time, or 3) account for the time-variant nature of the corrosion rate (Otieno et al. 2011a). Other issues with the measurement of corrosion rate include variability of results when different instruments are used for the same conditions and when different assessment techniques are used (Martinez et al. 2008), and the use of accelerated corrosion experiments.

Since the corrosion process is a lengthy process, accelerated corrosion tests are commonly used to gain better understanding of the process. However, this technique may not be representative of the actual corrosion process in the field and the results from these tests will, therefore, not be representative of field conditions. Some issues cited include the use of Faraday's law to obtain corrosion rates from accelerated tests, the assumption of $100 \%$ current efficiency (Otieno et al. 2011b), and the shape of the chloride profile (Gulikers 2012).

As the results from SLP models depend on the accuracy of the input parameters, it is important that test methods to accurately quantify the input parameters be developed, that the variability in the tests results be better understood and that better relationships between NDT measurements and concrete properties be developed (Breysee et al. 2012, Gulikers 2012).

A critical aspect of SLP models is the validation of these models. When validating the models, some considerations are the size of the test specimens and the sample size (Otieno et al. 2011b). As with any structural testing, the behavior obtained from reduced-scale specimens may not necessarily reflect the behavior of full-scale specimens, and often, tests involve the use single components (e.g., beam, slab) and the behavior may differ if the test involves the whole structure or a larger portion of the structure (e.g., single bay, frame, beam with slabs). To increase confidence in the reliability of a model, the sample size needs to be large enough to be statistically significant. Also, robustness of the model is an important consideration to account for varying concrete properties and environmental conditions. Long term studies such as the NDE for corrosion detection benchmark study by the Federal Highway Administration (FHWA) (Arndt 2009) and the SENSO project (Balayssac et al. 2009) would provide 
substantial information towards the validation of the SLP models and address the issue of accelerated tests. Long-term studies in realistic/field environments would be the ideal cases.

The standardized method ASTM C 876 to detect the presence of corrosion requires access to the reinforcement and cannot be applied to epoxy coated reinforcement or concrete with coated surfaces (Malhotra and Carino 2004). The new electromagnetic wave method described in Sung et al. (2011) shows promise as it does not require access to the reinforcement and can be applied to coated reinforcement; however, at present, the research results indicate that the presence of corrosion can only be detected up to a depth of about $5 \mathrm{~cm}$ of concrete.

All NDT tests provide information about the state of the concrete or steel at the time of the tests. Embedded sensors hold potential in providing long term monitoring of factors such as the presence of moisture, advancement of the carbonation and chloride fronts, temperature, humidity, oxygen availability, corrosion rate (Andrade 2010, Vennesland et al. 2007) in concrete. However, the use of embedded sensors is only practical for new construction, and the long-term performance would need to be validated.

In 2011, the National Research Council (NRC) prepared a report on research opportunities in corrosion science and engineering (National Research Council 2011). The report states that the "lack of fundamental knowledge about corrosion and its application to practice is directly reflected in the high societal cost of corrosion." This cost is estimated to be $2 \%$ to $4 \%$ of the US gross national product. In the report, four grand challenges in corrosion research were identified (National Research Council 2011):

- Development of cost-effective, environment-friendly, corrosion-resistant materials and coatings;

- High-fidelity modeling for the prediction of corrosion degradation in actual service environments;

- Accelerated corrosion testing under controlled laboratory conditions that quantitatively correlates to long-term behavior observed in service environments; and

- Accurate forecasting of remaining service time until major repair, replacement, or overhaul becomes necessary-i.e., corrosion prognosis.

\subsubsection{Meeting the SLP Model and Measurement Needs}

The following is a list of activities that would meet some of the most important needs for SLP modeling, primarily through measurement development:

1. Develop a standardized test method for permeability (hydraulic conductivity)

2. Develop and validate robust SLP models using results obtained from realistic/field environments

3. Develop accelerated corrosion tests under controlled laboratory conditions that quantitatively correlate to long-term behavior observed in service environments

4. Validate the results obtained from accelerated testing

5. Develop cost-effective, corrosion-resistant reinforcement bars

6. Determine the sources of variability in the critical chloride content and corrosion rate, and then develop standard test methods and industry best practice guidelines/methods to quantify these values 
7. Develop reliable embedded sensors for long-term monitoring

8. Develop databases of performance from long term studies under realistic/field conditions 


\subsection{Alkali-Silica Reaction}

Alkali-silica reaction (ASR) was identified decades ago (Stanton 1940) as a degradation mechanism in concrete whereby a reaction between the alkalis in the pore solution and certain siliceous phases in the aggregate produces a gel that absorbs water, causing stresses that lead to cracking and strength loss (Hansen 1944, Taylor 1990). Generally, the reaction rate is relatively slow, so the onset of cracking can occur years or decades after construction, depending on the reactivity of the mineral phases and the alkalinity of the pore solution.

The conceptual model for ASR is shown schematically in Figure 12, which was taken from Deschenes et al. (2009). Inside the concrete are reactive aggregates containing siliceous or microcrystalline silica phases. The hydroxyl $\left(\mathrm{OH}^{-}\right)$and alkali species (e.g., $\mathrm{K}^{+}$and $\left.\mathrm{Na}^{+}\right)$are in solution and react with the siliceous phases to form an expansive hydroscopic gel. As the gel absorbs water, it expands, generating stresses that can be in excess of $10 \mathrm{MPa}$ (Rigden et al. 1995). These stresses are sufficient to generate cracking, both in the aggregate and in the surrounding hardened cement paste, and can even cause macroscopic expansion of the structure.

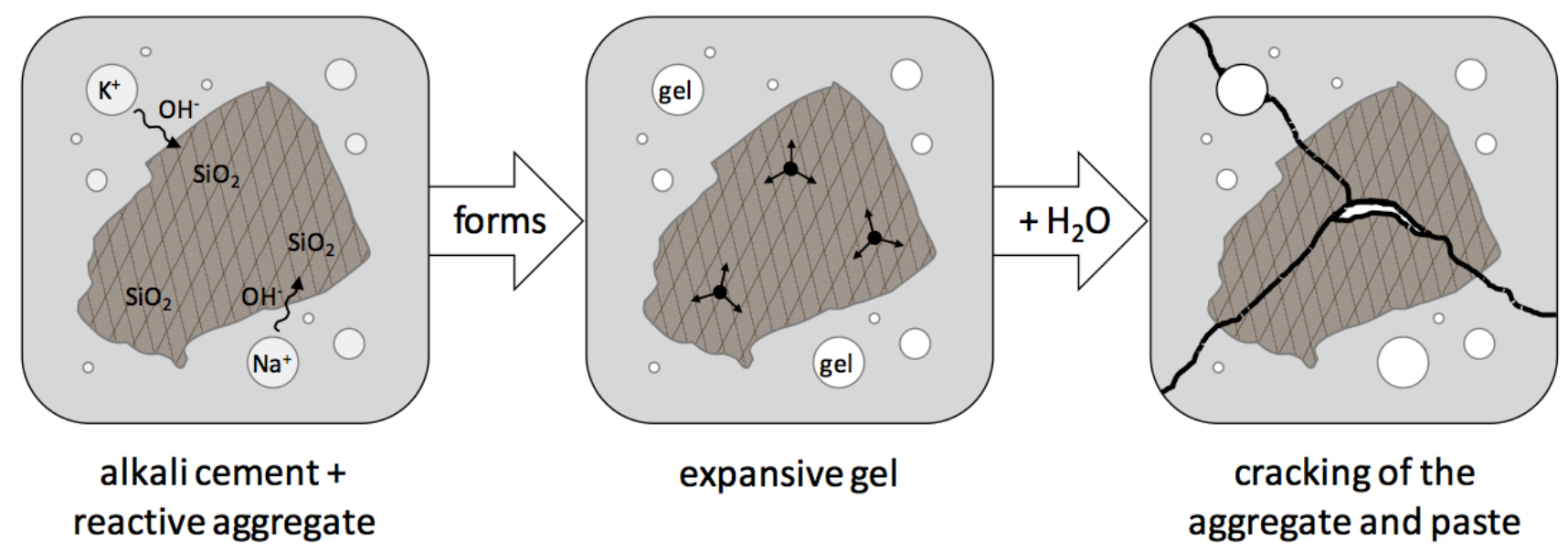

Figure 12. Schematic representation of alkali-silica reaction in concrete (from Deschenes et al. 2009).

In new construction, there is a growing consensus that the availability of non-reactive aggregate is diminishing, and that it is not a matter of if an aggregate is reactive, but rather how reactive the aggregate is. There are a number of tests for alkali-silica reactivity (Farny and Kerkhoff 2007), and these tests consider either the aggregate alone, the binder and a reactive aggregate, or a mixture of the proposed binder and aggregate. These tests, however, do not yield an indication of the expected service life. Rather, they are tests meant to yield a "go/no-go" indication; if the observed expansion is greater than a threshold value, the aggregate is deemed "reactive" and may not qualify for use. The observed expansion, however, depends upon the mix design. The alkalinity of the portland cement plays an important role, as does the use of supplemental cementitious materials that consume dissolved alkalis and the portlandite (calcium hydroxide) created by the portland cement hydration.

Because ASR has been studied for many years, laboratory and field experience has yielded a number of strategies for reducing the likelihood of the reaction to occur at sufficient rate or extent to cause deterioration. In some cases, these strategies have been become recommendations by agencies or 
organizations that own or specify concrete or aggregates. Recommendations have been developed by the Federal Highway Administration (FHWA) (Thomas et al. 2008), the Virginia State Department of Transportation (Lane and Ozyildirim 1995), the U.S. Navy (Malvar et al. 2001, Malvar et al. 2004), and the International Center for Aggregate Research (ICAR) (Tauma 2000). It is important to note that, along with reducing the amount of reactive aggregate, the quantity of alkalis, and access to water, there are other strategies for mitigating the effect of ASR. For example, there are chemicals or materials that one could add to the concrete mixture, such as lithium nitrate (Folliard et al. 2003) to reduce the expansion of the gel, Class N fly ash (Ballard et al. 2008), metal fibers to resist expansion (Bektas et al. 2006) after ASR starts, and starving the reaction by adding the coarse aggregate as a "reactive" powder (CarlesGibergues et al. 2008) that would uniformly distribute the reaction gel, reducing the likelihood of the localized stresses required for crack initiation.

\subsubsection{Scenario}

Alkali-silica reaction progresses in the following manner:

- Concrete contains aggregate with reactive siliceous mineral phases

- Upon hydration of the cementitious binding phases, the hydrated cement paste pore solution become alkaline $(\mathrm{pH}>13)$, balanced with potassium and sodium ions

- Over time, the hydroxyl ions will react with the reactive siliceous mineral phases, either by reacting with these phases located at the surface of the aggregate or by diffusing into the aggregate (along natural defects at mineral boundaries) and reacting with internal reactive inclusions

- The reaction produces a gel that imbibes water and alkalis $\left(\mathrm{K}^{+}\right.$and $\left.\mathrm{Na}^{+}\right)$that make the gel expand (n.b.: the incorporation of $\mathrm{Li}^{+}$, instead of $\mathrm{K}^{+}$and $\mathrm{Na}^{+}$, produces a gel that is not as expansive)

- If the rate of gel production is sufficiently great, the gel will generate an expansive stress within the microstructure

- If the stress is sufficiently great, cracks will form, and the concrete will begin to expand

- If gel generation continues at a sufficient rate, the cracks will propagate to the surface, and the concrete will exhibit macroscopic expansion

- The expansion will continue as long as there are sources of alkalis, water, and reactive siliceous aggregate

In new construction, the primary role of NDE techniques for SLP would be embedded sensors. There could be sensors for two of the three contributors to ASR: moisture sensors, and alkalinity sensors. If the potential for ASR cannot be ruled out, additional sensors could be used to detect the onset of the reaction. These could include sensors for ASR gel production, gel pressure, and the onset of cracking.

For existing structures, the use of NDE techniques is much more challenging. Sensors for alkalinity, moisture content, and gel pressure would require boring into the structure. The onset of cracking could be detected externally (acoustic emission), but only if the structure is sufficiently isolated from mechanical vibration. Macroscopic expansion of the structure could be detected at the surface, but evidence of this extent of expansion means that the ASR reaction has already progressed extensively. 
As for NDE techniques for SLP models, the options are somewhat limited. Although models do exist for ASR (e.g., Bažant and Steffens 2000, Bažant et al. 2000, Ulm et al. 2000), these models use the results of tests performed on the constituent materials, before construction. Estimating the remaining service life of an existing structure is more difficult. One would have to either extract the aggregate from the concrete or have a companion sample of aggregate from the same section of the quarry. Even then, there are no reliable models for predicting the future expansion and mechanical properties of the structure. As a result, there are no test methods for extracting key information from the structure for SLP. A complete list of the NDE relevant to ASR testing for SLP is shown in Table 6. 
Table 6. Methods applicable to service life prediction parameters for alkali-silica reaction.

\begin{tabular}{|c|c|c|}
\hline SLP Parameters & Standardized Methods & Indirect Methods \\
\hline Identifying reactive aggregates & $\begin{array}{l}\text { ASTM C295: Petrographic examination of aggregates } \\
\text { for concrete; } \\
\text { ASTM C1260: Mortar bar method } \\
\text { AASHTO T303: Mortar bar test; } \\
\text { ASTM C1293: Concrete prism test; } \\
\text { ASTM C1567: Accelerated mortar bar test for binders } \\
\text { and aggregates; } \\
\text { ASTM C227: Mortar bar test for cement-aggregate } \\
\text { combinations; }\end{array}$ & \\
\hline Monitoring the potential for ASR & & $\begin{array}{l}\text { Moisture sensors; } \\
\text { Alkalinity sensors; }\end{array}$ \\
\hline Determining the existence of ASR & $\begin{array}{l}\text { ASTM C856: Petrographic examination of hardened } \\
\text { concrete; } \\
\text { ASTM C856 Annex: (uranyl acetate and sodium } \\
\text { cobaltinitrite staining tests) }\end{array}$ & \\
\hline Determining the rate of reaction & & Strain Gauges; \\
\hline $\begin{array}{l}\text { Detecting crack initiation and } \\
\text { propagation }\end{array}$ & & $\begin{array}{l}\text { Acoustic Emission; } \\
\text { Bulk Electrical Conductivity: Wenner test being } \\
\text { developed at ASTM. }\end{array}$ \\
\hline Quantifying macroscopic expansion & & $\begin{array}{l}\text { Strain Gauges; } \\
\text { Laser Dilatometry }\end{array}$ \\
\hline Determining the extent of cracking & & $\begin{array}{l}\text { Crack Density } \\
\text { Ground Penetrating Radar }\end{array}$ \\
\hline $\begin{array}{l}\text { Determining the effect of cracks on } \\
\text { transport properties }\end{array}$ & $\begin{array}{l}\text { ASTM C1556: Determining the chloride diffusion } \\
\text { coefficient of cementitious mixtures by bulk diffusion } \\
\text { ASTM C1543: Determining chloride penetration by } \\
\text { ponding; } \\
\text { ASTM C1760: Bulk electrical conductivity of concrete }\end{array}$ & \\
\hline
\end{tabular}




\begin{tabular}{|c|c|c|}
\hline & ASTM C1585: Concrete sorptivity & \\
\hline Mechanical properties & & $\begin{array}{l}\text { ASTM C805: Standard Test Method for } \\
\text { Rebound Number of Hardened Concrete } \\
\text { (Rebound Hammer) } \\
\text { - ASTM C803: Standard Test Method for } \\
\text { Penetration Resistance of Hardened Concrete } \\
\text { (Windsor Probe) } \\
\text { - Ultrasonic pulse velocity - dynamic modulus }\end{array}$ \\
\hline $\begin{array}{l}\text { Detection of debonding of reinforcing } \\
\text { steel }\end{array}$ & & $\begin{array}{l}\text { - ASTM D4580 - Standard Practice for } \\
\text { Measuring Delaminations in Concrete Bridge } \\
\text { Decks by Sounding } \\
\text { ○ Cannot measure deep defects and } \\
\text { method depends on experience of } \\
\text { operator } \\
\text { - Ground penetrating radar } \\
\text { - Use of Quantitative Acoustic Emission (QAE) } \\
\text { method to detect the decrease of the pre- } \\
\text { stressing level in cables and reinforcement and } \\
\text { embrittlement of reinforcement (Muravin and } \\
\text { Ilina 2010). The QAE method was also able to } \\
\text { reveal, locate, typify and assess other flaws such } \\
\text { as debonding of reinforcement. } \\
\text { - Use of guided ultrasonic waves to detect } \\
\text { presence of corrosion and debonding (Sharma } \\
\text { and Mukherjee 2010). } \\
\text { Ultrasonic method and electromagnetic pulse method } \\
\text { were used to evaluate the debonding caused by } \\
\text { corrosion (Uchida et al. 2009). }\end{array}$ \\
\hline
\end{tabular}




\subsubsection{Resolving the Gaps}

For new structures, the best strategy is thorough testing of the aggregate with the proposed binders. If ASR is still possible, embedded sensors for the alkalinity and moisture content would be helpful to future SLP models, along with any measures of internal stresses being generated. These measurements, however, may still be limited without a careful description of the type, quantity, and distribution of reactive silica within the aggregate. This may be possible to determine from extraction of the existing structure. Otherwise, a review of the minimum requirements for characterizing the aggregate may be needed to ensure that sufficient information will be provided to future analysis.

For existing structures, the role of existing NDT techniques is primarily limited to monitoring, not prediction. The earliest ASR detection methods are the two staining tests (uranyl acetate and sodium cobaltinitrite, which are described in test method ASTM C856 on the petrographic examination of concrete). These tests, however, are only "pass/fail" tests for the presence of ASR, which should still be confirmed by laboratory petrographic examination.

For monitoring the progress of ASR, there are a number of viable existing NDT approaches. The first is to detect the onset of cracking through acoustic emission, but this is limited to applications where the structure is sufficiently isolated from mechanical vibration. Alternatively, one can use pulse velocity measurements to assess the evolution and extent of internal cracking (Fournier et al. 2004). Another useful NDT monitoring technique is dilatometry, but this technique yields reliable quantitative information only after the ASR has progressed extensively.

For existing structures where limited sample extraction is possible, a number of the laboratory tests for characterizing aggregate reactivity could be used by extracting a sample, crushing to remove the suspected aggregate, and then testing the aggregate in mortar bar or prism tests. As for the tests themselves, each is a semi-quantitative "pass/fail" test in which the observed expansion is compared with a predetermined critical value. In time, there may be new SLP models that can use the results of these tests, or modifications to these tests, to predict the remaining expansion to be expected in the structure.

The primary reason for the lack of tests for service life parameter estimation is the lack of a fundamental model for the chemical reaction and for the effect of the distress on the structural properties. Without a reliable model, there is no way to develop meaningful tests for service life, whether for the laboratory or the field.

Although the presence of ASR reaction can be determined conclusively based on standardized petrographic and staining tests, the extent and rate of the reaction cannot be quantified with an existing test. (The only caveat is that if testing a crushed sample of the aggregate in the mortar bar test yields no expansion, one could conclude that the reaction has completed.) The challenge lies in relating the quantity of gel produced, or the quantity of amorphous (or microcrystalline) reactive mineral phases remaining, to the observed cracking. The shape and duration of the expansion vs. time curve depends upon the rate of gel production, the microstructure, the degree of mechanical restraint, and the temperature. Therefore, the expansion vs. time curves generated during standardized testing will not necessarily reflect the expansion observed in the structural element.

Tests for existing structures would have to be developed that reflect the behavior of the reactive aggregate and the mixture design. The extent and rate of the reaction would either have to be determined from a newly developed petrographic examination, or by an analysis of the expansion vs. time curve. Either approach would have to be validated with large specimens, measured over long time intervals. 


\subsubsection{Meeting the SLP Model and Measurement Needs}

The following is a list of activities that would meet some of the most important needs for SLP modeling, primarily through measurement development:

1. Ensure that existing test methods for characterizing aggregate used in concrete sufficiently characterize and quantify the potentially reactive siliceous phases so that, if the structure exhibits ASR damage at a later date, there will be sufficient information about the aggregate on record.

2. Develop reliable sensors for moisture content and the pore solution alkalinity in concrete structures.

3. Develop reliable SLP models for ASR based on the chemistry of the binders, the availability of moisture, and the type and quantity of reactive siliceous phases. This model would also need to couple to the mechanical properties of the concrete. Such a model would help to guide the development of new laboratory and field NDT methods.

4. Develop NDT tests for the rate and the extent of the ASR reaction in existing concrete structures. This will likely involve test methods for quantifying the amount of unreacted expansive siliceous phases remaining in the concrete. This would provide useful information for monitoring strategies and for future SLP models.

5. Develop NDT tests for the rate and the extent of ASR expansion in existing concrete structures. These would have the immediate effect of supporting monitoring strategies, and in the future they could be used to provide feedback to SLP models.

6. Develop test methods for quantifying the remaining reactive siliceous phases in aggregate exhibiting ASR.

7. Develop test methods for relating the rate and extent of ASR to either the rate of crack generation (acoustic emission) or to the observed surface expansion (dilatometry).

Most of these objectives are very challenging. Developing a SLP model for ASR will require conclusive evidence for the role of calcium in the reaction, and will require a better understanding of the viscoelastic properties of the gel. Moreover, the model will need to relate the degree of the reaction to the specific type of aggregate. Predicting the swelling pressure of the ASR gel will be difficult because the properties of the gel are not known and the effect of restraint on the gel expansion is not known. Moreover, although it is known that pozzolans can help mitigate the reaction, the specifics are not understood. All of these challenges were recognized as critical gaps in the knowledge alkali-silica reactions nearly 20 years ago (Helmuth et al. 1993). 


\subsection{Cracking}

Cracking in concrete is a common phenomenon due to internal stress, external load, and a variety of causes (TRB 2006, ACI 224, Aktan and Attanayaka 2004). Figure 13 shows a list of common causes for cracking in concrete structures and Figure 14 illustrates a few types of cracking. Severe cracking affects the mechanical properties of the concrete and reduces the compressive strength and elastic modulus beyond the serviceability limit state. In this case, the microstructure, compressive strength, elastic modulus of the concrete, crack morphology (width, spacing), and crack growth rate are important service life prediction parameters.

Even if the formation of crack networks does not seriously reduce the strength, it may have a large effect on transport properties. The service life and utility of concrete strongly depend on its transport properties, e.g. fluid permeability, capillary suction, and ionic (e.g., chloride, sulfate) diffusivity through the fluidfilled pores. Visible cracking provides an easy pathway for the infiltration of aggressive solutions into the concrete to reach the reinforcing steel or other components of the structure leading to deterioration. Therefore, it is crucial to understand the effect of cracking on the transport properties of concrete in order to estimate degradation rate and to reduce uncertainty in service life predictions. The key SLP parameters are crack morphology (width, spacing), crack growth rate, permeability, transport properties, and other factors listed in the corrosion section.

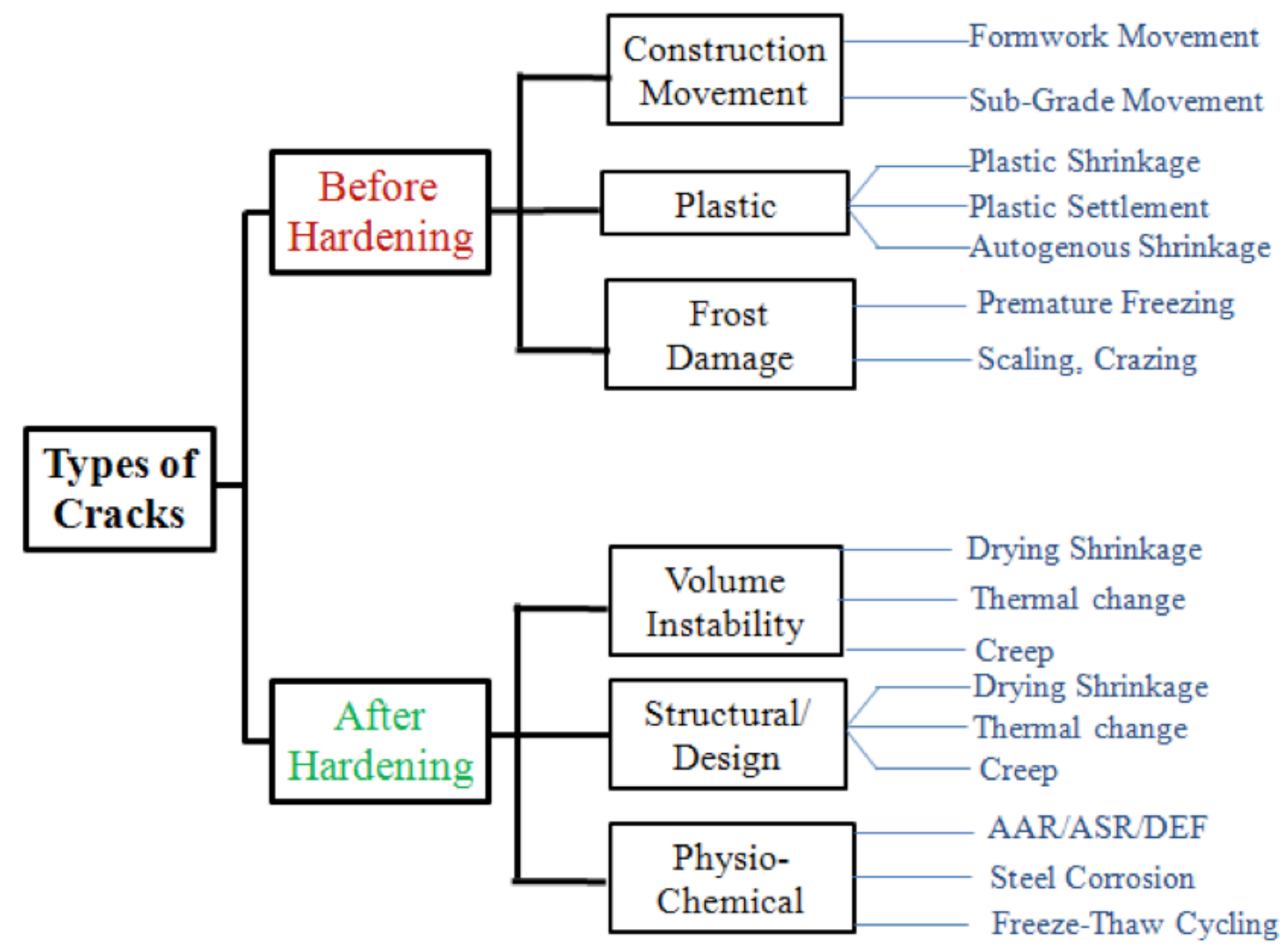

Figure 13. Common causes of cracking in concrete structures (from TRB 2006). 


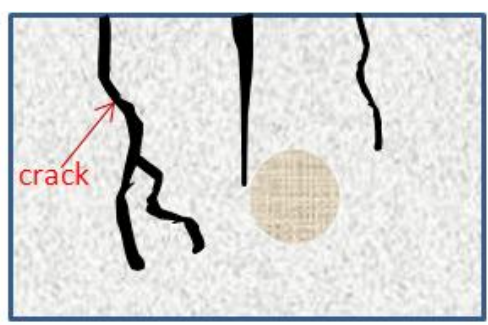

(a)



(c)



(b)

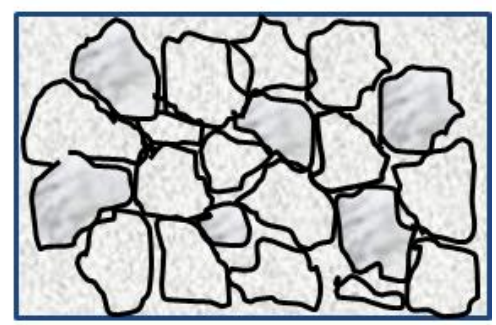

(d)

Figure 14. Some types of cracks from TRB (2006): (a) vertical cracking; (b) horizontal cracking or near surface, and parallel cracks, which may cause delamination; (c) cracking induced from chemical attacked from steel reinforcement bar corrosion; (d) map cracking by ASR. The black lines in (a)-(d) indicate cracks as labeled in (a).

\subsubsection{Scenario}

- Stresses are generated within the microstructure

○ Plastic shrinkage

○ Autogeneous shrinkage

- Drying shrinkage

- Thermal expansion/contraction

$\circ$ Freezing and thawing

- Chemical attack: steel reinforcement bar corrosion, sulfate attack, ASR, etc.

○ Unanticipated mechanical load: seismic, impact, etc.

- Cracks initiate

- Cracks propagate

- Mechanical/Structural properties adversely affected

- Transport properties change

- Vertical cracking provides direct access for deteriorating agents into the concrete interior

- Horizontal cracking or near surface parallel cracks cause delamination within concrete and reduce the bonding between the steel reinforcement bars and the concrete, exposed steel reinforcement to external environments

- Cracks provide easy access for the infiltration of aggressive solutions into the concrete and reach the reinforcing steel or, other components of the structure leading to deterioration

- Cracking can accelerate the ingress of corrosive agents, liquids, and dissolved ions and accelerate corrosion and deterioration

- Cracked concrete in contact with sulfate rich soil can lead to accelerated sulfate attack

- Flexural and shear cracks may be indicators of compromised structural performance 
- Micro crack networks create zones of high stress (localized strain) lead to rapid growth of cracks and further affect the structural performance of the concrete

- Upon reaching the critical extent of cracking (crack width and spacing of the crack), mechanical properties of the concrete are decreased to the extent that the structural capacity is below the design values 
Table 7. Service life prediction parameters related to cracking.

\begin{tabular}{|c|c|c|}
\hline SLP Parameters & Standardized Methods & Methods in Development/Research \\
\hline Surface damage due to cracking & Visual inspection & $\begin{array}{l}\text { - Visual inspection with improved digital sensing } \\
\text { and imaging processing techniques. } \\
\text { - } \quad \text { Flash thermography (FT)(Sham et al. 2008) }\end{array}$ \\
\hline Crack width & Photography & $\begin{array}{l}\text { - UPV (Anwar et al. 2007) } \\
\text { - Impact-Echo } \\
\text { - } \quad \text { Phase array ultrasonic testing } \\
\end{array}$ \\
\hline Crack depth & $\begin{array}{l}\text { ASTM C-597: Standard Test Method for Pulse } \\
\text { Velocity Through Concrete. }\end{array}$ & $\begin{array}{l}\text { - Non-linear ultrasonic (Haroon and Adams 2008, } \\
\text { Matysik et al. 2010) } \\
\text { - UPV with new method (Anwar et al. 2007): put } \\
\text { transducers on surface perpendicular and on any } \\
\text { available surface of the structure near crack. } \\
\text { - } \quad \text { Phase array ultrasonic testing } \\
\text { - Eddy Current array sensors } \\
\text { - Impact-Echo } \\
\text { - } \quad \text { GPR for large cracks, shallow depth } \\
\text { - AE (Acoustic Emission): detect small cracks, } \\
\text { movements and friction }\end{array}$ \\
\hline $\begin{array}{l}\text { Crack distribution/geometric features } \\
\text { of the cracks }\end{array}$ & Photography & $\begin{array}{ll}\text { - } & \text { Thermography } \\
\text { - } & \text { UPV with new method (Anwar et al. 2007) }\end{array}$ \\
\hline $\begin{array}{l}\text { Crack morphology } \\
\text { (micro and macro crack networks) }\end{array}$ & & $\begin{array}{l}\text { Flash thermography (FT) with water for crack } \\
\text { width < 0.5 mm (Sham et al. 2008) } \\
\text { Direct methods: Combination of microscopy, x- } \\
\text { ray imaging and thin sectioning (Hsu et al. } \\
\text { 1963; Isenberg 1966; Slate and Olsefski 1963). } \\
\text { - X-ray computed tomography (CT), and 3D } \\
\text { microstructure reconstruction (Garboczi 2002). } \\
\text { - Acoustic emission, } \\
\text { - Impact echo and 3D volume rendering (Liu and } \\
\text { Yeh 2008) }\end{array}$ \\
\hline $\begin{array}{l}\text { Crack propagation (active/ passive; } \\
\text { growth rate) } \\
\text { Cracking monitoring }\end{array}$ & & $\begin{array}{ll}\text { - } & \text { Acoustic Emission } \\
\text { - } & \text { Ground Penetrating Radar }\end{array}$ \\
\hline
\end{tabular}




\begin{tabular}{|c|c|c|}
\hline Delamination & $\begin{array}{l}\text { ASTM C1383: Standard Test Method for Measuring } \\
\text { the P-Wave Speed and the Thickness of Concrete } \\
\text { Plates Using the Impact-Echo Method } \\
\text { ASTM D 4580: Standard Practice for Measuring } \\
\text { Delaminations in Concrete Bridge Deck by sounding-- } \\
\text { Chain Dragging (Manning and Holt 2007) } \\
\text { ASTM D 6087: Standard Test Method for Evaluating } \\
\text { Asphalt-Covered Concrete Bridge Decks Using } \\
\text { Ground Penetrating Radar. } \\
\text { ASTM D 4788: Standard Test Method for Detecting } \\
\text { Delaminations in Bridge Decks Using Infrared } \\
\text { Thermography }\end{array}$ & $\begin{array}{l}\text { - Impulse Response (IR) method (extent of } \\
\text { - } \quad \text { Ultrasonination) } \\
\text { - Impact echo (the depth of delamination) }\end{array}$ \\
\hline Compressive strength & $\begin{array}{l}\text { ASTM C 39: Standard Test Method for Compressive } \\
\text { Strength of Cylindrical Concrete Specimens } \\
\text { Rebound number (ASTM C 805) Rebound hammer } \\
\text { measures the elastic rebound from the surface of } \\
\text { concrete. The rebound is related empirically to the } \\
\text { compressive strength of the concrete. } \\
\text { Penetration resistance (ASTM C } 803 / C \text { C } 803 \mathrm{M} \text { ) } \\
\text { Winsor probe method. The depth of penetration of the } \\
\text { hardened steel probe is related empirically to the } \\
\text { compressive strength of the concrete. } \\
\text { EN 13791, Assessment of In-situ Compressive } \\
\text { Strength in Structures and Precast Concrete } \\
\text { Components, European Standard, } 2007\end{array}$ & $\begin{array}{l}\text { UPV method may be used to estimate the in-situ } \\
\text { concrete strength only if correlations between the pulse } \\
\text { velocity and compressive strength for the given type of } \\
\text { concrete are established. }\end{array}$ \\
\hline Elastic modulus & $\begin{array}{l}\text { ASTM C 469: Standard Test Method for Static } \\
\text { Modulus of Elasticity and Poisson's Ratio of Concrete } \\
\text { in Compression }\end{array}$ & $\begin{array}{l}\text { - Ultrasonic (UPV)- in thin concrete elements. } \\
\text { - Stress-wave propagation }\end{array}$ \\
\hline
\end{tabular}




\subsubsection{Resolving the Gaps}

Cracks may or may not indicate structural problems. However, even cosmetic cracks can accelerate the degradation of the structure, and early detection of cracks is essential in extending the service life of the structure and preventing structural failure. Typical crack characteristics are size, location, and dimensional changes. The determination if a crack is growing requires repeated measurements. When cracks are determined to be potentially dangerous, then automated or frequent monitoring (routine crack inspections) are required, or in some severe cases, immediate removal of the structure from service. As shown in Table 7, there are many direct (such as thermography, microscopy, x-ray imaging) or indirect methods (NDT methods- e.g., linear and nonlinear ultrasonic methods, UPV, impact-echo, AE, GPR) for crack detection and assessment of crack damage. However, most NDT methods have their advantages and limitations, and no single method is sufficient for detecting crack size and morphology. It is even harder to determine the crack depth when the crack is farther from the concrete surface. A combination of various NDT tools is needed and standard terminology/procedures are also required for researchers and technicians to communicate.

A standard practice for assessing cracking of concrete structures consisting of a four-level-activity research plan is proposed. Each level of activity is described as follows:

\section{L1: Detection-determine if cracks are present.}

A common practice of surface crack detection is visual inspection. Visual inspection is one of the most versatile and useful NDT methods, and it is typically one of the first steps in the evaluation of a concrete structure. The visual inspection methods have improved from traditional manual inspection (with the aid of flashing lights, sounding hammers, tape measures), to modern automated hand-held microscope with digital sensing and imaging processing techniques (thresholding, edge detection, image segmentation). Surface cracking such as map cracking, scaling can be detected and recorded, and with a crack comparator, the width of the openings of surface cracks can be measured accurately. Visual inspection can provide a wealth of information that may lead to correct identification of the cause of the observed distress. However, its effectiveness depends on the knowledge and experience of the inspector. Broad knowledge in structural engineering, concrete materials, and construction methods is needed to extract the most information from a visual inspection.

\section{L2: Localization-accurately locate the crack; locate the site of the damage due to cracking.}

Visual inspection can identify the cracking on the concrete surface and open cracks (vertical cracks) into the structures. Accurately locating the cracking and measuring the width, depth, and distribution of cracks is not simple. Direct methods, such as microscopy, $\mathrm{x}$-ray imaging and thin sectioning or the high resolution x-ray computed tomography (CT), and 3D microstructure reconstruction methods, are good for understanding the formation of the crack, and provide data for interpreting interplay of microcracking and mechanical loading, and predict possible fatigue failure analyses (Mihashi et al. 2006). However, these methods are not practical for in-situ, field inspection. NDT test methods are still the most viable tools due to their portability. However, even though there are many NDT tools and standard test methods for performing a particular task (for example, GPR, sounding, impact echo, infrared thermography can be used to detect delaminations in bridge decks), it is often difficult to decide which one is the best method. Inconsistent results have been observed when comparing the results from a single NDT or multiple NDT methods. For example, the measured GPR signals/images from a complex reinforced concrete structure 
can be difficult to interpret and the measured signals may change if the probing frequency and detection configuration are different. Furthermore, the results obtained from GPR and impact-echo methods may not be directly comparable due to different detection mechanisms. The variability of individual NDT and the correlation between different NDT methods are still a concern for the delamination detection.

As far as the NDT tools and test methods for crack detection are concerned, there is no existing standard test method for crack detection except some guidelines for implementing NDT such as ASTM C597 for pulse velocity through concrete. UPV test is considered to be one of the most effective tools for investigating concrete structures, predicting strength and determining the extension of cracks in concrete. Furthermore, UPV with a new test method proposed by Anwar et al. (2007) using transducers in multiple locations can improve measurement sensitivity in detecting not only cracks parallel to the surface but also vertical and inclined cracks. This improved UPV method also resulted in a better/more precise measurement of the location and depth of the cracks. Other advanced NDT methods such as phase array ultrasonic testing, eddy current array sensors, impact-echo, GPR, AE should also be considered for determining crack formation.

\section{L3: Assessment -estimate the amount (magnitude) of the damage due to the crack formation.}

The crack width, depth, geometric features of the cracks and crack concentration are important parameters to assess the severity of the damage due to the crack formation. Crack formation affects the integrity of the concrete by degrading both the mechanical and transport properties. The mechanical properties of the structure (such as the compressive strength and elastic modulus) decrease as cracking increases. At this stage, the use of computation models (Lu and Garboczi 2012) to understand the relationship between the physical fracture process and crack network is crucial for estimating the severity of the damage. Fatigue failure analyses combined with the compressive strength and elastic modulus measurements are needed to provide an accurate assessment of the "current" structural capacity.

In addition to the mechanical properties, the impact of cracks on the transport properties of the concrete (e.g., air and moisture permeability) and the chemical state of the concrete (e.g., moisture content) are also important to analyze to ensure the integrity of the concrete. Many of the measurements methods made to determine transport properties are based on experiments on uncracked concrete as opposed to cracked concrete. Thus, research efforts in modeling and measurements in linking the crack formation to the mechanical and transport properties are lacking and are greatly needed.

\section{L: Prognosis -conduct a life-cycle assessment of the condition; estimate the future progress of the damage and the remaindering life of the structure.}

Use the damage assessment from L3 to assign a severity level. However, even for a low level of severity, crack monitoring is essential. It is critical to determine if the crack is active/ passive, and to obtain the growth rate if it is active. Crack propagation is a key factor in the life-cycle assessment of the remaining service life because rapid crack growth and fast crack propagation indicates the potent for a catastrophic event and requires immediate attention. To achieve this, implementing NDT techniques and/or sensors to monitor the future progress of the damage (crack growth) is the major task. Currently, there are no clear guidelines and programs to aid inspectors and users. 
As described in each level above, some standard test methods exist but they may not be suitable for crack detection measurements. In most cases, such as measuring crack depth, microcracking, crack propagation monitoring, there are no standard test methods or guidelines, especially in the use of NDT tools. This deficiency is due primarily to the lack of fundamental knowledge of the underlying physics of NDT probes and their interaction with the defects (crack, for example). Many NDT tools have been used to detect crack morphology (crack width, depth, and geometric features), but there are no recommended methods. Note that most of the more advanced NDT tools are still in the research stages; it requires expensive equipment and highly skilled operators to process and analyze the complex signals and data. The proposed four-level-activity research plan is reasonable for assessing cracking of concrete structures; however, it is difficult to proceed if the data obtained are inadequate and inaccurate (in L1-L3). Clearly, standard test methods or guidelines for charactering and detecting crack morphology are greatly needed. Other measurement tools are also needed for monitoring crack propagation under external loads or realistic/field (containing critical chloride content) environments.

\subsubsection{Meeting the SLP Model and Measurement Needs}

The following is a list of activities that would meet some of the most important needs for SLP modeling, primarily through measurement development:

1. Establish a test bed of artifact-based standard reference materials/structures with known crack formation to evaluate current available NDT tools.

2. Develop accurate 3-D models to help understand how different NDT methods may be used to detect cracks; develop theoretical and computational methods to provide a scientific interpretation to NDT response and improve the sensitivity of the techniques.

3. Develop a test method for crack morphology detection - starting with crack width and depth.

4. Develop a test method for quantifying the extent of crack propagation under external loads or realistic/field environments.

5. Develop surface or embedded, non-contact sensors combined with NDT tools and computing capabilities (high speed, large data storage, and advanced signal processing techniques) for long term structural and performance monitoring.

6. Evaluate the effectiveness of crack-resistant binders or the additions of stiffeners or fibers that resist crack growth.

7. Develop modeling/computer simulation and measurements for examining the effect of the crack formation on the mechanical and transport properties, and validation of the results obtained from field data. 


\section{COMMONALITIES AMONG GAPS}

There are broad gaps in the existence of coupled NDT methods and reliable SLP models. This gap is due, in small part, to the SLP methods being developed (largely) in laboratory conditions to ensure reliable validation. The researchers had the flexibility to control the environmental exposure conditions and to measure critical model parameters under ideal laboratory conditions. Moreover, because SLP models are typically developed for new construction, the models are (almost) never developed with the constraint of limiting model parameters to quantities that can be quantified by existing NDT methods. As a result, NDT method development typically lags behind SLP model development. Correspondingly, SLP model development for existing structures lags behind SLP model development for new construction because estimating remaining service life is a greater technical challenge.

Common material properties are the moisture content, the transport properties (e.g., diffusivity, permeability, sorptivity), and the spatial distribution of the chemical composition of the pore solution. One possible strategy is to develop reliable models that can relate relative changes in the electrical conductivity and moisture content to relative changes in the transport properties. Depending on the extent of the electrical sensors and the extent of any cracks present, the effects of the cracks on the transport coefficient could be incorporated into the revised prediction of the bulk (averaged) transport coefficient. (The effects of localized cracking on the corrosion of steel reinforcement bars, however, would be a more demanding strategy.) Another benefit is that the effects of cracking from one degradation scenario (e.g., ASR) could be incorporated into an SLP model for corrosion.

Until sensors can be developed for the rate/extent of chemical reactions, or for coupled moisture and electrical methods for estimating the effects of cracks on bulk transport properties, NDT methods are needed for detecting the onset and propagation of cracks. Even though the onset of cracks is an indication that the degradation has progressed to the extent of stress generation, early detection of cracks will help to inform the monitoring program of the potential for problems. Furthermore, if the location of the cracking can be determined, this would provide additional information, such as the type of degradation that might be occurring.

The ultimate consideration, however, is the mechanical properties of the structural element. Although there exist indirect NDT methods for estimating the mechanical properties (through correlation), there are no direct methods, particularly for characterizing the concrete- reinforcement bar bond strength. Unless direct methods can be developed, models are needed to relate measureable quantities to the structural characteristics. One approach is to use correlations to samples that have been degraded in the laboratory at the time of construction. For an existing structure, however, developing reliable correlations can be far more problematic.

Given the magnitude of the challenges, the effort forward might be divided between two strategies, depending upon whether the degradation scenario leads to a "fast" or "slow" degradation of the mechanical properties. For scenarios that can occur over shorter time frames (e.g., drying shrinkage cracking, corrosion of the steel reinforcement), improved models are needed for predicting the effects of degradation on the remaining service life are needed. These models should be developed in the context of NDT methods: either the model is developed to use existing NDT methods to obtain critical model parameters, or new NDT methods are developed as needed. For degradation scenarios that typically require longer to manifest themselves (and assuming the rate of strength loss also occurs at a relative slow rate), sensors may be unreliable over these very long time periods, and developing comprehensive SLP models will be challenging. In these cases, a comprehensive monitoring strategy may be the best approach. Sensing the onset and propagation of cracking, would provide extremely useful information. 
This could be coupled with surface electrical resistivity measurements to develop a general sense of how the transport properties might be changing. 


\section{SUMMARY}

A number of nondestructive testing (NDT) methods for characterizing the physical and chemical state of a concrete structure have been identified and characterized in the context of long-term performance assessment. Although NDT methods have been used with limited success to evaluate the current state of a structure, this report is one of the first to view these techniques in the context of supporting long-term performance assessments. More specifically, the NDT methods have been discussed in the context of supporting service life prediction (SLP) models.

The NDT methods that appear in the report were chosen because they might contribute to service life prediction in a number of ways. Service life prediction can support a number of building evaluation and maintenance activities, including performance assessments and monitoring and repair strategies. As part of either of these activities, NDT methods may be used to perform any of the following functions:

- Quantify the physical and chemical input parameters to a model

- Detect the onset of degradation or damage

- Quantify the amount of degradation or damage

- Provide feedback on whether detected degradation is continuing

- Provide feedback to the service life model as part of a monitoring program

The utility of various NDT techniques for SLP was discussed in the context of three degradation scenarios relevant to nuclear power plants: corrosion of the steel reinforcement, alkali-silica reaction (ASR), and cracking (which could be due to a number of possible causes). Each degradation scenario was described in sufficient detail to illuminate the significant factors or parameters for SLP models. For each factor or parameter, the relevant NDT methods were identified. These methods included both standardized tests and tests in research or development. For a number of factors, however, no standardized tests exist, or the tests in development were of limited use.

Based on an assessment of the NDT methods available for evaluating these degradation scenarios, a number of common challenges remain:

- Service life prediction models developed for new construction are typically developed in the laboratory and are not developed in the context of existing NDT methods.

- Although sophisticated physicochemical SLP models can, in principle, be applied to existing concrete structures (as specific initial conditions), they were not developed with the assurance that NDT methods exist to quantify these initial conditions accurately.

- A general approach to estimating materials properties may be to use a combination of sensors or NDT methods for moisture content and conductivity to estimate relative changes in the bulk transport properties.

- Until reliable long-term sensors are developed, sensors to detect the initiation and propagation of cracks may be a vital support tool for a comprehensive monitoring strategy, whereby the location of the cracking may help to identify the degradation mechanism.

- Reliable NDT, with emphasis on non-destructive, methods are needed for determining the in-situ mechanical properties of reinforced concrete. 
Given the magnitude of the challenges that remain, one possible solution is to develop parallel plans, one for "fast" acting degradation scenarios and another for "slow" acting degradation scenarios. For the faster degradation scenarios such as corrosion of the steel reinforcement, develop comprehensive predictive models that are coupled to NDT methods. For these scenarios, the degradation has progressed relatively far by the time there is external evidence of distress. Even when using a monitoring program, the predictive nature of a SLP model will help to develop a more reliable monitoring schedule that uses chemical state monitoring for the earliest detection, and NDT methods for characterizing the "current" condition of the reinforced concrete. For the slower degradation mechanisms like ASR, the chemical and physical mechanisms may be quite complex, so a comprehensive physicochemical SLP model may require years of development. In these cases, a monitoring strategy that is based on early detection of cracks, and pinpointing where those cracks are occurring, along with moisture and electrical conductivity measurements, may help to identify the type of degradation occurring and estimate some measure to which the transport properties are changing. When plans are developed for creating or improving SLP models, they should either state how they would use measurement data from existing NDT methods and sensors, or what new NDT methods and sensors need to be developed to support the model.

For both types of scenarios, NDT methods are needed for quantifying the in-situ mechanical properties of the concrete. These methods could be divided between correlations (between measureable quantities and mechanical properties) and methods for measuring these properties directly in existing structures. There exist a number of promising techniques for developing these correlations for new construction. For existing structures, considerable effort is needed to develop reliable relationships between the results from NDT methods and SLP models. 


\section{REFERENCES}

ACI (2004), "Nondestructive Test Methods for Evaluations of Concrete in Structures," ACI 228.2R-98 (Reapproved 2004), American Concrete Institute, Farmington Hills, MI.

ACI Committee 224, Control of Cracking in Concrete Structures, ACI 224R-01, American Concrete Institute, Farmington Hills, MI.

ACI Committee 228, In-Place Methods to Estimate Concrete Strength, ACI 228.1R-03, American Concrete Institute, Farmington Hills, MI.

ACI Committee 437, Strength Evaluation of Existing Concrete Buildings, ACI 437R-03, American Concrete Institute, Farmington Hills, MI.

Aktan H, Attanayaka U (2004), "Causes and cures for cracking of concrete barriers,” MDOT RC-1448, Michigan DOT.

Aktan H, Krueger M (2007), "Non-Destructive Evaluation (NDE)"

(http://www.seami.org/pdf/Non_Destructive_Evaluation.pdf)

Andonov, A., Stefanov, D., and Kostov, M. (2010), “An Approach for Reliability - Based Control of VVER 1000 Containment Structure," Paper presented at the International Symposium on Reliability Engineering and Risk Management, Shanghai, China.

Andrade, C. and Alonso, C. (2004), "Test Methods for On-Site Corrosion Rate Measurement of Steel Reinforcement in Concrete by Means of the Polarization Resistance Method," Materials and Structures, Vol. 37, No. 9, pp. 623-643.

Andrade, C. (2012), Corrosion Data Interpretation in Concrete Structures, Advances in Modeling Concrete Service Life, Proceedings of the $4^{\text {th }}$ International RILEM PhD Workshop held in Madrid, Spain, Nov. 19, 2010, Andrade, C. and Gulikers, J. (Eds), Springer, p. 1 - 10.

Angst, U., Elsener, B., Larsen, C. K., and Vennesland, O. (2009), Critical Chloride Content in Reinforced Concrete - A Review, Cement and Concrete Research, Vol. 39, p. 1122-1138.

Aoki, Y., Hashimoto, S. (2002), Accurate extraction and measurement of fine cracks from concrete block surface image, IECON 02, Industrial Electronics Society, IEEE 2002 28th Annual Conference, Vol. 3, pp. $2202-2207$.

Anwer, A.M., Hattori, K., Ogata, H, Ashraf, M. Goyal (2007), New approach towards Crack dtermination in concrete using UPV test, $32^{\text {nd }}$ Conference on OUR WORLD IN CONCRETE \& STRUCTURES: 28-28 August 2007, Singapore.

Arndt, R., and Jalinoos, F. (2009), NDE for Corrosion Detection in Reinforced Concrete Structures - A Benchmark Approach, NDTCE'09, Non-Destructive Testing in Civil Engineering, Nantes, France, June $30^{\text {th }}-$ July $3^{\text {rd }}$.

Baker-Jarvis, J., Sung, K., Surek, J., Duthinh, D., Stutzman, P., and Garboczi, E. (2013), Electromagnetic Variations of Concrete, in preparation. 
Balayssac, J. P., Laurens, S., Arliguie, G., Ploix, M. A., Breysse, D., Derrobert, X., and Piwakowski, B. (2009), "Evaluation of concrete structures by combining non-destructive testing methods (SENSO project)," Non-Destructive Testing in Civil Engineering, Nantes, France, June 30 - July 3, 2009.

Ballard, Z.J., Caires, W.S., and Peters, S.R. (2008), Alternate Mitigation Materials for Alkali-Silica Reaction (ASR) in Concrete, CDOT-2008-10, Colorado Department of Transportation, Denver, CO.

Barneyback, R.S. (1983), Ph.D. Thesis, Purdue University, U.S.A.

Barneyback, R.S. and Diamond, S. (1981), Cement Concrete Research, vol. 11, p. 279.

Bažant, Z.P. and Steffens, A. (2000), Mathematical model for kinetics of alkali-silica reaction in concrete, Cement and Concrete Research, Vol. 30, pp. 419-428.

Bažant, Z.P., Zi, G., and Meyer, C. (2000), Fracture mechanics of ASR in concretes with waste glass particles of different sizes, Journal of Engineering Mechanics, Vol. 126, pp. 226-232.

Bektas, F., Turanli, L., and Ostertag, C.P. (2006), New approach in mitigating damage caused by alkalisilica reaction, Journal of Materials Science, vol. 51, pp. 5760-5763.

Bentur, A., Berke, N. S., and Li, L. (2006), Integration of Technologies for Optimizing Durability Performance of Reinforced Concretes, International RILEM-JCI Seminar on Concrete Durability and Service Life Planning, ConcreteLife'06, 14- 16 March 2006, Ein-Bokek, Dead Sea, Israel, Konstantin Kovler (Ed), RILEM Publications, pp. 247-258.

Bentz, D. (2007), “A virtual rapid chloride permeability test," Cement and Concrete Composites, Vol. 29 (10), pp. 723-731.

Bentz., D., Snyder, K. A., Cass, L. C., and Peltz, M. A. (2008), "Doubling the service life of concrete structures. I: Reducing ion mobility using nanoscale viscosity modifiers," Cement \& Concrete Composites, Vol. 30, pp. 674-678.

Berriman, J., Gan, T.H., Hutchins, D. A., Purnell, P. (2003), "Non-Contact Ultrasonic Interrogation of Concrete," International Symposium (NDT-CE 2003), Non-Destructive Testing in Civil Engineering 2003, Berlin, Germany.

Bishop, J.A., Pommerenke, D.J., Chen,G. (2011), “A rapid-acquisition electrical time-domain reflectometer for dynamic structure analysis," IEEE Transactions on Instrumentation and Measurement, Vol. 60, No. 2, pp. 655-661.

Breysse, D. (2011), Recent developments in analyses techniques for non-destructive testing and assessment of concrete properties. Paper presented at the AMP 2010 - International Workshop on Ageing Management of Nuclear Power Plants and Waste Disposal Structures (EFC Event 334), Toronto, Canada.

Breysse, D., Larget, M., Sbartai, Z. M., Lataste, J-F., Balayssac, J-P. (2011), “Quality of NDT Measurements and Accuracy of Concrete Physical Properties Quantitative Assessment," European Journal of Environmental and Civil Engineering, Vol. 15, No. 4, pp. 619-632. 
Busse, G., Busse, G., Hemelrijck, D. V., and Solodov, I. (2007), Emerging technologies in nondestructive testing, Proceedings of the 4th International Conference of Emerging Technologies in NonDestructive Testing (ETNTD 4), Stuttgart, Germany.

Carino, N.J. and Clifton, J.R. (1995), Prediction of Cracking in Reinforced Concrete Structures, NISTIR 5634.

Carino, N. J. (2001), "The Impact-echo method: An Overview," The proceeding of the 2001 Structures Congress \& Exposition, May 21-23, 2001, Washington, DC, Peter C. Chang, Editor, American Society of Civil Engineers, Reston, VA, 18 pp.

Carles-Gibergues, A., Cyr, M., Moisson, M. and Ringot, E. (2008), "A simple way to mitigate alkalisilica reaction," Materials and Structures, Vol. 41, pp. 73-83.

Castellote, M. and Andrade, C. (2006), "Round-Robin Test on Methods for Determining Chloride Transport Parameters in Concrete," Materials and Structures, Vol. 39, pp. 955-990.

Chang, C.-Y., and Hung, S.-S. (2012), "Implementing RFIC and sensor technology to measure temperature and humidity inside concrete structures," Construction and Building Materials, Vol. 26, No. 1, pp. 628-637.

Chaki, S., and Bourse, G. (2009), "Guided ultrasonic waves for non-destructive monitoring of the stress levels in prestressed steel strands," Ultrasonics, Vol. 49, No. 2, pp. 162-171.

Charrett, T. O. H., Francis, D., and Tatam, R. P. (2011), "Quantitative shearography: error reduction by using more than three measurement channels," Applied Optics, Vol. 50, Issue 2, pp. 134-146.

Chen, X.J., Kim, J.-., Kurtis, K.E., Qu, J., Shen, C.W. and Jacobs, L.J. (2008), "Characterization of progressive microcracking in Portland cement mortar using nonlinear ultrasonics," NDT and E International, Vol. 41, No. 2, pp. 112-118.

Cho, Y. S., Hong, S. U., and Lee, M. S. (2009), "The assessment of the compressive strength and thickness of concrete structures using nondestructive testing and an artificial neural network," Nondestructive Testing and Evaluation, Vol. 24, No. 3, pp. 277-288.

Choi, S., Park, S., Hyun, C.-H., Kim, M.-S., and Choi, K.-R. (2010), "Modal parameter identification of a containment using ambient vibration measurements," Nuclear Engineering and Design, Vol. 240, No. 3, pp. 453-460.

Chou, S. G., Stutzman, P. E., Wang, S., Garboczi, E. J., Egelhoff, W. F., Plusquellic, D. F. (2013), "High-Resolution Terahertz Optical Absorption Study of the 2 Antiferromagnetic Resonance Transition in Hematite $(\alpha-\mathrm{Fe} 2 \mathrm{O} 3), "$ accepted for publication in Journal of Physical Chemistry.

Cui, J., Huston, D. R., Arndt, R., and Jalinoos, F. (2010), "Data Fusion Techniques of Multiple Sensors Nondestructive Evaluation of a Concrete Bridge Deck," NDE/NDT for Highways Bridges: Structural Materials Technology (SMT 2010), August 16-20, 2010, NYC, NY, by ASNT American Society of Nondestructive Testing (ASNT). 
Darwin, D., Browning, J., O’Reilly, M., Xing, L., and Ji, J. (2009), “Critical chloride corrosion threshold of galvanized reinforcing bars," ACI Materials Journal, Vol. 106, pp. 176-183.

de Beer, F.C., le Roux, J.J., Kearsley, E.P. (2005), “Testing the durability of concrete with neutron radiography," Nuclear Instruments and Methods in Physics Research, Vol. A 542, pp. 226-231.

Dérobert, X., Aubagnac, C., and Abraham, O. (2002), "Comparison of NDT techniques on a posttensioned beam before its autopsy," NDT \& E International, Vol. 35, No. 8, pp. 541-548.

Deschenes, D.J., Bayrak, O., and Folliard, K.J. (2009), “ASR/DEF-Damaged Bent Caps: Shear Tests and Field Implications," Technical Report No. 12-8XXIA006, University of Texas, Austin, TX, 258 pp.

DeSouza, S.J. (1996), “Test Method for the Evaluation of Durability of Covercrete,” M.A.Sc. Thesis, Department of Civil Engineering, University of Toronto.

Dorf, V., Krol, I., and Krasnovsky, R. (2009), "Predicting Durability and Residual Service Life of Reinforced Concrete Structures," $2^{\text {nd }}$ International RILEM Workshop on Concrete Durability and Service Life Planning (ConcreteLife'09), 7-9 September 2009, Haifa, Israel.

Drnevich, V.P. (2012), "Water content, cement content, water/cement ratio, and Compressive Strength of Concrete from Time Domain Reflectometry," http://otc-prf.org/sites/default/files/techprofiles/63081_2012_01_12_ncs.pdf

Duan, W. H., Wang, Q., and Quek, S. T. (2010), “Applications of piezoelectric materials in structural health monitoring and repair: selected research examples," Materials, Vol. 3, pp. 5169-5194 (doi:10.3390/ma3125169).

EN 13791 (2007), “Assessment of In-situ Compressive Strength in Structures and Precast Concrete Components,” European Standard.

Farny, J.A. and Kerkhoff, B. (2007), "Diagnosis and Control of Alkali-Aggregate Reactions in Concrete," Portland Cement Association, Skokie, IL, 26 pp.

Ferraro, C. C. (2003), "Advanced nondestructive monitoring and evaluation of damage in concrete materials," Masters Thesis, University of Florida, 2003.

FHWA (1997), “Guide to Nondestructive Testing of Concrete,” FHWA-SA-97-105 (G.I. Crawford), Federal Highway Administration, Washington, DC.

FHWA (2005), "Tech Brief: Use of Magnetic Tomography Technology to Evaluate Dowel Bar Placement," FHWA-IF-06-002, Concrete Pavement Technology Program, Federal Highway Administration, Washington, DC, (http://www.fhwa.dot.gov/pavement/pccp/pubs/06002/06002.pdf).

Folliard, K.J., Thomas, M.D.A., Kurtis, K.E. (2003), "Guidelines for the Use of Lithium to Mitigate or Prevent Alkali-Silica Reaction (ASR),” FHWA-RD-03-047, Federal Highway Administration, McLean, VA, 86 pp. 
Fournier, B., Bérubé, M.A., Thomas, M.D.A., Smaoui, N., and Folliard, K.J. (2004), "Evaluation and Management of Concrete Structures Affected by Alkali-Silica Reaction - A Review," Report MTL 200411, CANMET Materials Technology Laboratory, 59 pp.

Garboczi, E. J. (2002), “Three-dimensional mathematical analysis of particle shape using X-ray tomography and spherical harmonics: Application to aggregates used in concrete," Cement and Concrete Research, Vol. 32, No. 10, pp. 1621-1638.

Gautschi, G. (2002), Piezoelectric Sensorics, Force, Strain, Pressure, Acceleration and Acoustic Emission Sensors, Materials and Amplifiers, Springer-Verlag, New York.

Groves, R. M., Chehura, E., Li, W., Staines, S. E., James, S. W., and Tatam, R. P. (2007), “Surface strain measurement: a comparison of speckle shearing interferometry and optical fibre Bragg gratings with resistance foil strain gauges," Measurement Science and Technology, Vol. 18, pp. 1175-1184.

Groves R. M., Furfari, D., Barnes, S. E., James S. W., Fu, S., Irving, P. E., and Tatam, R. P. (2006), "Full-field laser shearography instrumentation for the detection and characterization of fatigue cracks in titanium 10-2-3,” J. ASTM. International, Vol. 3, Issue 4, April (DOI: 10.1520/JAI12757).

Groves, R. M., James, S. W., and Tatam, R. P. (2003), "Pipe weld investigation using shearography," Strain, Vol. 39, Issue 3, pp. 101-105.

Gulikers, J. (2012), "Pitfalls and Practical Implications in Durability Design of Reinforced Concrete Structures," Advances in Modeling Concrete Service Life, Proceedings of the $4^{\text {th }}$ International RILEM PhD Workshop held in Madrid, Spain, Nov. 19, 2010, Andrade, C. and Gulikers, J. (Eds), Springer, pp. 11-20.

Guthrie, G.D. and Carey, J.W. (1997), “A Simple, Environmentally Friendly, and Chemically Specific Method for the Identification and Evaluation of the Alkali-Silica Reaction," Cement and Concrete Research, Vol. 27, No. 9, pp. 1407-1417.

GD Guthrie, G.D. and JW Carey, J.W. (1998), "Geochemical methods for the identification of ASR gel," LA-UR-98-3570, Los Alamos National Laboratory.

Hall, C. (1989), "Water Sorptivity of Mortars and Concretes: A Review", Magazine of Concrete Research, Vol. 41, No. 147, pp. 51-61.

Hansen, W.C. (1944), "Studies relating to the mechanism by which the alkali-aggregate reaction produces expansion in concrete," Journal of the American Concrete Institute, Vol. 15, pp. 213-227.

Haroon, M, and Adams, D.E. (2008), "Implementation of Nonlinear Acoustic Techniques for Crack Detection in a Slender Beam Specimen," Health Monitoring of Structural and Biological Systems 2008, edited by Tribikram Kundu, Proc. of SPIE, Vol. 6935, 69350P,

Hartt, W. H., Powers, R. G., Lysogorski, Liroux, V., Virmani, Y. P. (2007), "Corrosion Resistant Alloys for Reinforced Concrete," FHWA-HRT-07-039, Federal Highway Administration, McLean, VA, 132 pp. 
Hartt, W. H., Powers, R. G., Marino, F. P., Paredes, M., Simmons, R., Yu, H., Himiob, R., Virmani, Y. P. (2009), "Corrosion Resistant Alloys for Reinforced Concrete," FHWA-HRT-09-020, Federal Highway Administration, McLean, VA, 146 pp.

Helmuth, R., Stark, D., Diamond, S., and Moranville-Regourd, M. (1993), "Alkali-Silica Reactivity: An Overview of Research," SHRP-C-324, Strategic Highway Research Program, National Research Council, Washington, D.C., 105 pp.

Henault, J. M., Salin, J., Moreau, G., Delepine-Lesoille, S., Bertand, J., Taillade, F., Quiertant, M., and Benzarti, K. (2011a), "Qualification of a truly distributed fiber optic technique for strain and temperature measurements in concrete structures," Paper presented at the AMP 2010 - International Workshop on Ageing Management of Nuclear Power Plants and Waste Disposal Structures (EFC Event 334), Toronto, Canada.

Henault, J. M., Salin, J., Moreau, G., Delepine-Lesoille, S., Bertand, J., Taillade, F., Quiertant, M., and Benzarti, K. (2011b), "Monitoring of concrete structures using OFDR technique," AIP Conference Proceedings, Vol. 1335, No. 1, pp. 1386-1393.

Hignett, C. and Evett S.(2000), "Comparison of Soil Water Measurement Using the Neutron Scattering, Time Domain Reflectometry and Capacitance Methods," IAEA-TECDOC-1137, International Atomic Energy Agency, Vienna, Austria.

Hock, V. F., Morefield, S. W., Weiss Jr., C. A., Malone, P. G., and Koenigstein, M. L. (2009), “The Use of Vitreous Enamel Coatings to Improve Bonding and Reduce Corrosion in Concrete Reinforcing Steel and Stay-in-Place Forms at Army Installations," 2009 DoD Corrosion Conference,

https://www.corrdefense.org/Technical\%20Papers/THE\%20USE\%20OF\%20VITREOUS\%20ENAMEL $\%$ 20COATINGS\%20TO\%20IMPROVE\%20BONDING\%20AND\%20REDUCE\%20CORROSION\%20 IN\%20CONCRETE\%20REINFORCING\%20STEEL.pdf

Hsu, T. T. C., Slate, F. O., Sturman, G. M., and Winter, G. (1963). "Microcracking of plain concrete and the shape of the stress-strain curve," Journal of American Concrete Institute Proceedings, Vol. 60, pp. 209-224.

Hurley, M. F. and Scully, J. R. (2006), “Threshold Chloride Concentrations of Selected CorrosionResistant Rebar Materials Compared to Carbon Steel," Corrosion, Vol. 62, pp. 892-904.

Huston, D. (2011), "Structural sensing, health monitoring, and performance evaluation," Series in Sensors, CRC Press, Boca Raton, FL.

IAEA (2002), "Guidebook on non-destructive testing of concrete structures," IAEA-TCS-17 (ISSN 1018-5518), International Atomic Energy Agency, Vienna (Austria).

IAEA (2005), "Non-destructive testing for plant life assessment," IAEA-TCS-26 (ISSN 1018-5518), International Atomic Energy Agency, Vienna (Austria).

Isenberg, J. (1966), "A study of cracks in concrete by x-radiography." RILEM Bull, Vol. 30, pp. $107-114$.

Jana, D (2007) “DELAMINATION - A STATE-OF-THE-ART REVIEW," Proceedings of the $29^{\text {th }}$ Conference on Cement Microscopy, May 20-24, 2007, Quebec City, PQ QUEBEC CITY, PQ, Canada. 
Jhang, K.-Y. (2009), "Nonlinear ultrasonic techniques for nondestructive assessment of micro damage in material: A review," International Journal of Precision Engineering and Manufacturing, Vol. 10, No. 1, pp. $123-135$

Kahl, S. (2007), “Corrosion Resistant Alloy Steel (MMFX) Reinforcing Bar in Bridge Decks,” R-1499, Michigan Department of Transportation, September, 31 pp.

Kanare, H.M. (2008), “Concrete Floors and Covers,” EB119, Portland Cement Association, Skokie, IL, and National Ready Mixed Concrete Association, Silver Spring, MD, 176 pp.

Khan, M. S. (2003). “Detecting Corrosion-Induced Delaminations,” Concrete International, No. 7 , pp 73-78.

Kim, B. H., Kim, S. J., Yeo, K. S., Jang, J.-B., and Lee, H.-P. (2011), "Estimating effective prestress force on grouted tendon by impact responses," Paper presented at the IMAC-XXVIII, Jacksonville, Florida.

Kim, D.-S., and Kim, H.-W. (2004), "Non-destructive testing and evaluation of civil infrastructures using stress wave propagation," Proceedings of the 11th Asian Pacific Conference on Nondestructive Testing, November 3, 2003 - November 7, 2003, Jeju Island, Korea.

Klinghoffer, O., Kristensen, A., Jovall, O., and Rydén, N. (2011), "Condition assessment of concrete structures at nuclear power plants by state of the art non-destructive testing," Paper presented at the AMP 2010 - International Workshop on Ageing Management of Nuclear Power Plants and Waste Disposal Structures (EFC Event 334), Toronto, Canada.

Lane, D.S. and Ozyildirim, H.C. (1995), "Use of Fly Ash, Slag, or Silica Fume to Inhibit Alkali-Silica Reactivity,” Report No. 95-R21, Virginia Transportation Research Council, 41 pp.

Lawson, I., Danso, K. A., Odoi, H. C., Adjei, C. A., Quashie, F. K., Mumuni, I. I., and Ibrahim, I. S. (2011), "Non-destructive evaluation of concrete using ultrasonic pulse velocity," Research Journal of Applied Sciences, Engineering and Technology, Vol. 3, No. 6, pp. 499-504.

Liu, P.-L., Yeh, P.-L. (2008), "Imaging of internal cracks in concrete structures using the volume rendering technique," $17^{\text {th }}$ world Conference on Nondestructive testing 25-28 Oct 2008, Shanghai, China.

Longuet, P., Burglen, L., and Zelwer, A. (1973), Revue des Materiaux, Vol. 1, p. 35.

Longuet, P. (1976), Silicates Industriels, Vol. 7/8, p. 321.

Lopes, H., Ribeiro, J. E., Vaz, M., and Gomes, J. M. (2010), “The measurement of the model strain fields using digital shearography," Proceedings of ICEM 14 - 14th International Conference on Experimental Mechanics, Poitiers, France.

Lu, Y., and Garboczi, E. (2013), "Crack and transport review,” NISTIR, to be published.

Madaras, E.I., Anastasi, R. F., Smith, S. W., Seebo, J. P., Walker, J. L., et al. (2008), “Application of Terahertz Radiation to the Detection Of Corrosion Under The Shuttle's Thermal Protection System," Review of Progress in Quantitative Nondestructive Evaluation, Vol. 27, pp. 421-428. 
Maierhofer, C., Zacher, G., Kohl, C., and Wöstmann, J. (2008), "Evaluation of radar and complementary echo methods for NDT of concrete elements," Journal of Nondestructive Evaluation, Vol. 27, No. 1, pp. 47-57.

Malhotra, V. M. and Carino, N. J. (2004), "Handbook on Nondestructive Testing of Concrete," $2^{\text {nd }}$ edition, ASTM International and CRC Press.

Malvar, L.J., Cline, G.D., Burke, D.F., Rollings, R. Sherman, T.W., and Greene, J. (2001), “Alkali-Silica Reaction Mitigation State-of-the-Art," Technical Report TR-2195-SHR, Naval Facilities Engineering Service Center, Port Hueneme, CA.

Malvar, L.J., Cline, G.D., Burke, D.F. (2004), “Addressing Alkali-Silica Reaction in DOD Construction, Naval Facilities Engineering Service Center," Port Hueneme, CA.

Manning, D. G., and Holt, F. B. (1980), "Detecting Delamination in Concrete Bridge Decks," Concrete International, Vol. 2, pp. 34-41.

Martinez, I., Andrade, C., Rebolledo, N., Bouteiller, V., Marie-Victoire, E., and Olivier, G. (2008), "Corrosion Characterization of Reinforced Concrete Slabs with Different Devices," Corrosion, Vol. 64, No. 2, pp. 107-123.

Matysik, M., Plskova, I., Korenska, M, (2010a), "Nonlinear Ultrasonic Spectroscopy Methods Proper for Defectoscopy of Concrete Parts," Czech Society for Nondestructive Testing, NDE for Safety /

DEFEKTOSKOPIE 2010, November 10 - 12, 2010, Pilsen Czech Republic

Matysik, M.; Plskova, I.; Korenska, M.; Kucharczykova, B. (2010b), "NDT of Mechanical Damaged Concrete Specimens by Nonlinear Acoustic Spectroscopy Method," Transactions on Transport Sciences, Vol. 2, No. 4, pp. 166 - 171.

McLaskey, G. C., Glaser, S. D., and Grosse, C. U. (2010), "Beamforming array techniques for acoustic emission monitoring of large concrete structures," Journal of Sound and Vibration, Vol. 329, No. 12, pp. 2384-2394.

Mihashi, H., Ahmed, S., Mizukami, T., and Nishiwaki, T. (2006). "Quantification of Crack Formation Using Image Analysis and its Relationship with Permeability," International Journal of Restoration of Buildings and Monuments, Vol. 12, No. 4, pp. 335-348.

Millard, S. and Sadowski, L. (2009), "Novel method for linear polarisation resistance corrosion measurement," NDTCE'09 Non-Destructive Testing in Civil Engineering, Nantes, France, June $30^{\text {th }}-$ July $3^{\text {rd }}$.

Mollo L. and Greco, R.(2011), "Moisture Measurements in Masonry Materials by Time Domain Reflectometry," Journal of Materials in Civil Engineering, Vol. 23, pp. 441-444.

Monteiro, A. and Goncalves, A. (2009), "Assessment of characteristic compressive strength in structures by the rebound hammer test according to EN 13791: 2007," NDTCE'09, Non-Destructive Testing in Civil Engineering, NDTCE'09, Nantes, France, June 30 ${ }^{\text {th }}-$ July $3^{\text {rd }}, 2009$. 
Muravin, G. and Ilina, E. (2010), "Revealing, typifying and assessing flaws and age-related degradation in nuclear power plant containments using the quantitative acoustic emission non-destructive inspection method," Journal Scientific Israel - Technological Advantages, Vol. 12, No. 1.

Natesaiyer, K. and Hover, K. C., (1988), "Insitu Identification of ASR Products in Concrete," Cement and Concrete Research, Vol. 18, No. 3, pp. 455 - 463.

National Research Council (2011), "Research Opportunities in Corrosion Science and Engineering," National Academy of Sciences.

Naus, D.J. (2009), "Inspection of Nuclear Power Plant Structures - Overview of Methods and Related Applications,” ORNL/TM-2007/191, Oak Ridge National Laboratory, Oak Ridge, TN.

Olympus-NDT (2010), "Phase Array Testing, Basic theory for industrial applications," http://www.olympus-ims.com/data/File/books-2/Olympus-Phased_Array_Testing.en.pdf

Otieno, M., Beushausen, H., and Alexander, M. (2011a), "Prediction of Corrosion Rate in RC Structures - A Critical Review, Modelling of Corroding Concrete Structures," Andrade. C. and Mancini, G. (Eds), RILEM Bookseries 5, pp. 15-37.

Otieno, M., Beushausen, H., and Alexander, M. (2011b), "Modelling Corrosion Propagation in Reinforced Concrete Structures - A Critical Review," Cement \& Concrete Composites, Vol. 33, pp. 240245.

Oyama, Y., Zhen, L., Tanabe, T., and Kagaya, M. (2009), "Sub-terahertz Imaging of Defects in Building Blocks," NDT\&E International, Vol. 42, pp. 28-33.

Pacheco, J. and Polder, R. (2012), "Corrosion Initiation and Propagation in Cracked Concrete - A Literature Review," Advances in Modeling Concrete Service Life, Proceedings of the $4^{\text {th }}$ International RILEM PhD Workshop held in Madrid, Spain, Nov. 19, 2010, Andrade, C. and Gulikers, J. (Eds), Springer, pp. 85-93.

Page, C. L. (2009), "Initiation of Chloride-Induced Corrosion of Steel in Concrete: Role of Interfacial Zone," Materials and Corrosion, Vol. 60, pp. 586-592.

Paris, O. Brédif, Ph., Roy, O, Rambach, J.M., Nahas, G. (2003), "Study of phased array techniques for cracks characterization in Concrete Structures," International Symposium (NDT-CE 2003), NonDestructive Testing in Civil Engineering.

Payan, C. Varnier, and Moysan, J. (2010), "Potential of Nonlinear Ultrasonic Indicators for Nondestructive Testing of Concrete," Hindawi Publishing Corporation, Advances in Civil Engineering, Volume 2010, Article ID 238472, 8 pages, doi: 10.1155/2010/238472.

Pei, K.C., Kan, Y.-C., Lin, T-W, Yen, T (2010), "Acoustic Emission Monitoring on the Fracture Behaviors of RC and Light RC Structural Elements In the Load Tests," Paper presented at the CECAR5 (The 5th International Civil Engineering Conference in the Asian Region) Sydney, Australia. 
Ploix, M. A., Garnier, V., Breysse, D., and Moysan, J. (2009), "Possibilistic NDT data fusion for evaluating concrete structures," Non-Destructive Testing in Civil Engineering, Nantes, France, June 30 July 3, 2009.

Ploix, M. A., Garnier, V., Breysse, D., and Moysan, J. (2011), "NDE data fusion to improve the evaluation of concrete structures," NDT \& E International, Vol. 44, Issue 5, pp. 442-448.

Purnell, Gan, Hutchins, \& Berriman (2004), "Noncontact ultrasonic diagnostics in concrete: A preliminary investigation," Cement and Concrete Research, Vol. 34, pp. 1185-1188.

Ramadan, S., Gaillet, L., Tessier, C., and Idrissi, H. (2008), "Detection of stress corrosion cracking of high-strength steel used in prestressed concrete structures by acoustic emission technique," Applied Surface Science, Vol. 254, No. 8, pp. 2255-2261.

Rao, M. B., Bhat, M. R., Murthy, C. R. L., Madhav K. V., Asokan, S. (2006), "Structural health monitoring (SHM) using strain gauges, PVDF film and fiber bragg grating (FBG) sensors: A comparative study," Proc. National Seminar on Non-destructive Evaluation, Hyderabad, India, Dec. 7 9, 2006.

Rebolledo, N. and Andrade, C. (2012), "From Corrosion Rate to Accumulated Corrosion Depth to Loss in Cross Section of Reinforcements," Advances in Modeling Concrete Service Life, Proceedings of the $4^{\text {th }}$ International RILEM PhD Workshop held in Madrid, Spain, Nov. 19, 2010, Andrade, C. and Gulikers, J. (Eds), Springer, p. 43-51.

REMR (1991) Technical Notes CS-ES-1.10, "Nondestructive testing of Concrete with Ultrasonic PulseEcho.” Repair, Evaluation, Maintenance, Rehabilitation Research Program, 4 pp, http://wri.usace.army.mil/remr/technical_notes/concrete/CS-ES-1-10.pdf.

Rigden, S.R., Majlesi, Y., and Burley, E. (1995), "Investigation of factors influencing the expansive behavior, compressive strength and modulus of rupture of alkali-silica reactive concrete using laboratory mixes." Magazine of Concrete Research, Vol. 47, No. 170, pp. 11-21.

RILEM TC 178-TMC (2002), “Analysis of total chloride content in concrete, Recommendation of RILEM TC 178-TMC," Materials and Structures, Vol. 35, pp. 583-585.

Rosenberg, A., Gaidis, J., Kossivas, T., and Previte, R. (1977), “A Corrosion Inhibitor Formulated with Calcium Nitrite for Use in Reinforced Concrete,” (STP 629), ASTM International.

Saad, J. A. (2011), “Thick film electronic ceramic sensors for civil structures health monitoring," $\mathrm{PhD}$ Thesis, Edinburgh Napier University, May.

Sadowski, L. (2010), "New non-destructive method for linear polarisation resistance corrosion rate measurement," Archives of Civil and Mechanical Engineering, Vol. 10 (2), pp. 109-116..

Shao, Z. (2011), "Design and application of a small size SAFT imaging system for concrete structure.". Reviews of Scientific Instruments, Vol. 82 (7), 073708, (DOI: 10.1063/1.3610459) 
Sharma, S. and Mukherjee, A. (2010), "Longitudinal Guided Waves for Monitoring Chloride Corrosion in Reinforcing Bars in Concrete," Structural Health Monitoring, Vol. 9(6), p. 555-567,

(DOI: $10.1177 / 1475921710365415)$.

Shen, G., Tyson, W. R. (2009), "Crack Size Evaluation Using Unloading Compliance in SingleSpecimen Single-Edge-Notched Tension Fracture Toughness Testing," Journal of Testing and Evaluation (JTE), Vol. 37, No. 4, pp. 240-243.

Shi, C. (2004), "Effect of Mixing Proportions of Concrete on its Electrical conductivity and the Rapid Chloride Permeability Test (ASTM C1202 or ASSTHO T277) Results," Cement and Concrete Research, Vol. 34, pp. 537-545.

Slate, F. O., and Olsefski, S. (1963), "X-ray for study of internal structure and microcracking of concrete," Journal of American Concrete Institute Proceedings, Vol. 60, pp. 575-588.

Smaoui, N., Bissonnette, B., Bérubé, M.A., Fournier, B., and Durand, B. (2006), "Mechanical properties of ASR-affected concrete containing fine or coarse reactive aggregates," Journal of ASTM International, Vol. 3, No. 3, pp. 1-16.

Smith, J. L. and Virmani, Y. P. (2000), "Materials and Methods for Corrosion Control of Reinforced and Prestressed Concrete Structures in New Construction," FHWA RD-00-081, Federal Highway Administration, McLean, VA, 82 pp.

Song, G., Gu, H., and Mo, Y. (2008), "Smart aggregates: multi-functional sensors for concrete structures - a tutorial and a review," Smart Materials and Structures, Vol. 17, 033001 (doi:10.1088/09641726/17/3/033001).

Stanton, T.E. (1940), "Expansion of Concrete Through Reaction Between Cement and Aggregate," Proceedings, American Society of Civil Engineers, Vol. 66, pp. 1781-1811.

Stark, D (1990), "Handbook for the Identification of Alkali-Silica Reactivity in Highway Structures," Report No. SHRP-C-/FR-91-101, Strategic Highway Research Program, National Research Council, Washington, D.C.

Sun, M., Staszewski, W. J., and Swamy, R. N. (2010), "Smart sensing technologies for structural health monitoring of civil engineering structures," Advances in Civil Engineering, Vol. 2010, 724962, 13 pp. (doi:10.1155/2010/724962).

Sung, K., Surek, J., and Baker-Jarvis, J. (2011), "Electromagnetic Metrology on Concrete and Corrosion," Journal of Research of the National Institute Standards and Technology, Vol. 116, No. 3, May-June, pp. 655-669.

Tauma, W.E. (2000), “Alkali-Silica Reaction in Portland Cement Concrete: Testing Methods and Mitigation Alternatives,” Research Report ICAR-301-1f, Austin, TX, 505 pp.

Terzić, A. M., and Pavlović, L. M. (2010), “Application of results of nondestructive testing methods in the investigation of microstructure of refractory concretes," Journal of Materials in Civil Engineering, Vol. 22, pp. 853-857. 
Texas DOT (2005), “Test Procedure for Determining Chloride and Sulfate Contents in Soil," TEX-620-J, Effective August 2005.

Thompson, R.B. (1990), "Physical Principles of Measurements with EMAT Transducers," Ultrasonic Measurement Methods, Physical Acoustics Vol XIX, Edited by R.N. Thurston and Allan D. Pierce, Academic Press.

Transportation Research Board (TRB) (2006), "Control of Cracking in Concrete: State of the Art," Circular E-C107, Transportation Research Board, Washington, DC.

Trtnik, G., Kavčič, F., and Turk, G. (2009), "Prediction of concrete strength using ultrasonic pulse velocity and artificial neural networks," Ultrasonics, Vol. 49, No. 1, pp. 53-60.

Ucida, S., Kamada, T., Hirofumi, M., Minezawa, H., and Munakata, K. (2009), "Nondestructive Evaluation of Deterioration Around Reinforcing Bar due to Corrosion in RC Members," NDTCE'09, Non-Destructive Testing in Civil Engineering, Nantes, France, June $30^{\text {th }}-$ July $3^{\text {rd }}, 2009$.

Ulm, F.-J., Coussy, O., Kefei, L., and Larive, C. (2000), "Thermo-chemo-mechanics of ASR expansion in concrete structures," Journal of Engineering Mechanics, Vol. 126, pp. 233-242.

van Breugel, K. (2006), “Key Factors For Producing Durable Concrete Structures,” International RILEM-JCI Seminar on Concrete Durability and Service Life Planning, ConcreteLife'06, 14- 16 March 2006, Ein-Bokek, Dead Sea, Israel, Konstantin Kovler (Ed), RILEM Publications, pp. 302-309.

Vannesland, O, Raupach, M., and Andrade, C. (2007), "Electrochemical techniques for measuring corrosion in concrete - measurements with embedded probes," Materials and Structures, Vol. 40, pp. 745-758.

Virmani, Y.P. and Clemana, G.G. (1998), "Corrosion Protection - Concrete Bridges," FHWA-RD-98088, Federal Highway Administration, McLean, VA, 72 pp.

Walker, H.N., Lane, D. Stephen, and Stutzman, P.E. (2006), "Petrographic Methods of Examining Hardened Concrete: A Petrographic Manual,” FHWA-HRT-04-150, Federal Highway Administration, McLean, VA, $351 \mathrm{pp}$.

Wenner, F. (1916), "A method of measuring earth resistivity," Bulletin of the Bureau of Standards, Vol. 12, Issue 4, 469-478, (http://dx.doi.org/10.6028/bulletin.282).

Wittmann, F. H. (2010), "Neutron radiography applied to study deteriorating mechanisms in cracked concrete structures," SciTopics,

(http://www.scitopics.com/Neutron_radiography_applied_to_study_deteriorating_mechanisms_in_crack ed_concrete_structures.html)

Yang, Z., Fishcher, H., and Polder, R. (2012), "Possibilities for improving corrosion protection of reinforced concrete by modified hydrotalcites - a literature review," Advances in Modeling Concrete Service Life, Proceedings of the $4^{\text {th }}$ International RILEM PhD Workshop held in Madrid, Spain, Nov. 19, 2010, Andrade, C. and Gulikers, J. (Eds), Springer, pp. 95-105. 
Yasarer, H. I. (2010), "Characterizing the Permeability of Concrete Mixes Used in Transportation Applications: A Neuronet Approach,” Master Thesis, Kansas State University, Manhattan , Kansas, 2010.

Ye, H.-W., and Peng, G.-F. (2009), "Assessment of concrete permeability by a nondestructive method," Key Engineering Materials, Vol. 405-406, pp. 309-314 (DOI: 10.4028/www.scientific.net/KEM.405406.309).

Yenilmez, A., Yapici, A., Velez, C., and Tansel, I. N. (2007), "Development of piezoelectric strain gages for structural health monitoring applications," AIP Conference Proceedings, Vol. 894, pp. 902-909, Review of Progress in Quantitative Nondestructive Evaluation, 30 July-4 August, Portland, Oregon, doi:http://dx.doi.org/10.1063/1.2718064.

Yu, X., Drnevich, V.P., Olek, J. (2004), “Time domain reflectometry for measuring watercement ratio of concrete," International RILEM Symposium on Concrete Science and Engineering: A Tribute to Arnon Bentur, RILEM Publications SARL.

Zaitsev, V., Nazarov, V., Gusev, V. and Castagnede, B. (2006), "Novel nonlinear-modulation acoustic technique for crack detection," NDT and E International, Vol. 39, No. 3, pp. 184-194.

Zhao, P., Pisani, D., Lynch, C. S. (2011), "Piezoelectric strain sensor/actuator rosettes," Smart Materials and Structures, Vol. 20, 102002.

Zheng, Y.-G., and Li, H.-Q. (2011), "Evaluation of protective quality of prestressed concrete containment buildings of nuclear power plants," Journal of Central South University of Technology, Vol. 18, No. 1, pp. 238-243.

Zhou, Z., He, J., Chen, G., and Ou, J. (2009), “A Smart Steel Strand for the Evaluation of Prestress Loss Distribution in Post-tensioned Concrete Structures," Journal of Intelligent Material Systems and Structures, Vol. 20, No. 16, pp. 1901-1912. 